\title{
An Early Survey of Best Practices for the Use of Small Unmanned Aerial Systems by the Electric Utility Industry
}

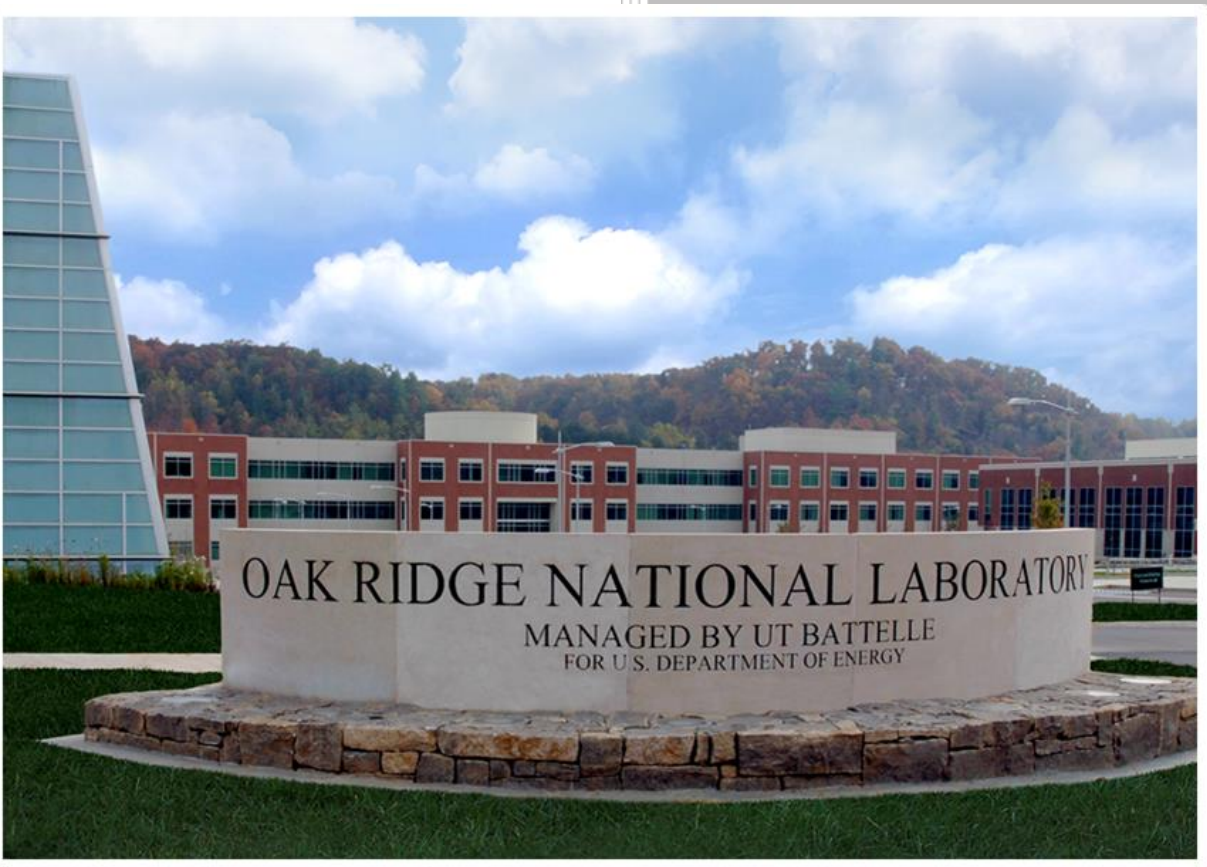

Approved for public release. Distribution is unlimited.

Richard M. Lusk

William H. Monday

February 2017 


\title{
DOCUMENT AVAILABILITY
}

Reports produced after January 1, 1996, are generally available free via US Department of Energy (DOE) SciTech Connect.

\section{Website http://www.osti.gov/scitech/}

Reports produced before January 1, 1996, may be purchased by members of the public from the following source:

\author{
National Technical Information Service \\ 5285 Port Royal Road \\ Springfield, VA 22161 \\ Telephone 703-605-6000 (1-800-553-6847) \\ TDD 703-487-4639 \\ Fax 703-605-6900 \\ E-mail info@ntis.gov \\ Website http://classic.ntis.gov/
}

Reports are available to DOE employees, DOE contractors, Energy Technology Data Exchange representatives, and International Nuclear Information System representatives from the following source:

Office of Scientific and Technical Information

PO Box 62

Oak Ridge, TN 37831

Telephone 865-576-8401

Fax 865-576-5728

E-mail reports@osti.gov

Website http://www.osti.gov/contact.html

This report was prepared as an account of work sponsored by an agency of the United States Government. Neither the United States Government nor any agency thereof, nor any of their employees, makes any warranty, express or implied, or assumes any legal liability or responsibility for the accuracy, completeness, or usefulness of any information, apparatus, product, or process disclosed, or represents that its use would not infringe privately owned rights. Reference herein to any specific commercial product, process, or service by trade name, trademark, manufacturer, or otherwise, does not necessarily constitute or imply its endorsement, recommendation, or favoring by the United States Government or any agency thereof. The views and opinions of authors expressed herein do not necessarily state or reflect those of the United States Government or any agency thereof.

\section{Legal Notice}

This work contains findings that are general in nature. Users are reminded to perform due diligence in applying these practices and findings to their specific needs, as it is not possible for Oak Ridge National Laboratory (ORNL), or any of the other contributors to this manual, to have sufficient understanding of any specific situation to ensure applicability of the practices and findings in all cases. Neither the authors or ORNL, managed by the University of Tennessee Battelle Corp., LLC., assume liability for how users may apply, interpret, or use the information, apparatus, method, or process contained herein. In addition, the authors and ORNL make no warranty or representation that the use of these contents does not infringe on privately held rights. 
Computational Sciences and Engineering Division

\title{
AN EARLY SURVEY OF BEST PRACTICES FOR THE USE OF SMALL UNMANNED AERIAL SYSTEMS BY THE ELECTRIC UTILITY INDUSTRY
}

\author{
Richard M. Lusk* \\ William H. Monday**
}

\begin{abstract}
*Director, Unmanned Aerial Systems (UAS) Research Center (UASRC) and Data System Sciences and Engineering Group Leader

**UASRC Project Manager in the Data System Sciences and Engineering Group within the Computing and Computational Sciences Directorate
\end{abstract}

Date Published: February 2017

\author{
Prepared by \\ OAK RIDGE NATIONAL LABORATORY \\ Oak Ridge, TN 37831-6283 \\ managed by \\ UT-BATTELLE, LLC \\ for the \\ US DEPARTMENT OF ENERGY \\ under contract DE-AC05-00OR22725
}





\section{DEDICATION}

Sometimes the motivation and inspiration to complete a daunting task comes at the oddest times and in the most unexpected places. In this case, a chance encounter with a person standing next to me in the customer service line in the Guntersville, Alabama, Walmart.

I dedicate this manual to the Hubble Foundation and its President, Bridgette Hester, $\mathrm{PhD}$. The Hubble Foundation is dedicated to promoting support for and assistance to families of fallen telecommunications technicians, as well as to promoting the safety of all workers at elevation.

(It's amazing what you can find in the Guntersville Walmart.)

Let's risk the machines, not the humans 



\section{CONTENTS}

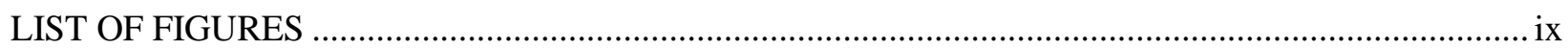

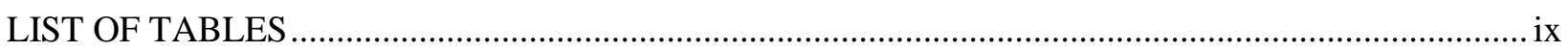

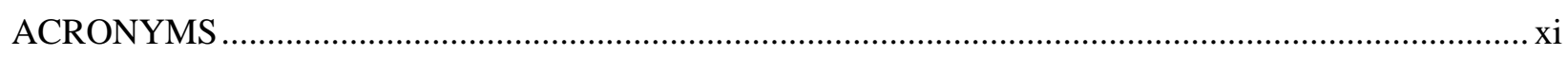

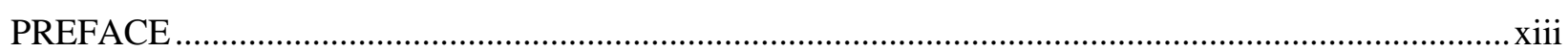

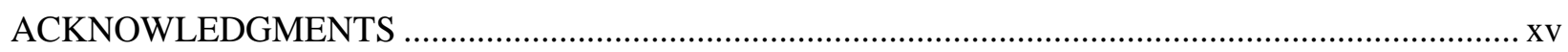

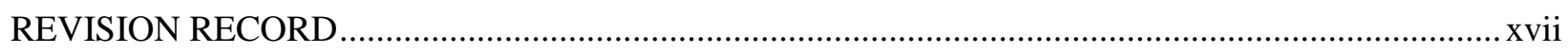

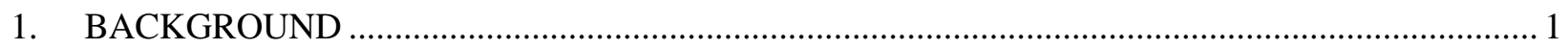

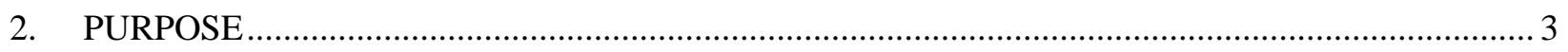

3. OVERVIEW: FEDERAL AVIATION ADMINISTRATION'S SMALL UNMANNED

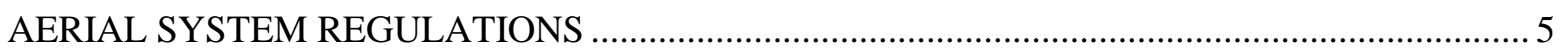

3.1 COMPREHENSIVE NEW REGULATIONS FOR SMALL UNMANNED AERIAL

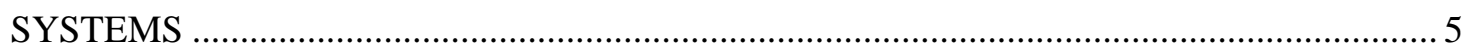

3.2 SUMMARY OF 14 CFR PART 107 (FAA RULE/PART 107) ........................................ 5

3.2.1 Small Unmanned Aerial System Operational Limitations ............................................. 5

3.2.2 Remote Pilot in Command Certification and Responsibilities .................................. 7

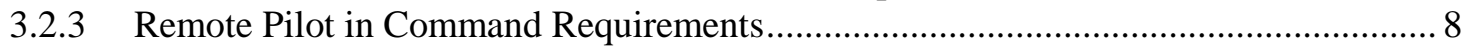

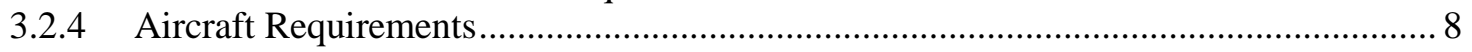

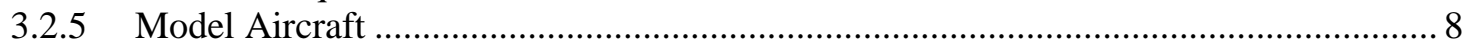

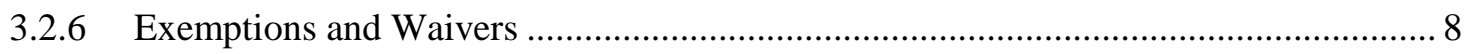

3.2.7 Websites for Regulatory and General Unmanned Aerial System Operation

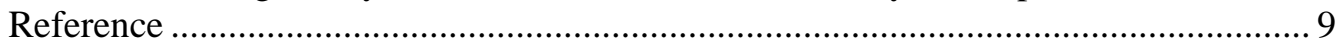

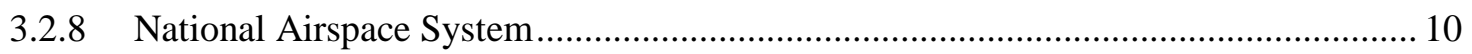

3.2.9 Unmanned Aerial System Operations in Foreign Airspace ...................................... 10

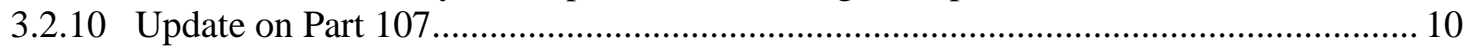

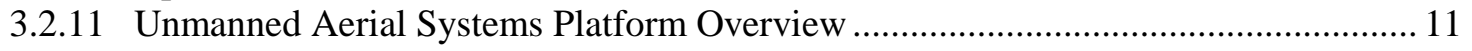

4. BEST PRACTICES FOR USE OF SMALL UNMANNED AERIAL SYSTEMS BY THE

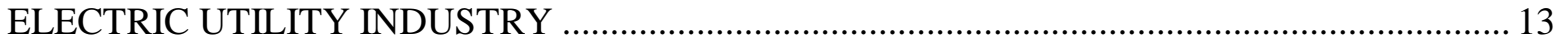

4.1 WHY UNMANNED AERIAL SYSTEMS FOR THE ELECTRIC UTILITY

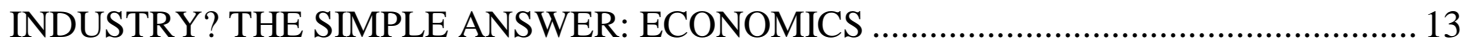

4.1.1 Unmanned Aerial System Work Benefits and Drawbacks ....................................... 15

4.1.2 Unmanned Aerial System Visual Inspection of Electric Utilities' Infrastructure

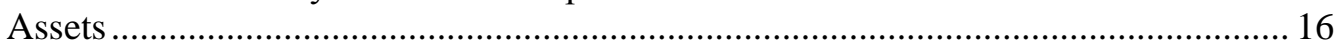

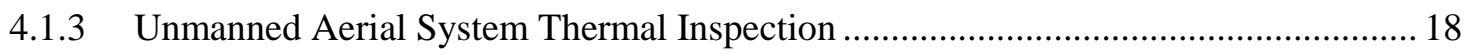

4.1.4 Unmanned Aerial System Support for Electric Utility Storm Damage

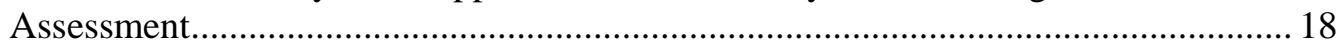

4.1.5 Unmanned Aerial System Support for Electric Utility Vegetation Management ........ 18

4.2 UNMANNED AERIAL SYSTEM CONCEPT TO SUPPORT ELECTRIC UTILITY

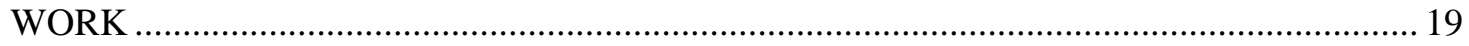

4.2.1 Unmanned Aerial System Mission Planning for Electric Utility Work...................... 20

4.2.2 Unmanned Aerial System Electric Utility Work Inspection Execution....................... 21

4.2.3 Considerations for Using Unmanned Aerial Systems Near Energized Infrastructure. 
4.2.4 Effect of Electromagnetic Interference on Unmanned Aerial Systems ...................... 31

4.2.5 Procedures While Operating Unmanned Aerial Systems Near Wind

Infrastructure

4.2.6 Procedures While Operating Unmanned Aerial Systems Near Nuclear Power

Plants

4.2.7 Unmanned Aerial System Applications at Electric Power Plants ............................... 34

4.2.8 Overview: Visual Line of Sight UAS Operations..................................................... 34

4.2.9 Overview: Beyond Visual Line of Sight and Night Unmanned Aerial System

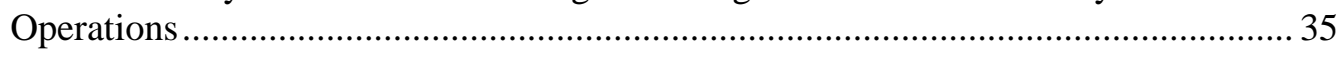

4.3 UNMANNED AERIAL SYSTEM ELECTRIC UTILITY MISSION PLANNING ................ 36

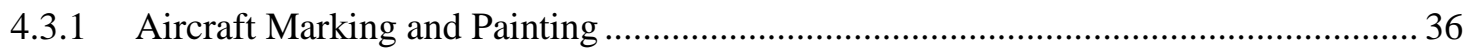

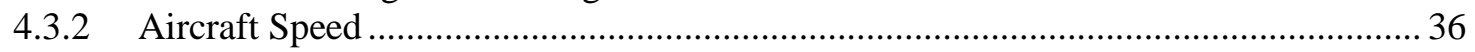

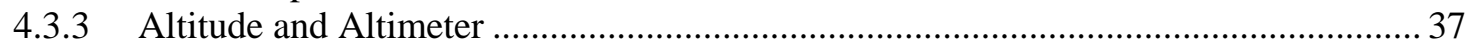

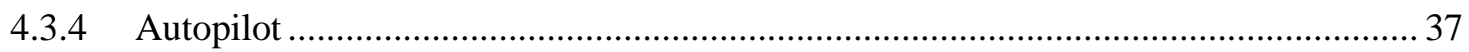

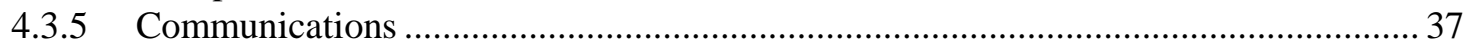

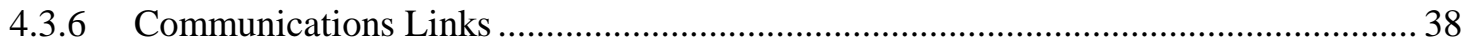

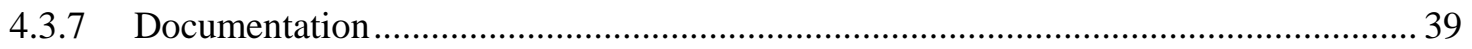

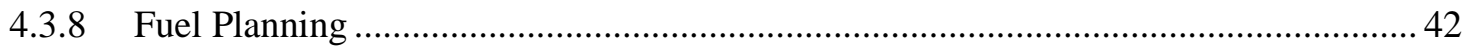

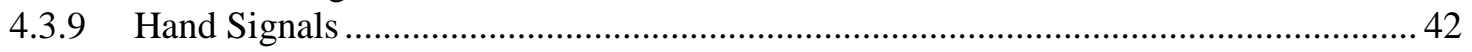

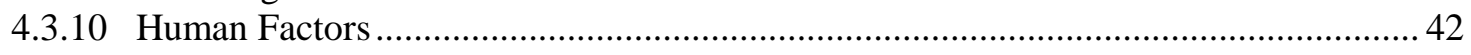

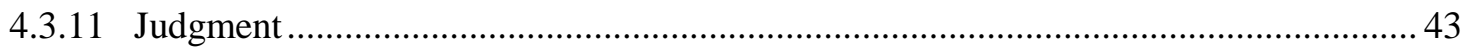

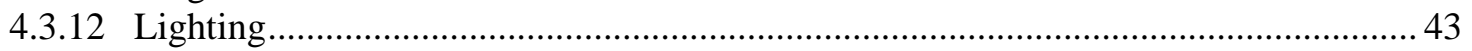

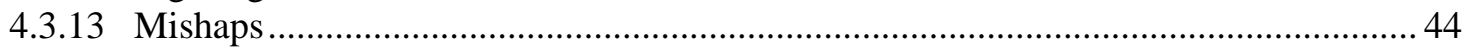

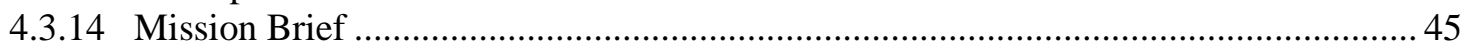

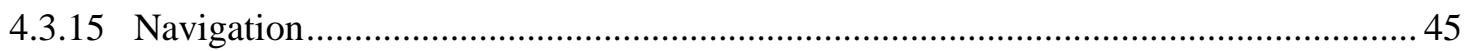

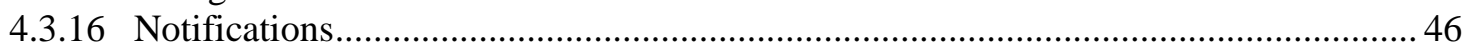

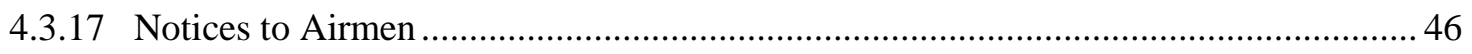

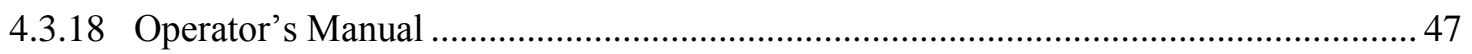

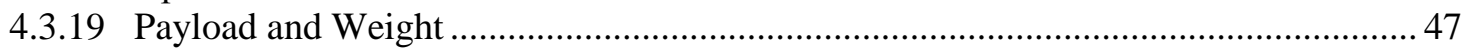

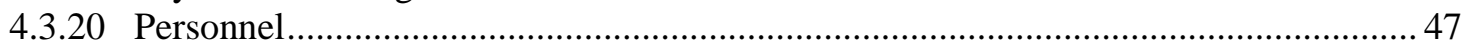

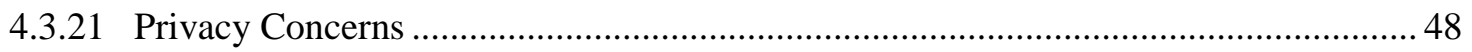

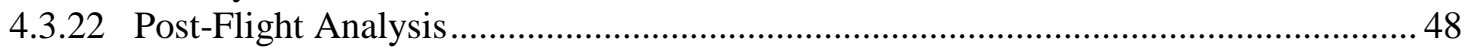

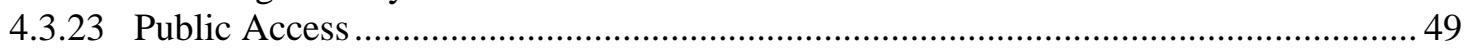

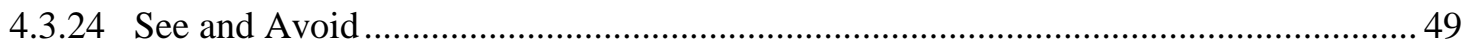

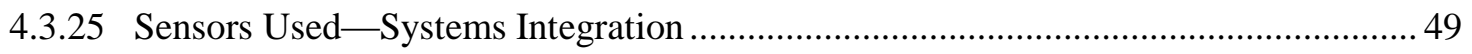

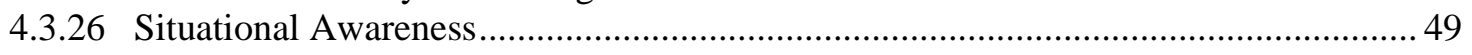

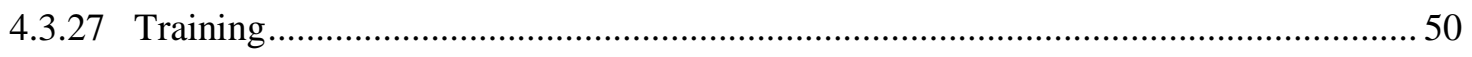

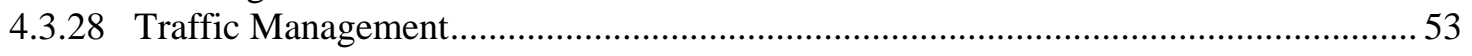

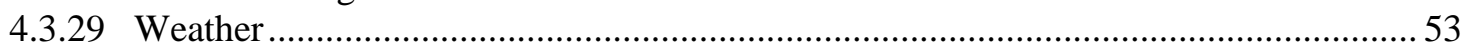

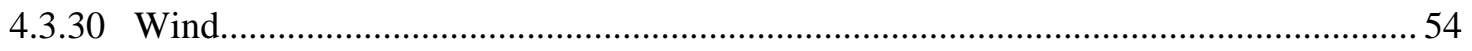

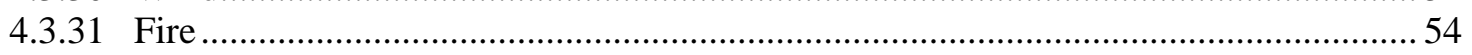

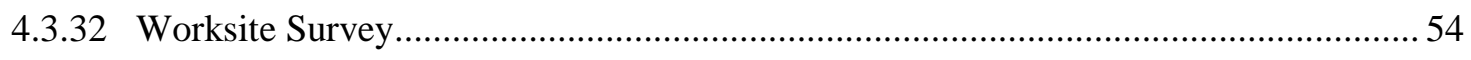

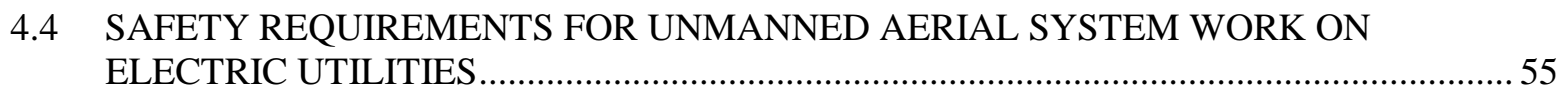

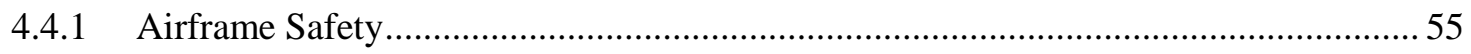

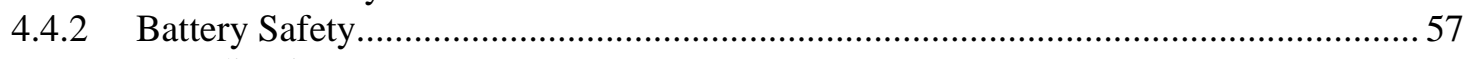

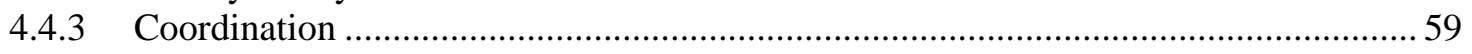

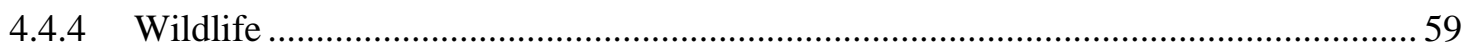

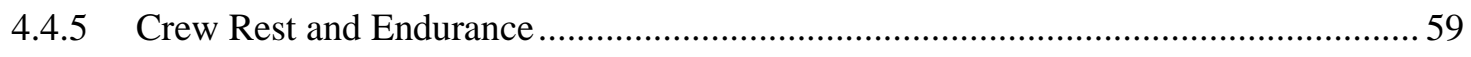

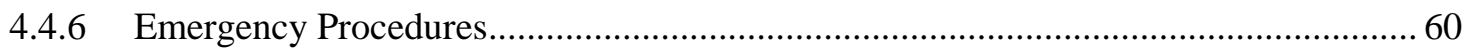


4.4.7 Hazards

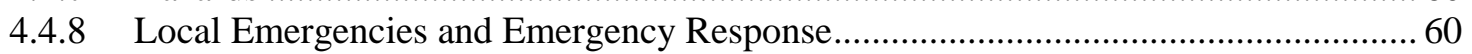

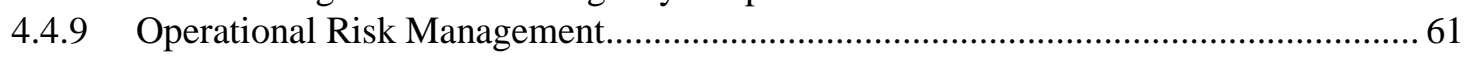

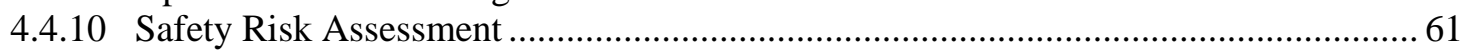

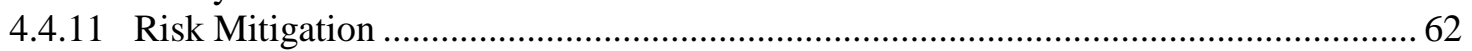

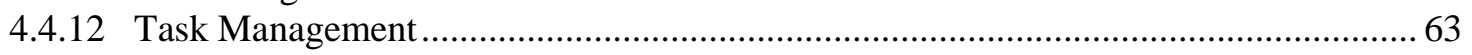

4.5 UNMANNED AERIAL SYSTEM FLIGHT OPERATION EXECUTION FOR ELECTRIC UTILITIES.

4.6 UNMANNED AERIAL SYSTEM OPERATIONAL FLIGHT MINIMUMS-

PRINCIPAL "TAKE-AWAYS”. 64

5. UNMANNED AERIAL SYSTEM TYPES FOR ELECTRIC UTILITIES .

5.1 CONSIDERATIONS FOR SELECTING A UNMANNED AERIAL SYSTEM COMMERCIAL OPERATOR 67

5.2 CONSIDERATIONS BEFORE PURCHASING AN UNMANNED AERIAL SYSTEM ...... 67

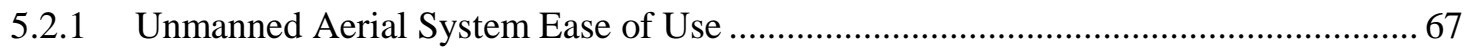

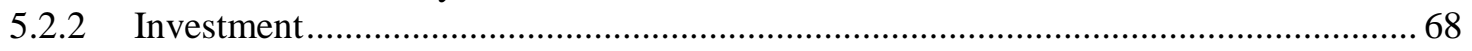

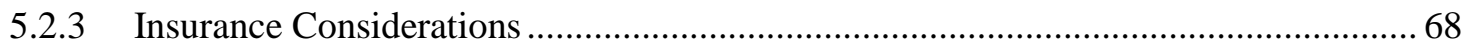

6. UNMANNED AERIAL SYSTEM-MOUNTED SENSORS AND APPLICATIONS FOR ELECTRIC UTILITIES 71

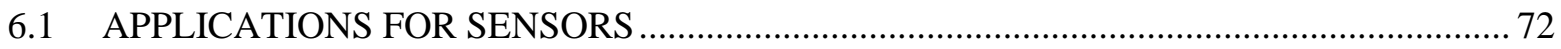

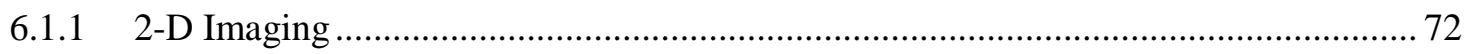

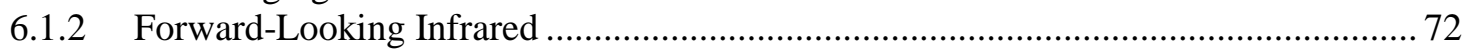

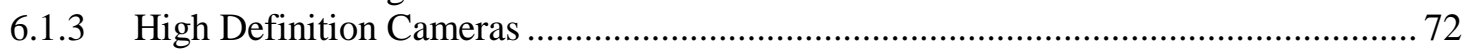

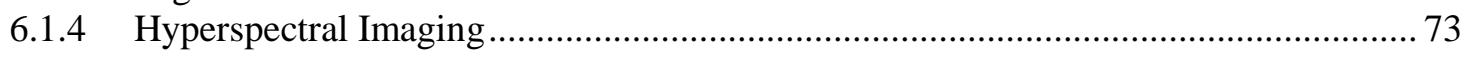

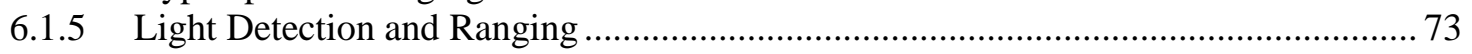

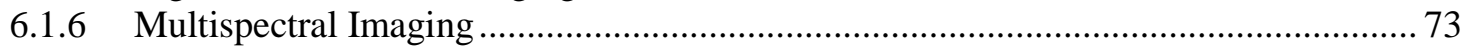

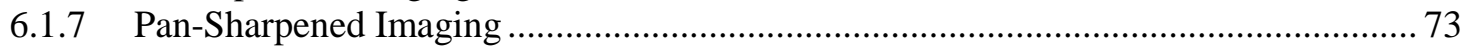

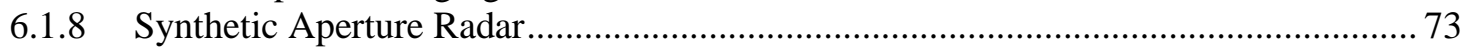

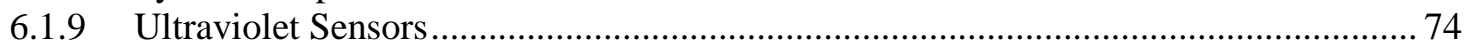

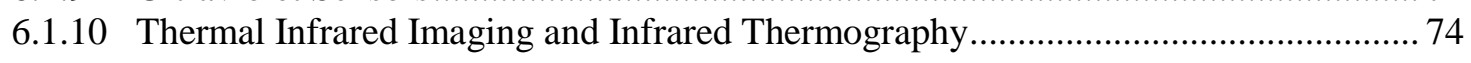

6.2 DATA COLLECTION AND ANALYSIS CONSIDERATIONS ....................................... 74

6.3 INTERNET OF THINGS, UNMANNED AERIAL SYSTEMS, AND THE

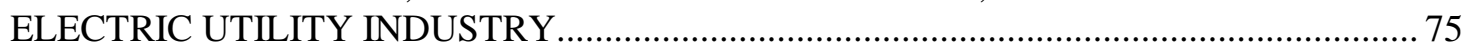

7. PRIVACY AND PROPER UNMANNED AERIAL SYSTEM OPERATIONAL

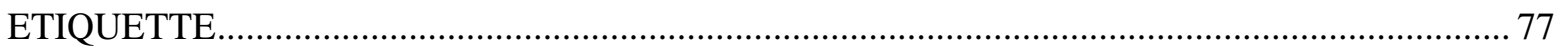

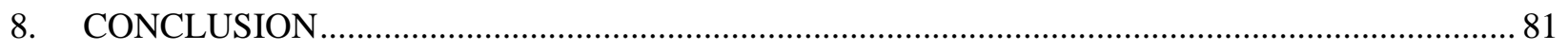

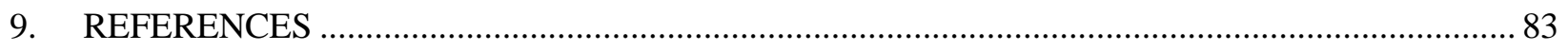

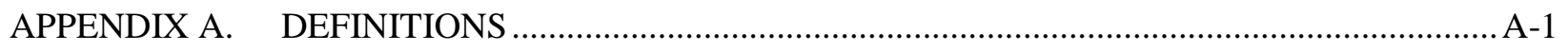

APPENDIX B. UNMANNED AERIAL SYSTEM OPERATIONS_PUBLIC

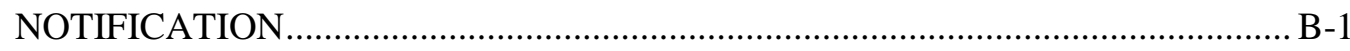

APPENDIX C. UNMANNED AERIAL SYSTEM WORK IN SUPPORT OF

ELECTRIC UTILITIES-MISSION PLAN …................................................... C-1

APPENDIX D. UNMANNED AERIAL SYSTEM MISSION PLANNING

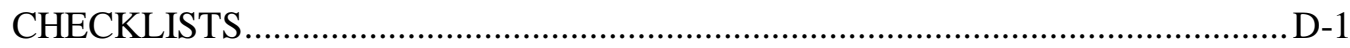


APPENDIX E. UNMANNED AERIAL SYSTEM PRE-FLIGHT CHECKLISTS .......................... E-1

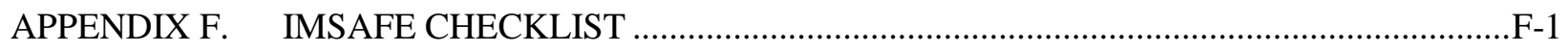

APPENDIX G. UNMANNED AERIAL SYSTEM FLIGHT OPERATIONS-

EXECUTION CHECKLIST .........................................................................

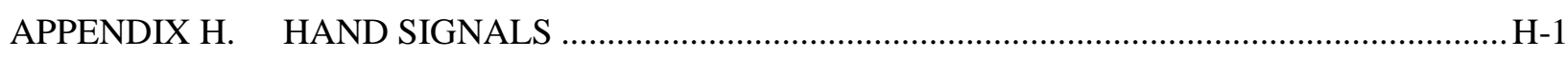

APPENDIX I. UNMANNED AERIAL SYSTEM POST-FLIGHT CHECKLIST ...............................

APPENDIX J. SMALL UNMANNED AERIAL SYSTEM MAINTENANCE AND

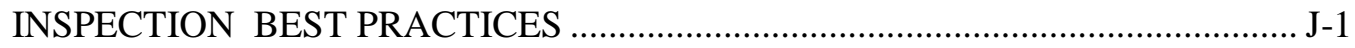

APPENDIX K. PILOT LOGBOOK EXAMPLE .........................................................................

APPENDIX L. CONSIDERATIONS FOR USING UNMANNED AERIAL

SYSTEMS NEAR WIND INFRASTRUCTURE .............................................. L-1

APPENDIX M. FAQS REGARDING UNMANNED AERIAL SYSTEM USE FOR

THE ELECTRIC UTILITY INDUSTRY ......................................................... M-1

APPENDIX N. FAA CONTROLLED AIRSPACE CLASSIFICATIONS …....................................

APPENDIX O. FAA ACCIDENT REPORTING AND REGIONAL OPERATIONS

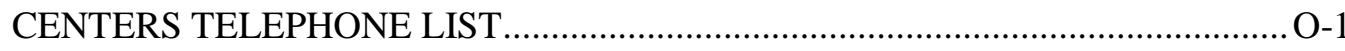

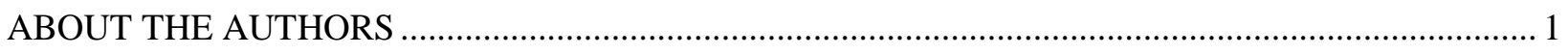

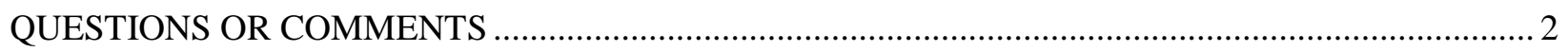




\section{LIST OF FIGURES}

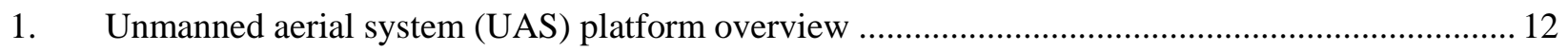

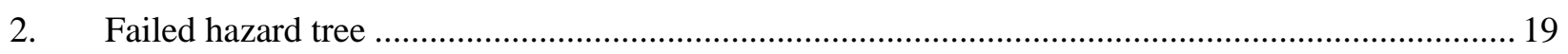

3. Unmanned aerial system required and optional crew members …............................................ 22

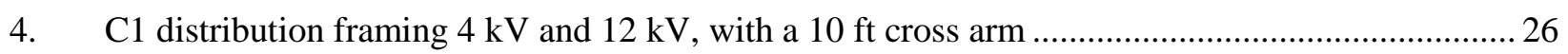

5. $\mathrm{C} 4$ distribution framing $4 \mathrm{kV}$ and $12 \mathrm{kV}$ vertical double dead end; lateral view ...........................2 27

6. $\mathrm{C} 4$ distribution framing $4 \mathrm{kV}$ and $12 \mathrm{kV}$ vertical double dead end; top view ................................28

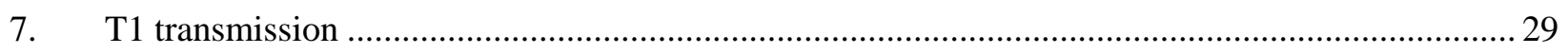

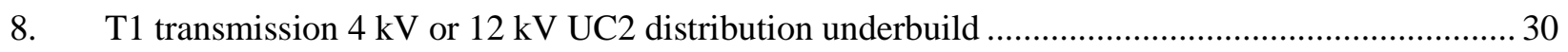

9. Ascend, lock-on, and fall (ALF) for unmanned aerial system wind infrastructure

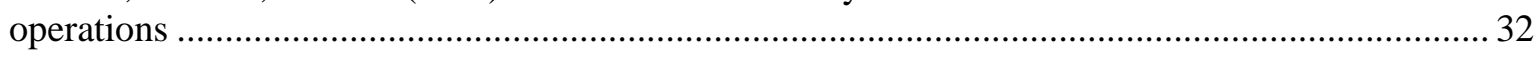

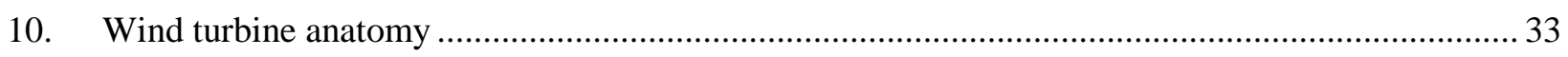

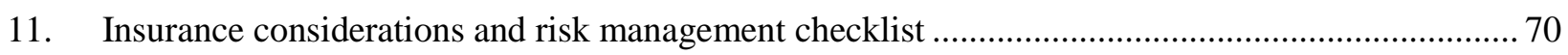

\section{LIST OF TABLES}

1. Types of FAA Unmanned Aerial System Operating Authorities Including Certificates of Waiver or Authorization (COAs)......

2. Benefits (green shading) and Drawbacks (red shading) of Unmanned Aerial

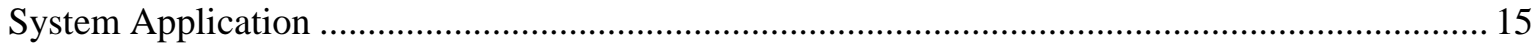

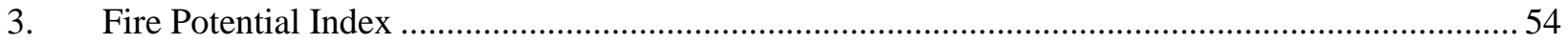

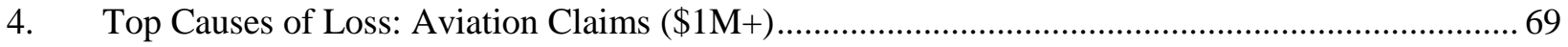





\section{ACRONYMS}

\begin{tabular}{|c|c|}
\hline AP & autopilot \\
\hline AGL & above ground level \\
\hline ATC & air traffic control \\
\hline BVLOS & beyond visual line of sight \\
\hline $\mathrm{C} 2$ & Command and Control \\
\hline CICA & Convention on International Civil Aviation \\
\hline $\mathrm{COA}$ & certificate of authorization \\
\hline CFR & Code of Federal Regulations \\
\hline COW & certificate of waiver \\
\hline $\mathrm{CS}$ & control station \\
\hline CTAF & Common Traffic Advisory Frequency \\
\hline $\mathrm{DoD}$ & US Department of Defense \\
\hline DROTAM & Drone Notice to Airmen \\
\hline EM & electromagnetic \\
\hline EMI & electromagnetic interference \\
\hline EPRI & Electric Power Research Institute \\
\hline FAA & Federal Aviation Administration (US Department of Transportation) \\
\hline FPV & first-person view \\
\hline GPS & Global Positioning System \\
\hline HD & high definition \\
\hline ICAO & International Civil Aviation Organization \\
\hline IFR & instrument flight rule \\
\hline IoT & Internet of Things \\
\hline lidar & light detection and ranging \\
\hline MAD & minimum approach distance \\
\hline MOA & military operations area \\
\hline $\mathrm{mph}$ & miles per hour \\
\hline MPO & mission payload operator \\
\hline MSL & mean sea level \\
\hline NAS & National Airspace System \\
\hline NM & nautical mile \\
\hline NOTAM & Notice to Airmen \\
\hline NSA & National Security Area \\
\hline NTIA & $\begin{array}{l}\text { National Telecommunications and Information Administration (US Department of } \\
\text { Commerce) }\end{array}$ \\
\hline NUASCP & National Unmanned Aircraft Systems Credentialing Program \\
\hline NWS & National Weather Service \\
\hline ORM & operational risk management \\
\hline ORNL & Oak Ridge National Laboratory \\
\hline PIC & pilot in command (for UAS operations, referred as remote pilot in command) \\
\hline RPAS & remotely piloted aircraft system \\
\hline RTB & return to base \\
\hline
\end{tabular}




$\begin{array}{ll}\text { RTF } & \text { ready-to-fly } \\ \text { SA } & \text { situational awareness } \\ \text { SAR } & \text { Synthetic Aperture Radar } \\ \text { SD } & \text { secure digital } \\ \text { SOSC } & \text { Systems Operations Support Center (FAA) } \\ \text { SUA } & \text { special use airspace } \\ \text { sUAS } & \text { small unmanned aerial system } \\ \text { TFR } & \text { temporary flight restriction } \\ \text { TIR } & \text { thermal infrared } \\ \text { TSA } & \text { Transportation Security Administration (US Department of Homeland Security) } \\ \text { UA } & \text { unmanned aircraft } \\ \text { UAS } & \text { Unmanned Aerial System; Unmanned Aircraft System } \\ \text { UASRC } & \text { Unmanned Aerial Systems Research Center } \\ \text { UAV } & \text { unmanned aerial vehicle } \\ \text { VFR } & \text { visual flight rule } \\ \text { VHF } & \text { very high frequency } \\ \text { VLOS } & \text { visual line of sight } \\ \text { VMC } & \text { visual meteorological condition } \\ \text { VO } & \text { visual observer }\end{array}$




\section{PREFACE}

This technical manual is about doing things safely. It isn't so much a how-to guide as it is a collection of best practices from unmanned aerial system (UAS) operators from all over the world. The desired end state is to provide a touchstone for utility businesses, directors, managers, and operators that will inform them as they begin to strategize, plan, and incorporate this technology into day-to-day operations.

Unmanned aircraft have been around longer than anyone reading this preface. Previously the domain of military operations and some dedicated hobbyists, the technology has become commoditized.

Miniaturization of computational components, mixed with ubiquitous GPS access and leveraged manufacturing economies of scale, has introduced relatively aerodynamically stable personal drones into everyday life.

The change that is upon us now is that the barrier for access to this technology is a few hundred US dollars. A person with no training or experience can purchase one of these machines and fly it into the National Air Space the same day. The following analogy is one I frequently use when discussing this three-dimensional risk with people who have little experience with aviation, airspace, or UASs.

Let us say that someone goes into a big-box store and purchases a go-cart. Upon leaving the store, he starts the go-cart and immediately drives it across the parking lot; across the interstate, obeying no right of ways or traffic laws or signs; and across people's property, at random. People respond, "That's crazy. No one would do that!" However, that is exactly what many, and perhaps most, new drone "drivers" do.

Most people living in modern societies with automobiles and well-marked roads inherently understand that such behavior would pose unacceptable risk to public safety, security, and privacy. However, knowledge of airspace and the risks associated with UAS flight is not as widespread as knowledge of the risks associated with manned terrestrial vehicles.

At this early stage of small UAS use, there isn't a widely shared mindset of norms and behaviors concerning drone use, much less expertise. Policies, regulations, and laws are still being written, while the technology improves and the ownership numbers increase. In the United States, the Federal Aviation Administration has set regulations for safe flying and certification requirements for commercial UAS operators. However, commercial use of small UASs is still in its infancy in the United States.

In this manual, what we hope to provide energy companies is a body of knowledge to inform their steps moving forward. Possible uses of the information may include as a baseline to start a UAS program or for developing a scoring rubric for vetting potential UAS contract operators. Not all of the topics will be relevant to every organization, location, or mission, but it is hoped that the manual will reduce or mitigate the risks associated with UAS activities - especially to our critical energy infrastructure. 



\section{ACKNOWLEDGMENTS}

This document would not have been possible without many talented people sharing their hard-won knowledge and sometimes costly lessons learned in the field. Their motivation to move the UAS industry forward, safely and professionally, has made this endeavor possible. I gratefully acknowledge contributions from the following persons and organizations for this manual.

My friend of 25 years, and only very recent technical collaborator, William H. (Bill) Monday, without whom this knowledge would have remained a collection of files on my hard drive-Semper Fi.

Words cannot express my debt to the editor, V.J. Ewing, for her skills in taking a data collection, with random narrative, and making it into a cogent and readable technical manual.

None of this would be possible without Dr. Shaun Gleason and Dr. Jeff Nichols who had faith in my vision for founding a UAS Research Center at Oak Ridge National Laboratory (ORNL), the US Department of Energy's largest science and energy laboratory.

Thanks to my key collaborator and legitimizer, Dr. Peter Fuhr, Distinguished Scientist at ORNL and the Technology Director for the ORNL Unmanned Aerial Systems Research Center. He helps me see the future.

Finally, thanks to the following supporters who saw the need and potential for such a publication and provided a lion's share of the information contained herein and are now part of a genius network.

- Lilian Bruce, Director of Strategic Planning, Electric Power Board

- Dexter Lewis, Senior Research Engineer, Southern Company

- Jerry Hendrix, Executive Director, Lone Star UAS Center of Excellence and Innovation, Texas A\&M University, Corpus Christi, Texas

- Taylor Abington, UAS Program Manager, Avion Solutions Inc.

- Doug Olsen, UAS Project Management, UAS Center of Excellence, University of North Dakota •

- John Bridewell, PhD, Professor of Aviation, University of North Dakota

- Doug Campbell, UAS Operations Manager, Middle Tennessee State University

- Walter Stockwell PhD, Director of Technical Standards, DJI

- Joshua M. Riedy PhD, Chief Operating Officer, EdgeData

- Eoin Ross, Transpower New Zealand Limited

- Josh Hendrix, Program Manager, AUV Flight Services

- Hector Ubiñas, UAS Program Lead, San Diego Gas and Electric

- Fabio Bologna, Program Manager, Electric Power Research Institute
- Adam Tolentino, Engineer II, Hawaiian Electric

- Brian Sloboda, Senior Program Manager, National Rural Electric Cooperative Association

- Dennis H. Yankee, Senior Manager, Tennessee Valley Authority

- Tim Trebilcock, Project Technician, Ontario Power Generation

- Philip Owen, Director of UAV Operations, enrGies

- Gregory Crutsinger, PhD, Scientific Program Director, Parrot

- Lance "Sky" King, Senior Policy Advisor, Northrop Grumman Corporation

- Robert J. Coullahan, President and Chief Operating Officer, Readiness Resource Group

- Tero Heinonen, Chief Executive Officer, Sharper Shape Inc.

- Terry Miller, President, Transport Risk Management, Inc.

- Marty Rogers, Director, Alliance for System Safety of UAS through Research Excellence

- $\quad$ Eric S. Hare, Chief Operating Officer, Talon Aerolytics, LLC

- Christian Smith, Chief Executive Officer, Interactive Aerial 



\section{REVISION RECORD}

\begin{tabular}{|l|l|l|l|}
\hline \multicolumn{1}{|c|}{ Version } & Date of Update & Updated by & Comments on Updates \\
\hline $\begin{array}{l}\text { An Early Survey of Best Practices for the Use } \\
\text { of Small Unmanned Aerial Systems by the } \\
\text { Electric Utility Industry }\end{array}$ & 14 February 2017 & Rick Lusk & Initial Draft \\
\hline & & & \\
\hline & & & \\
\hline & & & \\
\hline & & & \\
\hline & & & \\
\hline
\end{tabular}





\section{BACKGROUND}

Remotely piloted aerial vehicles have been used, primarily by military forces, since the Second World War. Recent technological advancements in microprocessor computing power, miniaturization of sensors, and purpose-built software have enabled unmanned aerial system (UAS) technology to establish a significant new niche in the evolution of aviation. Alternatively labeled unmanned aircraft systems, unmanned aerial vehicles, or simply drones, small UASs (sUASs) are becoming readily accessible for commercial, governmental, and private use across a myriad of far-ranging applications.

The purpose of this document is to examine UAS applications as related to the electric utility sector and provide an early survey of best practices for safe operations. The combination of an inexpensive and widely assessable technology platform with a public and industry with a near-zero knowledge baseline motivated this effort. As adoption and implementation of these aircraft accelerates and becomes more mainstream, it is imperative that safe practices be promulgated as quickly and as widely as possible to ensure the safety of the public and the security of our power generation, transmission, and distribution critical infrastructure.

We hope that this document serves as a simple stepping off point to inform policy makers, utilities, regulators, and operators about safely using UAS for the electric utility industry moving forward. As the early adopter phase transitions into majority use, there will be greater bodies of work and practice to draw on for this community of interest.

Oak Ridge National Laboratory (ORNL) is the largest science and energy laboratory within the US Department of Energy national laboratory complex. ORNL has partnered with members from various organizations in academia, the commercial industry, and government to advance collaboration on research and development programs that will safely and successfully integrate UAS into the national and international airspace to fulfill identified requirements, with technical training being one of those requirements.

On November 1, 2015, the ORNL Unmanned Aerial Systems Research Center (UASRC) was founded and dedicated to use cutting-edge science to identify and create applicable solutions to the multidisciplinary challenges facing this nascent technology. UASRC connects commercial industry with world-class research tools and capabilities to translate scientific breakthroughs into commercial applications. By advancing the engineering and integration of technology subsystems, UASRC maximizes the power to design and develop innovative, transformative UAS solutions that improve safety, productivity, and use.

UASRC focuses on UAS performance and durability in a variety of markets:

- Energy: The exploration of future resources and acquisition of data for accurate life-cycle assessment.

- Environment: The ability to reach remote areas and repeatedly conduct rapid and comprehensive inspections.

- Infrastructure: The remote inspection, monitoring, and assessment of man-made structures.

- Public Safety: The ability to quickly analyze disaster areas to expedite the deployment of firstresponders and activation of emergency management strategies.

- Security: The tactical surveillance and real-time monitoring of high-risk areas and hazardous conditions. 
By leveraging ORNL's diverse capabilities and state-of-the-art facilities, UASRC can identify and respond to real-world challenges at an accelerated pace:

- Computational Science and Data Analytics: Quickly capture, analyze, and steward large volumes of data.

- Energy Storage: Use simulations to identify battery limitations and develop alternative technologies.

- Materials Science: Characterize material integrity to design and test new processing methods.

- Navigation and Communications: Enhance system integration to advance navigation platforms and communications networks.

- Power Electronics: Design scalable electronic systems to increase efficiency and optimize in-flight charging capabilities.

- Propulsion: Utilize advanced platform technology to reduce system stress and improve operating performance.

- Sensors: Expand sensor capabilities to enable greater and more precise measurements and data collection.

UASRC was established to provide innovative, technology-based applications for the marketplace. ORNL offers industry a range of mechanisms to partner with UASRC.

- Cooperative Research and Development Agreement

- Technology Licensing Agreement

- Small Business Innovation Research

- Small Business Technology Transfer 


\section{PURPOSE}

This best practices manual is intended to help professionalize the safe and proper operation of UAS work. UAS technology has become a leader in advanced aeronautical technologies and is the next step for aviation in the United States and the world. The current and potential uses of UASs are massive and far ranging. UASs of all types have already been used in a wide variety of applications in practical ways such as aerial photography, agriculture, commercial delivery, entertainment, exploration, national defense, public safety, surveying, and thermography. Envisioned future applications will allow for advances in precision agriculture, energy sector remote sensing, national security and law enforcement reconnaissance, utilities analysis, etc.

For this manual, we have specifically narrowed the range of interest to the training and operational application of UASs for work such as site surveying, critical infrastructure inspection, and power line inspection in the electric power industry while also addressing the future requirements of the technology for full integration into the National Airspace System (NAS).

First, there needs to be some basic terminology clarification: UASs are also known as drones, or remotely piloted aircraft systems (RPASs), unmanned aircraft (UA), or unmanned aerial vehicles (UAVs) —all these terms are interchangeable, and for the purposes of this document, we will refer to the technology and the aircraft platform as "UAS." (See Appendix A for a complete list of definitions related to UASs.) UASs have become readily available to the public and private sectors, and their use has provided a new perspective to our world.

For many electric utility industry observers, it's not a matter of whether UASs will be integrated into the operational landscape, but when. The practical applications of UASs are poised to transform the electric power industry, along with several other industries, resulting in a critical need for worker safety, system reliability, and data collection and storage. The prospect of obtaining an aerial view of transmission and distribution (T\&D) lines, towers, and poles without deploying a line crew is very attractive to many utilities for the savings in money and time it offers.

After evaluating systems and processes that exist or that still need to be fully developed, this operating manual provides information on the best practices to be used by electric sector operators in the application of UASs in their work to professionalize and standardize the subject areas and important topics relevant to UASs use in the electric utilities industry. This manual may serve to help develop standards enabling the energy utility industry to operate UASs for electric grid monitoring, and to further practical applications, energy exploration research, and infrastructure inspection.

T\&D utilities have traditionally performed line inspections and maintenance, storm damage assessments, and vegetation management using line crews, manned aircraft, and third-party inspection service companies. Working on T\&D systems is cost-intensive, difficult, and highly dangerous. UASs have demonstrated their wide effectiveness in other government and commercial applications and some electric power utilities have already begun using them on $T \& D$ infrastructure for collecting data in remote areas and over long distances in a more efficient and cost-effective manner than would be required of traditional, on-site manned inspections.

It should be noted that the nation's electric power grid and the T\&D network that directly supports it are all a part of our nation's critical infrastructure. This best practices manual will provide the basics of UASs use and application for electric utility work, including the types of sensor systems that could be used by a utility, the UASs allowable work environment and limitations, and numerous references on how best to use this new tool in a safe and professional manner. 
Most of the topics discussed include safety checklists, flight planning, emergency procedures, and other considerations when flying in NAS. More specifically, airspace operations in utilities inspection will be emphasized. Along with providing refresher information to experienced pilots, the guidelines serve to act as an educational tool for new UASs pilots and those who wish to become pilots in the future.

Finally, checklists are in place to ensure the operation is executed to an acceptable standard. In the manned aviation world, pilots must follow 14 CFR 121.315 Cockpit Check Procedure before launch. Should the UAS community desire to merge into NAS, standards and practices that mirror general aviation and the existing safety culture will be required. (Lone Star UAS Center Excellence and Innovation, 2016) 


\section{OVERVIEW: FEDERAL AVIATION ADMINISTRATION'S SMALL UNMANNED AERIAL SYSTEM REGULATIONS}

\subsection{COMPREHENSIVE NEW REGULATIONS FOR SMALL UNMANNED AERIAL SYSTEMS}

The Federal Aviation Administration's (FAA's) comprehensive new regulations for the routine, nonrecreational use of sUASs - more popularly known as drones - went into effect August 29, 2016. The provisions of the new rule, known as Part 107 or Rule 107 (14 CFR Part 107), are designed to minimize risks to other aircraft and people and property on the ground. A summary of Rule 107 follows.

The FAA has put several processes in place to help you take advantage of the rule.

Waivers: If your proposed operation does not completely comply with Part 107 regulations, you'll need to apply for a waiver of some restrictions. You will have to prove the proposed flight will be conducted safely under a waiver. Users must apply for these waivers at the online portal located at https://www.faa.gov/uas.

Airspace Authorization: You can fly your drone in Class G (uncontrolled) airspace without air traffic control (ATC) authorization, but operations in any other airspace [i.e., instrument flight rules (IFRs)] need air traffic approval. You must request access to controlled airspace via the electronic portal at https://www.faa.gov/uas, not from the individual air traffic facilities.

The FAA tries to approve requests as soon as possible, but the actual time will vary depending on the complexity of an individual request and the volume of applications received. Requests should be submitted at least 90 days before the intended flight date in controlled airspace.

Aeronautical Knowledge Test. Testing centers nationwide now administer the Aeronautical Knowledge Test required under Part 107. After passing the test, you must complete an FAA Airman Certificate and/or Rating Application at https://iacra.faa.gov/IACRA/Default.aspx to receive your remote pilot certificate.

It may take up to 48 hours for the website to record that you have passed the test. The FAA expects to validate applications within 10 days. You will then receive instructions for printing a temporary airman certificate, which is good for 120 days. The FAA will mail a permanent Remote Pilot Certificate within 120 days.

The new regulations do not apply to "model aircraft operations" that meet all the criteria specified in Section 336 of Public Law 112-95 (which is now codified in part 101), including the stipulation they be operated only for hobby or recreational purposes. (FAA, 2016)

\subsection{SUMMARY OF 14 CFR PART 107 (FAA RULE/PART 107)}

The FAA Part 107 regulations, which legalize commercial drone use, dramatically increase the potential number of UAS users. Anyone can now legally operate a UAS as part of a business after first passing an aeronautical knowledge test and then registering with the FAA. In the first 2 days after the test became available, 1,338 people had completed the test with an $88 \%$ pass rate.

\subsubsection{Small Unmanned Aerial System Operational Limitations}

The following restrictions and limitations are based on "Operation and Certification of Small Unmanned Aircraft Systems; Final Rule" as published in the Federal Register, vol. 81(124), June 28, 2016, pp. 42063-42214. (FAA, 2016) 
- $\quad$ sUASs must weigh less than $55 \mathrm{lb}(25 \mathrm{~kg})$.

- sUASs must remain within visual line of sight (VLOS) of the remote pilot in command (PIC) and the person manipulating the flight controls of the sUAS. Alternatively, the sUAS must remain within VLOS of the visual observer (VO).

- sUASs must remain close enough to the remote PIC and the person manipulating the flight controls of the sUAS for those people to be capable of seeing the aircraft with vision - unaided by any deviceother than corrective lenses. One of the top hazards to flight is improper operation of flight controls.

- sUASs may not operate over any persons not directly participating in the operation, not under a covered structure, and not inside a covered stationary vehicle.

- $\quad$ sUASs are limited to daylight-only operations, or civil twilight (30 min before official sunrise to 30 min after official sunset, local time) with appropriate anticollision lighting.

- $\quad$ sUASs must yield right of way to other aircraft.

- $\quad$ sUASs may use VOs, UAS mission payload operators (MPOs), ${ }^{1}$ or other subject matter experts (SMEs) for missions, but it is not required.

- First-person view cameras cannot satisfy "see-and-avoid" requirements but can be used as long as requirements are satisfied in other ways.

- sUASs are limited to a maximum ground speed of $100 \mathrm{mph}$ (87 knots) and a maximum altitude of $400 \mathrm{ft}$ above ground level (AGL) or, if higher than $400 \mathrm{ft}$ AGL, remain within a $400 \mathrm{ft}$ radius of a structure; fly no higher than $400 \mathrm{ft}$ above structure's uppermost limit.

- sUASs must observe a minimum weather visibility of 3 miles from the control station (CS).

- sUASs may operate in Class B, C, D, and E airspace with the required ATC permission. (When a sUAS is within controlled airspace and controlled by an ATC, it is called "positive control.")

- $\quad$ sUASs may operations in Class G airspace without ATC permission. No clearance (i.e., IFRs) is required.

- No person may act as a remote PIC or VO for more than one UAS operation at one time.

- No operations from a moving aircraft.

- No operations from a moving vehicle unless the operation is over a sparsely populated area.

- No careless or reckless operations.

- No carriage of hazardous materials.

- $\quad$ sUAS operations require preflight inspection by the remote PIC.

\footnotetext{
${ }^{1}$ A mission payload operator may also be referred to as a sensor operator.
} 
- A person may not operate a sUAS if he or she knows or has reason to know of any physical or mental condition that would interfere with the safe operation of a sUAS.

- Foreign-registered sUASs are allowed to operate under Part 107 if they satisfy the requirements of Part 375.

- External load operations are allowed if the object being carried by the UAS is securely attached and does not adversely affect the flight characteristics or controllability of the aircraft.

- Transportation of property for compensation or hire is allowed provided that

○ the aircraft, including its attached systems, payload, and cargo weigh less than $55 \mathrm{lb}$ total;

○ the flight is conducted within VLOS and not from a moving vehicle or aircraft; and

0 the flight occurs wholly within the bounds of a state and does not involve transport between (1) Hawaii and another place in Hawaii through airspace outside Hawaii; (2) the District of Columbia and another place in the District of Columbia; or (3) a territory or possession of the United States and another place in the same territory or possession.

Most of the restrictions enumerated above are waivable if the applicant demonstrates that his or her operation can safely be conducted under the terms of a certificate of waiver (COW).

\subsubsection{Remote Pilot in Command Certification and Responsibilities}

The following requirements and responsibilities were taken from Table 1 of the executive summary of Part 107 as published in the Federal Register, June 28, 2016. (FAA, 2016)

- Part 107 establishes a remote PIC position.

- A person operating a sUAS must either hold a remote pilot airman certificate with a sUAS rating or be under the direct supervision of a person who does hold a remote pilot certificate (i.e., remote PIC).

- To qualify for a remote pilot certificate, a person must

○ Demonstrate aeronautical knowledge by either

- passing an initial aeronautical knowledge test at an FAA-approved knowledge testing center or

- hold a part 61 pilot certificate other than student pilot, complete a flight review within the previous 24 months, and complete a sUAS online training course provided by the FAA.

- Be vetted by the Transportation Security Administration (TSA).

$\circ$ Be at least 16 years old.

- Part 61 pilot certificate holders may obtain a temporary remote pilot certificate immediately upon submission of their application for a permanent certificate. Other applicants will obtain a temporary remote pilot certificate upon successful completion of TSA security vetting. FAA anticipates that it will be able to issue a temporary remote pilot certificate within 10 business days after receiving a completed remote pilot certificate application.

- Until international standards are developed, foreign-certificated UAS pilots will be required to obtain an FAA-issued remote pilot certificate with a sUAS rating. 


\subsubsection{Remote Pilot in Command Requirements}

The following requirements and responsibilities were taken from Table 1 of the executive summary of Part 107 as published in the Federal Register, June 28, 2016. (FAA, 2016)

- Make the sUAS available to FAA, upon request, for inspection or testing, including any associated documents/records required to be kept under the rule.

- Report to the FAA within 10 days of any operation that results in serious injury, loss of consciousness, or property damage of at least $\$ 500$.

- Complete a preflight inspection, including specific aircraft and CS system checks, to ensure the sUAS is in a condition for safe operation.

- Ensure that the sUAS complies with the existing registration requirements specified in 14 CFR $\S 91.203(a)(2)$.

Note: A remote PIC may deviate from the requirements of this rule in response to an in-flight emergency.

\subsubsection{Aircraft Requirements}

FAA airworthiness certification is not required. However, the remote PIC must complete a pre-flight check of the sUAS to ensure that it is in a condition for safe operation.

\subsubsection{Model Aircraft}

Part 107 does not apply to model aircraft that satisfy all of the criteria specified in Section 336 of Public Law 112-95. The rule codifies the FAA enforcement authority in part 101 by prohibiting model aircraft operators from endangering NAS safety. (FAA, 2016)

\subsubsection{Exemptions and Waivers}

For specialized situations, an operator can apply to FAA for an exemption or waiver to most any of the above individual limitations if the operator can demonstrate a safety case for doing so. However, because Part 107 is so new, it may take some time before waivers are routinely granted by FAA.

A Part 107 operator's waiver may ask to use an aircraft heavier than $55 \mathrm{lb}$, to conduct operations at night, to operate beyond visual line of sight (BVLOS), etc. However, such exceptions will be granted by FAA only on a case-by-case basis and after careful consideration of the specific situation and the associated safety risks. Any waivers granted for any of the rules will be for a specific operator and application (e.g., electric utility work).

With specific regard to PL 112-095 Section $333^{2}$ operators, each holder of a Section 333 exemption may have differences that apply just to it, though most approvals granted have limits similar to those established by the basic Part 107 rule set. Whether operating under Part 107 or Section 333, any operator who violates the terms of its flight authorization puts not only its own aircraft and any ground/infrastructure below at significant risk but more importantly the lives of those aboard other

\footnotetext{
${ }^{2}$ By law, any aircraft operation in the national airspace requires a certificated and registered aircraft, a licensed pilot, and operational approval. Section 333 of the FAA Modernization and Reform Act of 2012 (PL 112-095) grants the Secretary of Transportation the authority to determine whether an airworthiness certificate is required for a UAS to operate safely in the National Airspace System.
} 
aircraft. Such actions are also subject to significant fines or other enforcement action by FAA, the latter of which can include partnerships with state and local law enforcement agencies. (Olsen, 2016)

\subsubsection{Websites for Regulatory and General Unmanned Aerial System Operation Reference}

Even if your organization has approved UAS work, one must acquire FAA approval to fly. FAA has established a number of UAS regulations for various civil and public entities. Depending on your organization, certain regulations may apply. Public entities may apply for public COWs or Certificates of Authorization (COAs) for their UAS permissions (Table 1). COAs can be restricted to a given area for a certain UAS operation or can have a nationwide reach below $400 \mathrm{ft}$ in Class $\mathrm{G}$ airspace. COAs may require Notices to Airmen (NOTAMs) to be published and operators to be trained. Some distinct advantages to public COAs are more flexibility for certain UAS uses and obtaining emergency COAs (e-COAs). Please note: FAA is required to approve or deny applications within 90 business days. You can contact 9-AJV-115USACOA@FAA.GOV for more information on public COAs. Also, see your organization COA document for a complete description of your flight requirements. (Lone Star UAS Center Excellence and Innovation, 2016)

Civil or commercial organizations are given a roadmap to achieve UAS compliance in the United States. Commercial operators have the choice to continue to use the Section 333 exemption process or to use the new Part 107 sUAS rules. Both processes allow the vendor to fly UASs with a few restrictions. An advantage to Part 107 over Section 333 exemptions is the ability to apply for exemptions or waivers through a submission of the organization's safety case analysis. Waivers for operation of sUASs include daylight operations and multiple aircraft operation. Part 107 pilots will require a remote pilot certificate. Taking the initial aeronautical knowledge test and paying the test fee at a Knowledge Testing Center will depend on whether you are an existing Part 61 pilot (manned aircraft) certificate holder. Visit the FAA website for a full list of waiver requests and pilot requirements.

Table 1. Types of FAA Unmanned Aerial System Operating Authorities Including Certificates of Waiver or Authorization (COAs)

\begin{tabular}{|l|l|}
\hline \multicolumn{1}{|c|}{ Category } & \multicolumn{1}{c|}{ Definition } \\
\hline Civil Operations (Nongovernmental) & $\begin{array}{l}\text { Any operation that does not meet the statutory criteria for public aircraft } \\
\text { operation is considered a civil aircraft operation and must be conducted in } \\
\text { accordance with all FAA regulations applicable to the operation. }\end{array}$ \\
\hline Model Aircraft (Hobby or Recreation Only) & Model aircraft operations are for hobby or recreational purposes only. \\
\hline Public Operations (Governmental) & $\begin{array}{l}\text { FAA issues a COA that permits public (government) agencies and } \\
\text { organizations to operate a particular aircraft, for a particular purpose, } \\
\text { in a particular area. FAA works with these organizations to develop } \\
\text { conditions and limitations for UAS operations to ensure they do not } \\
\text { jeopardize the safety of other aviation operations. }\end{array}$ \\
\hline
\end{tabular}

Hobbyist also have a few restrictions for flying UASs throughout the nation. Their UASs still must be less than $55 \mathrm{lb}$ and fly below $400 \mathrm{ft}$. Hobbyists have to operate in accordance with a community-based set of safety guidelines such as contacting the ATC tower when flying within 5 miles of an airport. UAS organizations and campaigns such as the Academy of Model Aeronautics and Know Before You Fly provide great education on the "ins" and "outs" of recreational flight. FAA has extended hobbyist rules to students, if the operation pertains to the principals of flights, aerodynamics, and airplane design and advances UAS-related knowledge. Please note that this is flown strictly for recreational use and not sensor or data-based research or UAS flight training. (Lone Star UAS Center Excellence and Innovation, 2016) 
For further guidance regarding the regulatory requirements of operating UASs under Part 107 and additional UAS use information and guidance refer to the following.

http://www.faa.gov.uas

https://www.faa.gov/uas/getting_started/fly_for_work_business/becoming_a_pilot/

http://www.faa.gov/uas/registration/

http://www.faa.gov/licenses_certificates/aircraft_certification/aircraft_registry/

http://www.faa.gov/regulations policies/faa regulations/

http://www.faa.gov/regulations_policies/advisory_circulars/

http://www.faa.gov/documentLibrary/media/Advisory Circular/AC 107-2.pdf

http://www.suasnews.com/faa-drone-333-exemption-holders/

http://www.knowbeforeyoufly.org

Keep in mind that federal, state, and local laws will take precedence over the guidance offered in this best practices manual. All personnel conducting UAS operations should become familiar with the applicable FAA regulations and any associated updates. If a COA has been granted by FAA, compliance will be in accordance with the specific guidance delineated within the assigned COA.

\subsubsection{National Airspace System}

Per FAA Part 107, UAS users are authorized to fly their UASs in Class G (uncontrolled) airspace without ATC authorization. UAS operations in any other airspace require air traffic approval. A UAS operator must request access to controlled airspace via the electronic portal at www.faa.gov/UAS, not from the individual air traffic facilities. Appendix N contains the "FAA Controlled Airspace Classifications" for reference. Appendix C, "Unmanned Aerial System Work in Support of Electric Utilities-Mission Plan," provides a checklist for airspace considerations before conducting UAS work on electric utilities.

Should the UAS community desire to merge into NAS, standards and practices that mirror those of the general aviation industry and its existing safety culture will be needed. Some sUAS manufacturers have already made strides in this area. DJI, the largest sUASs manufacturer, has incorporated a number of safety features. Its flight limitation system will prevent flights in restricted areas such as airports and sensitive institutes. By default, sUASs have a $400 \mathrm{ft}$ software flight limit. DJI's new software is allowing pilots to confirm that they have the FAA authorization to fly in certain areas. Nevertheless, the new software will still restrict flights over prisons, areas covered by temporary flight restrictions (TFRs), and critical infrastructure. (Lone Star UAS Center Excellence and Innovation, 2016)

\subsubsection{Unmanned Aerial System Operations in Foreign Airspace}

Each country has its own designated NAS regulatory agency to set flight rules. Any US-based electric industry companies with international operations should consult the regulators for each country in which they plan to conduct UAS operations and supporting work.

\subsubsection{Update on Part 107}

On September 27, 2016, several UAS industry representatives met with members of Congress and informed them that Part 107 "is a good first step toward boosting the growth of the unmanned systems industry, but it remains to be seen how fast and flexible the rules' waiver provisions will be." The recent FAA budget extension passed by Congress includes a call for the creation of a comprehensive UAS research and development roadmap and also extends the exemption process to allow for BVLOS operations. (AUVSI, 2016) 


\subsubsection{Unmanned Aerial Systems Platform Overview}

At this time, there are no official categories or classes defining the UASs other than the common configuration designations like fixed-wing, multi-copter, helicopter, and others (Figure 1). The only true distinction to FAA is the weight of the UAS - whether it is under or over $55 \mathrm{lb}$. The majority of sUAS platforms on the market today are battery-powered quadcopters carrying a simple camera or similar payload for a sensor and can only fly about 20 min before needing to land to be charged. 
UAS The nuts and bolts

Types of UAS

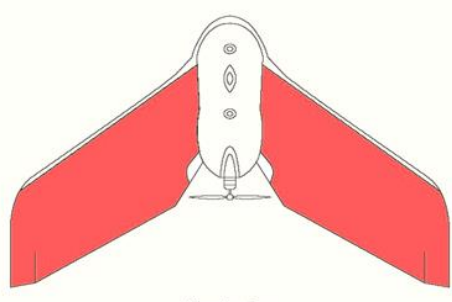

Fixed wing
UAS with airplane-like wings

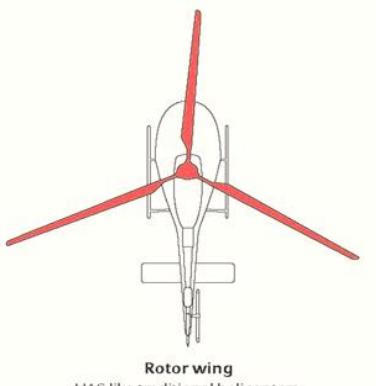

Rotor wing
UAS like traditional helicopters

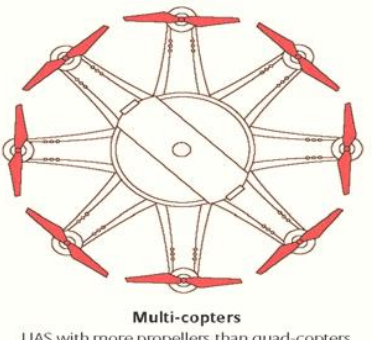

Multi-copters
UAS with more propellers than quad-copters

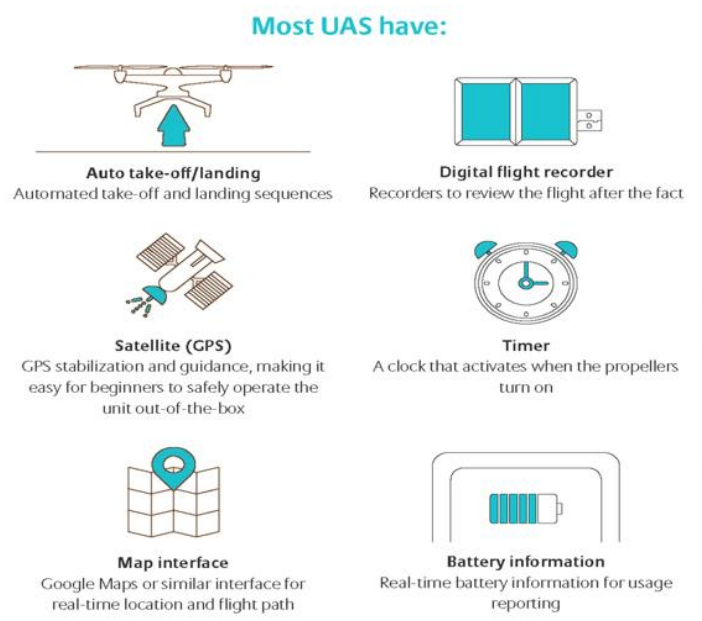

Some UAS have:

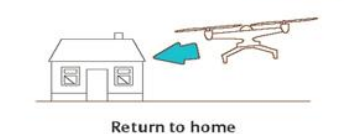

Return to home
Automatic return to home technology
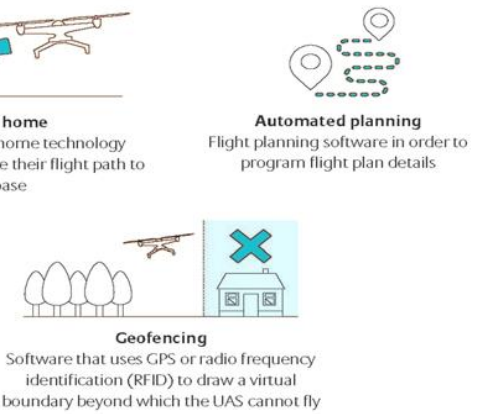

Controllers:

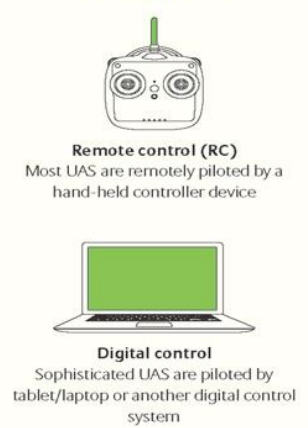

Cameras/sensors:

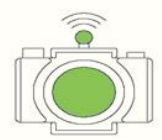

Normal/High-end All UAS have cameras and sensors. Some higher priced UAS have sophisticated
cameras and sensors that make up the most expensive part of the UAS package (up to $\$ 500,000$ for certain sensors)

What makes them fly?

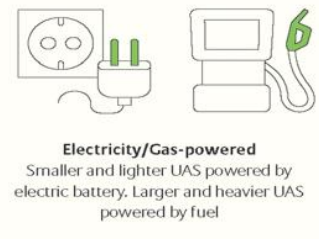

Figure 1. Unmanned aerial system (UAS) platform overview. (Transport Risk Management, Inc., Unmanned Risk Management, 2016). 


\section{BEST PRACTICES FOR USE OF SMALL UNMANNED AERIAL SYSTEMS BY THE ELECTRIC UTILITY INDUSTRY}

In 1989, the US Patent Office records indicate that a patent was granted for a, "Monitoring system for power lines and right-of-way using a remotely piloted drone."3 Although probably considered very futuristic at that time, the ability to conduct remote sensing with a remotely controlled UAS hovering over power lines has now become reality. Developments in aviation, sensing, and software technology have powered a revolution in unmanned flight. In the next decade, the burgeoning commercial drone industry is projected to generate more than $\$ 82$ billion for the US economy and, by 2025 , could support as many as 100,000 new jobs. (The White House, 2016)

The current, and future, legal and regulatory landscape regarding UASs is dynamic at best and will no doubt evolve as new applications and capabilities are developed and used. How other public, private, and academic organizations currently use UASs vary across a broad spectrum, and it is believed to continue to grow in its uses. In the meantime, the electric utility industry is must deal with both the positive and negative effects of this new technology. With specific regard to the latter, here are two examples, one in the United States and the other abroad, that have literally impacted work on the electric utility infrastructure.

- United States, October 26, 2015. A UAS flew into electric power lines, causing a power outage in West Hollywood for 647 customers. The outage lasted 4.5 hours before power was completely restored. The device involved was a DJI quadcopter. The owner/operator is unknown. (Aeriographer, 2015)

- New Zealand, September 9, 2015. In Waimate a UAS lost communications and automatically returned to base. On its return route, it struck a $220 \mathrm{kV}$ Roxburgh-Islington transmission line and became stuck. As a result, a line crew had to be dispatched, and the line had to be switched to a safe configuration for UAS retrieval. This retrieval process took 3 hours. A similar incident was recorded on the New Zealand Northpower's network within the same week. (Transpower New Zealand Limited, 2016)

The above instances are only two examples of known cases associated with UAS technology and the electric power industry. There are surely many more that go unreported.

On a positive note, UASs can be a great enabler when surveying infrastructure systems - especially when they are used to range over vast areas and inspect the greatly diverse components of the electric grid. Electric utilities should plan to assess how they will use UASs to change how they evaluate electric facilities. If it does not currently have one, your electric power utility should seriously consider the development of a UAS policy; and if it does, it should continually evaluate it with regard to how best to integrate - in whole or in part - the various dynamic aspects of both the industry and the new UAS technology.

\subsection{WHY UNMANNED AERIAL SYSTEMS FOR THE ELECTRIC UTILITY INDUSTRY? THE SIMPLE ANSWER: ECONOMICS}

The UAS technology innovation is transforming the electric utility industry. As a tool, UASs can be used to (1) conduct efficient electric T\&D infrastructure inspections, (2) effectively detect problems with electric equipment, (3) access equipment in difficult terrain, and (4) provide direct support for electric utility vegetation management (Table 2 ).

\footnotetext{
${ }^{3}$ US patent US4818990A granted April 4, 1989, to Roosevelt A. Fernandes.
} 
UASs can provide faster access to high-quality, real-time visual inspection for all types of utilities that may need to inspect power lines, oil and gas pipelines, transmission towers, buildings and bridges, wind turbines, and rotor blades enabling the inspector or team to access the information from a safe position. The inspection of complex infrastructure will benefit from regular aerial monitoring. The ability to sense in three dimensions, take thermal readings, and detect metal strain will greatly improve the results of infrastructure inspection. sUASs that can hover can get close enough to provide a new level of detail, improving support to maintenance, operations, and overall performance.

Use of the UAS technology should greatly increase safety of operations and maintenance, reduce the time needed to conduct inspections or surveys, and help reduce the overall cost of electric grid operations and maintenance. Manned aircraft typically cost between $\$ 1,000$ and $\$ 2,000$ per hour to operate. By comparison, UASs can cost as little as $\$ 200$ to $\$ 300$ per hour to conduct similar, or greater, tasks; provide higher quality service; and, if the work is properly conducted, provide an increased level of safety simply due to the fact that the collection platform is unmanned.

There are hundreds of thousands of miles of transmission lines, millions of miles of distribution lines and thousands of generation facilities in the United States. In March 2015, FAA approved Commonwealth Edison to use UASs in the inspection of its power line network, thus making it the first electric utility to receive authorization to operate drones in the field. (Utility Dive, 2015)

Now, electric utilities across the United States are wasting no time in taking advantage of the new FAA 107 Rule authorizing the use of UASs for commercial purposes. UASs are being viewed as a new enabling tool in the maintenance of the current, albeit aging, electric infrastructure and in the building of future, smarter electric infrastructure. More than 20 utilities - Duke Energy, Exelon, National Grid, Southern Company, Pacific Gas \& Electric, and Xcel Energy, to name a few-have already tested UASs for inspecting T\&D lines for anything from normal wear and tear to storm damage while using the previous, temporary rules from the FAA. With the recent approval of Part 107, electric utilities are ready to now expand this new capability. (USA Today, 2016)

It is foreseen that in the not-too-distant future electric utilities could place UASs on a line worker's utility truck, so when in the field, the crews could rapidly deploy the UAS and fly them up a utility pole to do inspections that would normally require the time and effort of someone climbing that same utility pole and all the previous effort that entailed.

UAS application would result in dramatic cost savings over manned fixed-winged and helicopter flights, as well as increased safety, especially over expansive wilderness and difficult terrain. Fixed wing platforms generally provide operators greater endurance for large aerial surveys. Rotary wing platforms on the other hand generally have lower endurances but more precise controls.

However, UASs equipped with sensors acquire data, not necessarily information, and users - especially utility workers - need timely, reliable information, not reams of data. So, whatever data the UAS captures needs to be converted into useful information for the user. But good information is only as good as the accuracy of the underlying sensor data.

The good news is UASs are flexible and can be flown with different sensors that can be configured to detect a variety of potential data requirements. Additionally, the sensor and data collection technology available for potential onboard UAS use by electric utilities and aerial imaging processing is progressing rapidly. Finally, aerial sensors can provide the data, but there needs to be an investment in time, money, skills, and software to get actionable insights from the data to convert it into useful information from which to develop a course of action. 
All this being said, the electric utility industry still has quite a way to go before fully incorporating UASs as a regular part of their operations by a professionalized workforce. The potential is great, and widespread future UAS incorporation within the nation's various electric utilities appears likely. Early adopters within the electric utility industry have already started preventative maintenance prioritization based on UAS collected data.

\subsubsection{Unmanned Aerial System Work Benefits and Drawbacks}

Table 2. Benefits (green shading) and Drawbacks (red shading) of Unmanned Aerial System Application

\begin{tabular}{|c|c|}
\hline Topic Area & Description \\
\hline Access & $\begin{array}{l}\text { Unmanned Aerial Systems (UASs) can fly at a low altitude and enter into isolated or remote } \\
\text { areas that are typically inaccessible via foot or by manned aircraft. }\end{array}$ \\
\hline $\begin{array}{l}\text { Needs versus } \\
\text { Cost }\end{array}$ & $\begin{array}{l}\text { UASs have the capacity to produce high-resolution images. Some can perform desired post- } \\
\text { processing as they conduct data collection. However, the higher the image resolution, the more } \\
\text { expensive the system required. An organization must determine how to balance data } \\
\text { requirements versus cost. }\end{array}$ \\
\hline $\begin{array}{l}\text { Data } \\
\text { Management }\end{array}$ & $\begin{array}{l}\text { UASs collect large quantities of data that may contain personally identifiable information. An } \\
\text { organization must have appropriate and secure storage for this data. }\end{array}$ \\
\hline Ease of Use & $\begin{array}{l}\text { Simply put, UASs are easier to operate and maintain than manned aircraft. Therefore, UASs } \\
\text { require less training. }\end{array}$ \\
\hline $\begin{array}{l}\text { Increased Image } \\
\text { Coverage }\end{array}$ & $\begin{array}{l}\text { UASs can provide various types of aerial collection. For example, imagery can be against } \\
\text { pinpoint targets using panoramic images, thermal imaging, etc. Thus, the capturing of views } \\
\text { that are not otherwise possible lends to the UASs' overall utility. }\end{array}$ \\
\hline Less Disruptive & $\begin{array}{l}\text { UASs can be quieter than manned aircraft and so less likely to disturb the general public, } \\
\text { wildlife, etc. or any other entities within the operating area. }\end{array}$ \\
\hline Low 0 & $\begin{array}{l}\text { Operating UASs to conduct inspections, logistical runs, surveys, etc. can be significantly less } \\
\text { expensive than obtaining satellite images, conducting ground surveys, and/or operating } \\
\text { manned aircraft with the overall cost expected to go down over time. }\end{array}$ \\
\hline $\begin{array}{l}\text { No or Low Cloud } \\
\text { Interference }\end{array}$ & $\begin{array}{l}\text { UASs typically fly at a low altitude. This means that cloud cover will usually not affect the } \\
\text { collection the same way it affects collections by other platforms. }\end{array}$ \\
\hline Noise Abatement & $\begin{array}{l}\text { Even though UASs typically make a reduced amount of noise compared to manned aircraft, } \\
\text { UASs do create noise that could negatively impact inhabitants within the operating area. }\end{array}$ \\
\hline $\begin{array}{l}\text { Post-Mission } \\
\text { Analysis }\end{array}$ & $\begin{array}{l}\text { If a UAS does not analyze data during in-flight collection, or if the analysis requirement is too } \\
\text { complex for that sort of automated analysis, the organization must often employ staff and } \\
\text { other computational resources to process the data. }\end{array}$ \\
\hline $\begin{array}{l}\text { Potential for } \\
\text { Accidents }\end{array}$ & $\begin{array}{l}\text { Although "sense and avoid" technology has improved, UASs still pose an increased potential } \\
\text { for airborne collisions with hazardous objects, including other aircraft. }\end{array}$ \\
\hline Safety & $\begin{array}{l}\text { UASs provide a safer alternative than traditional, manned methods of airborne operations for } \\
\text { infrastructure inspection, goods delivery, etc. }\end{array}$ \\
\hline $\begin{array}{l}\text { Sensitivity to } \\
\text { Weather }\end{array}$ & $\begin{array}{l}\text { Like manned aircraft, UASs are subject to the same sensitives resulting from inclement } \\
\text { weather, albeit to varying degrees. UASs can be more sensitive to wind or precipitation than } \\
\text { larger aircraft, but they may also be able to adapt to the weather changes with more agility due } \\
\text { to their lower operating altitudes. }\end{array}$ \\
\hline Short Endurance & $\begin{array}{l}\text { UASs generally possess shorter flight endurances than manned aircraft, which limits their } \\
\text { overall operations and work area. }\end{array}$ \\
\hline
\end{tabular}




\subsubsection{Unmanned Aerial System Visual Inspection of Electric Utilities' Infrastructure Assets}

The National Electrical Grid consists of a rapidly aging network. Despite widely varying and innovative maintenance and stop-gap improvements, the power grid, and its delivery infrastructure, continues to suffer from aging across the country. Contributing factors to the current state of the electric grid and its consequences include:

- Aging equipment: older equipment has higher failure rates, leading to customer interruption rates affecting the economy and society; also, older assets and facilities lead to higher inspection maintenance costs and further repair and restoration costs.

- Obsolete system layout: older areas require serious additional substation sites and rights-of-way that cannot be obtained in the currently supported areas and are forced to use existing, insufficient facilities.

- Outdated engineering: traditional tools for power delivery planning and engineering are ineffective in addressing current problems of aged equipment, obsolete system layouts, and modern deregulated loading levels.

- Old cultural value: planning, engineering, operating of system using concepts and procedures that worked in vertically integrated industry exacerbate the problem under a deregulated industry. (Willis, 2001)

Previously, electric companies routinely inspect their overhead lines by manned helicopters. Inspectors who flew aboard helicopters with binoculars and cameras to inspect the lines and recording the data in a logbook. Helicopter would hover over and around power lines and towers at the cost of safety to the pilot and the inspector. Today, manned helicopter employ automated video surveillance system to accomplish the same tasks in less time, but the element of danger still exists. Unmanned, remotely operated systems are the logical evolution in overhead power line inspection.

In a September 2003 study by the Utah State University Center for Self-Organizing and Intelligence Systems, a list of "targets," from largest to smallest, to be aerial surveilled for the electric utility industry was accomplished. (Chen, 2003) This list follows.

- Large

○ Broken/slack guyed and stay wires

$\circ \quad$ Leaning power poles

- Sagging power line spans

○ Vegetation encroachment

- Medium

- Air break switches

- Anti-climb guards

- Fuse units (low and high voltage)

- Pole mounted equipment

- Safety notices

- Small

- Arcing traces on fuse gear and switches

- Broken and chipped insulators

- Corroded joints on conductors 
The above list of targeted electric equipment and infrastructure could be used to determine the best UAS platforms and sensor configurations to be used for data collection by considering the size and location of the infrastructure to be inspected.

Use of UAS work offers a novel approach for electric utilities to save both money and time in the inspection of the network. UASs with advanced sensors can obtain detailed, close-up views or other data of communications towers, distribution lines, transmission lines, and additional electric infrastructure that could be impossible or unsafe for manned collection. Using UAS technology in place of, or in addition to, conventional methods to inspect and assess electric infrastructure has the potential to reduce costs by reducing the total number of hours required to complete these operations, increasing safety, and producing additional data the utility previously had not collected.

In the past, electric utility companies may have conducted maintenance inspections with ground crews every 4-5 years - especially in the case of infrastructure in difficult to access areas. With the advent of UASs carrying airborne sensors, they now have the ability to conduct these same inspections annually, at reduced cost, and most probably more effectively. Transmission systems are thus the most logical first step in UAS application due to the easy access to the T\&D lines and towers from aerial observations and the size of the structures. Additional areas where UAS inspections could be used for an electric utility include the following.

- $\mathrm{T} \& \mathrm{D}$
- Line construction
- Line maintenance
- Line rebuild
- Line design
- Line and safety training
- Pole inspection
○ Metering
- Power plant maintenance
- Fiber optic installations

- Substations

- Substation construction

- Substation modifications

UAS visual inspections of the electric utilities' infrastructure can be one of the most valuable and convenient tools for determining equipment problems when performed by experienced electrical technicians. UAS visual inspections using payload sensors whose images can be examined by the 'trained eye' of a thorough electrical technician could potentially save electric utilities millions of dollars should, for example, a catastrophic bushing failure occur. UAS visual inspections using high definition (HD) cameras are a good first step in the incorporation of UAS work into any electric utility maintenance program. The HD imagery potentially taken using a UAS for visual inspection could be used to supplement reporting; thus, giving more detailed data upon which to make a decision - such as the priority of a workload, or a more logical course of action. One of the top hazards to flight is improper inflight decisions or planning.

The influence that UAS imagery products could potentially have for both long- or short-term work scheduling impacts are worthy of consideration. For the former, long-term maintenance scheduling of inspection intervals could either increase, or decrease, based upon the specific equipment's condition and reliability requirements. For the latter, short-term emergency action or an immediate preventive maintenance by crews could be undertaken based upon the aerial inspection findings. 


\subsubsection{Unmanned Aerial System Thermal Inspection}

Thermal, or infrared, inspection is a proven nondestructive technology for the early detection of impending failures in electric systems. Infrared inspections are a simple way to ensure electric equipment is operating optimally. Past infrared inspections have reduced risk, increased operational safety, and bolstered production efficiency. For these same reasons, the integration of airborne thermal inspection with UASs offers to increase the effectiveness of proactive electric utility maintenance programs to protect against system breakdowns. Combining thermal inspections with the agility of the UAS technology only increases an already cost-effective means of testing during normal operations to keep electric equipment operating safely and efficiently. The benefits of electrical inspection work using UAS thermal inspection technology include increased safety, minimized preventative maintenance and troubleshooting time, quick detection of problems without service interruption, and significant reduction in unscheduled power outages.

\subsubsection{Solar Inspection}

Several utilities in Europe have been routinely inspecting solar panels for casualties by using visual inspection via thermal image sensors. Even during daylight hours, localized anomalous heat areas or "hot spots" on the surface of the panels can be detected indicating where a solar panel is not performing within operational norms.

When flying inspections over solar panels, it is usually considered prudent to fly with an offset viewing angle so that if aircraft power is lost, the aircraft will not fall onto the panels.

\subsubsection{Unmanned Aerial System Support for Electric Utility Storm Damage Assessment}

UASs are now being widely used for storm damage assessment. For example, the US Army Corps of Engineers is using UASs for surveillance during flood events. (US Army Corps of Engineers, 2016)

To improve electric infrastructure damage assessment, utilities can use UASs to assess how sensor technology may assist in collecting information on damage to electricity delivery systems following a major storm event. Sensor data collected during flyovers could be passed through computer-processing algorithms providing the location and details of damage, enabling a more focused response, proper crew resourcing, and accurate materials procurement.

However, UASs alone cannot replace storm damage assessment systems for the electric utility industry but rather can augment the data collection systems: foot/vehicle patrols, social media, work dispatch systems, and advanced distribution management systems or supervisory control and data acquisition systems. UASs are data collection tools and can integrate into larger solutions for collecting, analyzing, and operating the electric system.

A post-storm lesson learned resulting from Hurricane Matthew (2016) is to have UAS crews practice before severe weather events. As a part of utility emergency planning, UAS crews need to practice during good weather, checking UAS assets in rural areas and hidden rights-of-way before a severe weather event occurs.

\subsubsection{Unmanned Aerial System Support for Electric Utility Vegetation Management}

Vegetation-caused failures are among the top causes of electric distribution system interruptions.

"Vegetation management" for the electric utility industry is a broad term that includes the pruning of trees and vines and removal of underbrush that could otherwise negatively impact the electric utility network. 
The trees and bushes that make up the "utility forest" can cause clearance problems with overhead conductors (i.e., power lines and associated transformers). UASs can quickly and efficiently be used by electric utilities to identify both dangerous and hazardous trees located near power lines for the prioritization of threat removal.

Hazard trees and danger trees are not the same thing. Hazard trees are a subset of danger trees. These terms are defined in ANSI standards (ANSI 300 Part 7). Accordingly, a danger tree is any tree on or off the right of way that could contact electric supply lines. A hazard tree is a structurally unsound tree that could strike electric supply lines when it fails (Figure 2). (Guggenmoos, 2011)

Climbing vines can quickly work their way toward conductors or into switchgear busing compartments, and any type of vegetation can attract unwanted wildlife, which can cause additional issues. UASs will further optimize utility vegetation management by taking advantage of a wide array of sensor technologies.

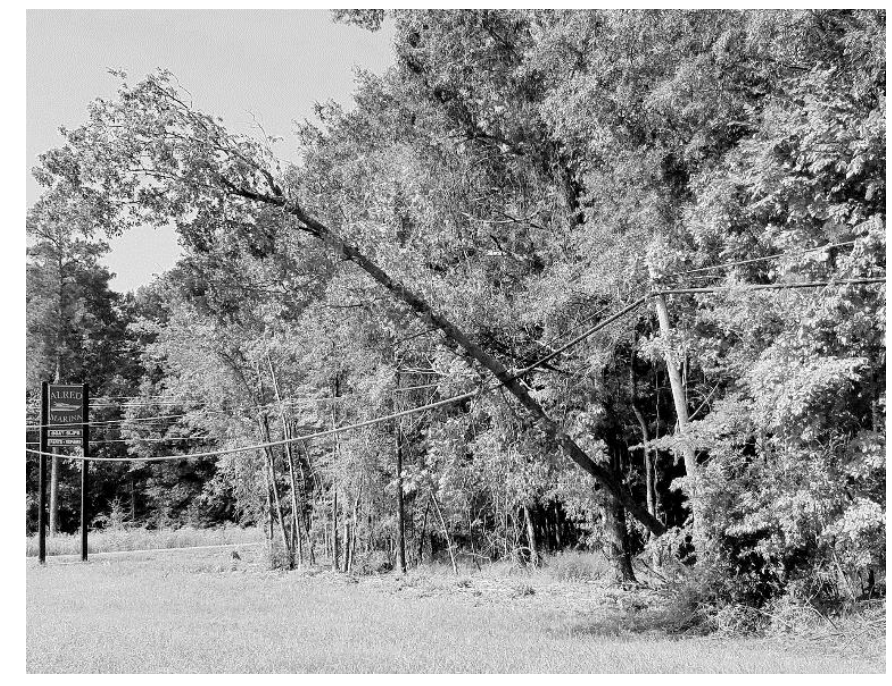

Figure 2. Failed hazard tree. (Source: Rick Lusk.)

\subsection{UNMANNED AERIAL SYSTEM CONCEPT TO SUPPORT ELECTRIC UTILITY WORK}

It is important to maintain the confidence of other airspace users, landowners, and FAA that the electric utilities' UAS work will be conducted in a professional and safe manner. To be able to operate missions of this nature, electric utilities should establish reputations as responsible UASs users. To achieve this, specific attention must be given to communications; detailed mission planning; inspection execution (with special considerations for using UASs near energized infrastructure); and, most importantly, safety. Successes in initial UAS applications in a visual flight rules (VFRs) environment could enable the expansion of UAS use by the electric utilities into more complex applications such as BVLOS, IFRs, and night operations. It is essential that electric utilities build reputations for well-managed, minimally intrusive UAS mission use.

In contrast to time lags inherent when using satellite and aircraft-based sensors, UASs have the capability to provide remote sensing data in near real time to crews in the field. It is this increased speed of the sensor data (e.g., imagery or radar) from the UASs that has the biggest potential for changing the priority of work and how to best respond. UAS operations and applications are far-ranging, including specific application to the electric energy sector. They may range from worksite surveying to critical infrastructure 
inspections to power line assessments. The following sections describe UAS best practices for both mission planning and inspection to support electric utility work.

\subsubsection{Unmanned Aerial System Mission Planning for Electric Utility Work}

Users of commercial and recreational UASs should be aware that in remote, rural, and agricultural areas, manned aircraft, including fixed-wing aircraft and helicopters, may be operating very close to ground level. Remote PICs conducting agricultural, easement survey, emergency medical, firefighting, law enforcement, and wildlife survey operations, as well as a variety of other services, all legally and routinely work in low-level airspace. Operators controlling UASs in these areas should maintain situational awareness (SA) and give way to and remain a safe distance from these low-level, manned airplanes and helicopters.

- Ad hoc unplanned operations should not be conducted except for emergency response to utility outages and/or manmade/natural disasters; if conducted, the application of the UAS emergency response work should be tightly controlled and regulated.

- Local utility system knowledge should be obtained before flight operations. The service providers involved in the UAS flight operations must familiarize themselves with this information and include related safety actions in work procedures.

- It is important to note that the configuration of T\&D lines and line routes may change over time. Previous knowledge should never be assumed to be current.

- All transmission lines must be treated as having a ground wire above the main conductors until the contrary is visually confirmed. Ground wires are normally of smaller diameter than the main conductors and are less visible. They may be at considerable heights above the main conductors, especially in mid-span. In some cases, ground wires are not continuous.

- Among the top hazards to flight is the failure to see and avoid objects or obstructions. Hazards and obstructions such as those for telecommunications, power distribution, and farming should be identified and avoided.

- Aeronautical charts or utility prints showing line locations should be used as reference and should never be treated as current.

- UAS flight operations should be concluded when clear visibility of power lines or other potential hazards are degraded by the effects of weather (e.g., low sun, cloud, dust, mist, rain, smoke, or snow). The UAS remote PIC should be located so as not to face into the sun while conducting flight operations.

- Among the top hazards to flight is mismanagement of fuel. A UAS flight mission should be able to be completed with $20 \%$ energy reserves (battery and/or fuel) remaining for safe return to base (RTB) in the event of an emergency. This has also been referred to as at least a 5 min reserve power or the manufacturer recommended reserve, whichever is greater.

- Safety planning should be conducted.

- Operational Risk Management (ORM) Process

○ IMSAFE Checklist (see Appendix F, "IMSAFE Checklist") 
○ Fire Safety

- No/No Emergency Parachute Use (parachute use on a UAS in the event of an airborne system failure could be a hazard for ongoing work within the electric power industry)

- Contingency planning should be conducted.

- Among the top hazards involving flight is inadequate pre-flight preparation and/or planning. A preflight checklist should be completed. The checklist should be designed so that the pilot and crew will not need to rely on their own memories for items to be checked (Lone Star UAS Center Excellence and Innovation, 2016).

- UAS flight paths should not pass directly over any buildings or populated areas unless prior consent has been given.

- If a flight path cannot be diverted around a building, then fast transit is acceptable (no hovering).

- Areas where pedestrians are likely to be present should be documented in the flight log. Flights in these areas should be planned for times when a low number of pedestrians is expected. If this is not possible, pedestrians should be directed away with signs, cones, and/or barriers, as appropriate.

\subsubsection{Unmanned Aerial System Electric Utility Work Inspection Execution}

One of the top hazards to flight is misjudgment of distance and speed. Routine inspection should approach only as close as is necessary to meet the inspection needs given the capabilities of the sensor. A typical combination of sensor capabilities and inspection needs may call for a standoff distance of 65$100 \mathrm{ft}(20-30 \mathrm{~m})$. For specialized inspection tasks requiring unique viewing angles for hard to reach areas (including potentially from below), 30-65 ft (10-20 m) may be required. Given potential variability due to wind gusts, aircraft stability, and other uncertainties, flights at less than $30 \mathrm{ft}(10 \mathrm{~m})$ from infrastructure should be done only under controlled conditions that are well understood by the UAS operator. In addition, the power industry customer needs to ensure the UAS operator is fully aware of any safety "keep out" zones or other limits on UAS operator locations such as required minimum distances from energized systems. (Olsen, 2016)

- $\quad$ Aircraft Speed. Maximum ground speed of $100 \mathrm{mph}$ (87 knots) or less.

- Altitude. Maximum altitude of $400 \mathrm{ft}$ AGL or, if higher than $400 \mathrm{ft}$ AGL, remain within $400 \mathrm{ft}$ of a structure. Preferred operational altitude of $330 \mathrm{ft}(100 \mathrm{~m})$ AGL ceiling for UAS electric utility work.

- Communications. Intra-organization radios and/or aviation bands. Implement redundant communications if possible.

- Control Link. Transceiver, communication/navigation data link transceiver, and antennas.

- Flight Route. Above and to the side of electric power lines. No overflight of public without notification or consent.

- Control Station. An interface used by the remote PIC or the person manipulating the controls to control the flight path of the sUAS (FAA, 2016). The CS is typically the location for launch and recovery of the UAS. The CS site should be surveyed before operations as the UAS to be used may require unique launching and landing areas such as a flat, $250 \mathrm{ft}(75 \mathrm{~m})$ landing zone. 
- Data Collection. All data collection (e.g., images, video) should be protected and maintained in strict compliance with organizational security policies and procedures. Whenever possible, the UAS should divert sensors away from occupied structures and uninvolved persons to minimize inadvertent, unapproved data collection.

- Flight Avoidance. Manned aircraft have right-of-way. Avoid flying near other aircraft, including other UASs.

- Infrastructure Overflight. Greater than $40 \mathrm{ft}(12 \mathrm{~m})$ above structures.

- Lateral Proximity to Electric Power Lines. Less than $500 \mathrm{ft}$ (152 m).

- Navigation. Global positioning system (GPS) and remain clear of other aircraft. Lateral proximity to electric power line - greater than $40 \mathrm{ft}(12 \mathrm{~m})$ and less than $500 \mathrm{ft}(152 \mathrm{~m})$. The use of visual reference landmarks, or pilotage, should be applied to the utmost.

- Notification. Notify landowners and other stakeholders as required of proposed operations area before conducting flight operations.

- Personnel. Remote PIC (required); UAS VO (optional); UAS MPO (optional); SMEs (e.g., electrical and safety) (optional). Minimum crew requirements will vary with organizational requirements and missions (Figure 3). General roles and responsibilities are described below.

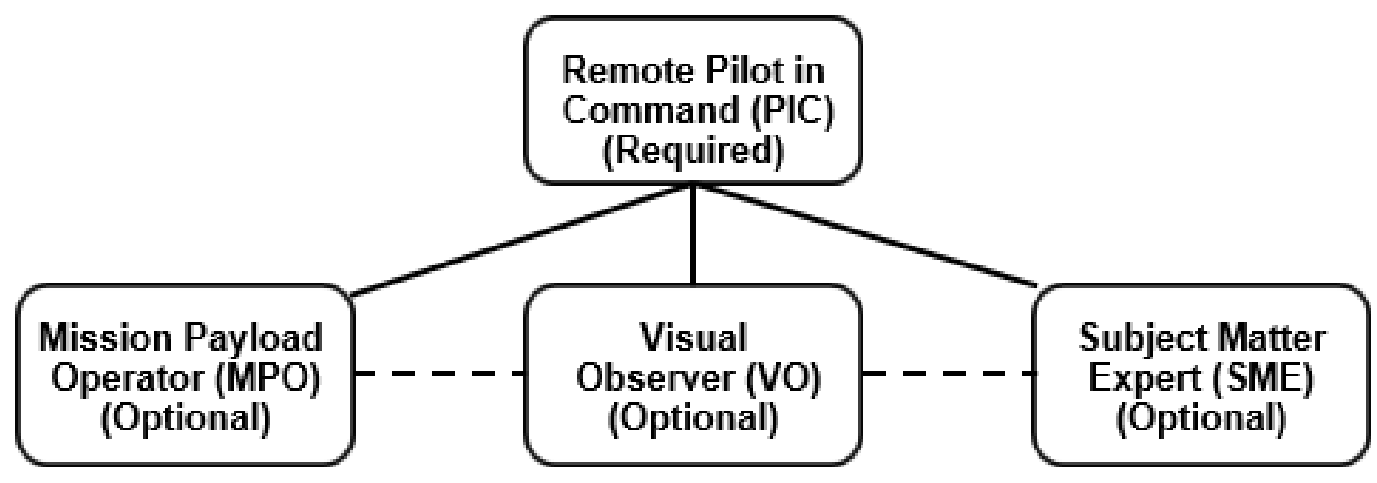

Figure 3. Unmanned aerial system required and optional crew members.

- Remote PIC or Remote Pilot. A person who holds a remote pilot certificate with a sUAS rating and has the final authority and responsibility for the operation and safety of a sUAS under Part 107. (FAA, 2016) The remote PIC is responsible for coordinating ground and flight operations including mission planning, execution, and debriefing; safe operation of the aircraft; aircrew resource management; and customer coordination and coordination with the public.

- MPO. Supports UAS flight operations by performing duties as an MPO for a particular academic, industrial, or technical area. Controls high priority UAS mission intelligence collection sensors. Controls and manages data as required. The MPO is responsible for assisting the remote PIC in coordinating ground and flight operations including mission planning, execution, and debriefing; safe operation of the aircraft; aircrew resource management; and customer coordination and coordination with the public. An MPO may also be referred to as a sensor operator (SO). 
- $V O$. A person acting as a flight-crew member who assists the remote PIC and the person manipulating the controls to see and avoid other air traffic or objects aloft or on the ground. (FAA, 2016) The VO is responsible for supporting the remote PIC in coordinating ground and flight operations including mission planning, execution, and debriefing; safe operation of the aircraft; aircrew resource management; and customer coordination and coordination with the public. A "VO" is sometimes referred to as a "spotter."

- Subject Matter Expert (SME). Supports UAS flight operations by performing duties as a SME for a particular academic, industrial, or technical area. The SME assists in the technical aspects of UAS mission operation and collection (i.e., sensor work). The SME is responsible for assisting the remote PIC in coordinating ground and flight operations including mission planning, execution, and debriefing; safe operation of the aircraft; aircrew resource management; and customer coordination and coordination with the public.

- Weather. All UAS flight operations should be conducted as daylight operations and only within the local flying area in visual meteorological conditions (VMCs) unless a waiver has been applied for and received. The minimum distance from clouds is no less than $500 \mathrm{ft}$ below and no less than $2,000 \mathrm{ft}$ horizontally. UAS flight operations are to be conducted in good visibility conditions and should be terminated when clear visibility of power lines or other potential hazards is degraded by the effects of weather.

- Visibility. Minimum visibility as observed from CS may not be less than 3 statute miles.

- Weight. UASs must not weigh more than $55 \mathrm{lb}(25 \mathrm{~kg})$ including payload.

\subsubsection{Considerations for Using Unmanned Aerial Systems Near Energized Infrastructure}

Hazards and operational skills should be considered when using a UAS near energized infrastructure. A UAS operator should possess and maintain a solid familiarity with the aircraft platform to be used. The remote PIC should be aware of details such as the size and momentum of the UAS being operated. The remote PIC should also know how long it takes to stop and fly at slow speeds.

Ensuring sound flight principles and procedures are followed for all operations regardless of the urgency of the mission will enable safe mission execution. The following subsections describe some of the items to be considered when conducting UAS operations at or near energized infrastructure.

\subsubsection{Balloons}

Balloons located at or near an operating area may be tethered to a ground site. Should a collision with a balloon occur, it could cause damage to the UAS or even entirely disable it. Therefore, balloons should be avoided entirely, including passing underneath them.

\subsubsection{Guyed Towers}

Guy wires add an additional level of complexity for flight operations. Standard procedure should be to transverse to another part of a structure by operating outside the wires. Passing between wires should not be performed. (National Association of Tower Erectors, 2016) 


\subsubsection{Recommended Approach Distances to Electric Infrastructure}

Safety should be the top priority for all work using sUASs near energized infrastructure. That is, safety of the public, safety of the personnel conducting the work, safety of the electric infrastructure, and safety of the NAS.

The ability to acquire and maintain a fix on the targeted object sensor's field of view while still maintaining a safe distance from the energized equipment and infrastructure could be challenging at times. One of the top hazards to flight is misjudgment of distance and speed. Line of sight, pilot proficiency, terrain, and weather are only a few of the elements that play a part in the safe collection of target information.

For routine inspection of energized infrastructure, UASs should approach only as close as is necessary to meet the inspection needs given the capabilities of the sensors. A typical combination of sensor capabilities and inspection needs may call for a standoff distance of 65-100 ft (20-30 m). For specialized inspection tasks requiring unique angles for hard to reach views (including potentially from below), 30$65 \mathrm{ft}(10-20 \mathrm{~m})$ may be required.

Given potential variability due to wind gusts, aircraft stability, and other uncertainties, flights at less than $30 \mathrm{ft}(10 \mathrm{~m})$ from energized infrastructure should be conducted only under controlled conditions that are well understood by the UAS operator; for example, targeting distribution poles that typically parallel roadways. In addition, the power industry customer needs to ensure the UAS operator is fully aware of any safety "keep out" zones or other limits on UAS operator locations, such as required minimum distances from energized systems. (Olsen, 2016)

In many instances, approaches for inspection may require even closer maneuvering to get better views. In those cases, extreme care should be exercised. In the case of a simple single-pole inspection, a few frames of video or a small number of still photographs may be adequate. A maintenance inspection of a section of power line will produce a large amount of video, still photographs, or possibly lidar data. Figures 4-8, from the Electric Power Board, display minimum approach distances for inspection of energized infrastructure.

- Inspections by UASs are to be conducted during good visibility conditions (i.e., VFRs).

- During UAS flight operations, when in transit the UAS should fly to one side of - and above the height of - the top conductor or ground wire, if installed, to minimize the wire-strike potential. At all times, the UAS and any protruding part must be kept well clear of the recommended minimum approach distance (MAD). Flight along a span should always be conducted so that the catenary of the highest conductor or ground wire, if installed, is visually confirmed up to the next structure.

- Where visual confirmation of the conductor within a span cannot be achieved, the remote PIC should increase altitude to a safe level that is higher than any of the supporting structures and continue further investigation from there.

- Inspection of power line components below the conductors should be done by first stopping forward motion above the level of the conductors and/or ground wire and then descending in good visibility through the hover to the chosen inspection height. A thorough inspection for collision hazards must precede the component inspection.

- On approaching a hazardous situation such as line over crossing, the remote PIC, SME, MPO, and/or VO must confer on the type of hazard expected, and each must obtain a positive visual identification before proceeding with the inspection. 
- When any crew member observes or is aware of an impending potential flight hazard, that person should immediately draw the remote PIC's attention to the hazard. If the hazard is, or is likely to become, an immediate danger, the details of the message must be clear and specific to alert the remote PIC for appropriate evasive action. Typical details for visible hazards are as follows.

O Object description (e.g., wire)

- Precise relative position (e.g., above, level, or below; left, in front, or right)

$\circ$ Distance (e.g., very close; close; or, where the hazard is not an immediate danger, the distance in hundreds of feet)

- Transmission lines must be crossed above the structures wherever possible. The minimum height for crossing a span should be a height that is above the highest of the supporting structures.

- If at any time it is necessary to turn back to reinspect the power line, the UAS should be turned in a manner to prevent dropping to an altitude below the top conductor and/or ground wire. The turn should preferably be initiated over a transmission structure. Under no circumstances should a line crossing be affected by flying underneath conductors.

- MAD of a UAS to natural or human-built structures is defined legally in many jurisdictions and also varies by industry guidelines (e.g., electric utilities unofficially recommend $40 \mathrm{ft}$ from power lines); however, there should be no overflight of the public or populated areas (e.g., farms, roadways, stadiums). (Transpower New Zealand Limited, 2016) 


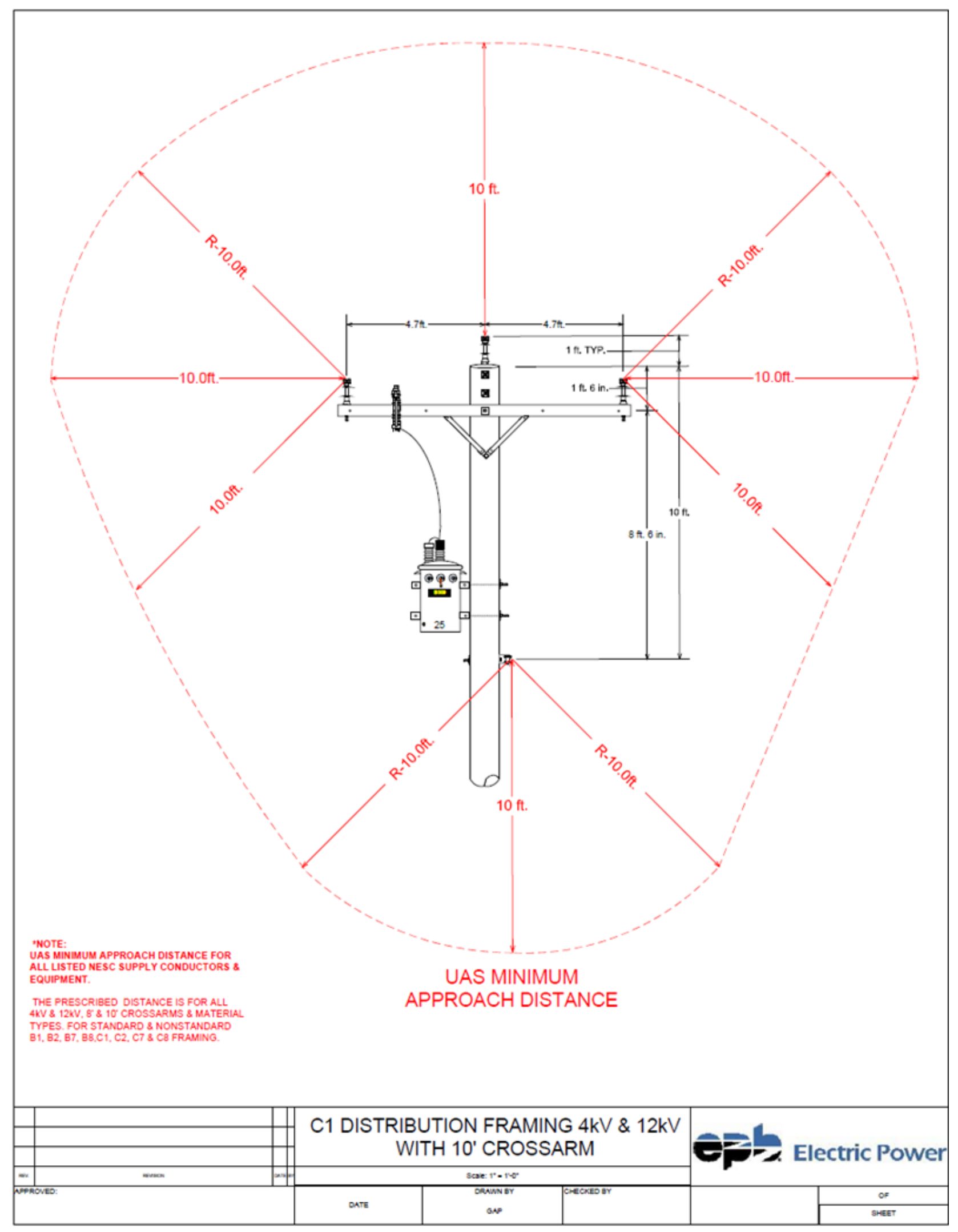

Figure 4. C1 distribution framing $4 \mathrm{kV}$ and $12 \mathrm{kV}$, with a $10 \mathrm{ft}$ cross arm. (Electric Power Board, 2016) 


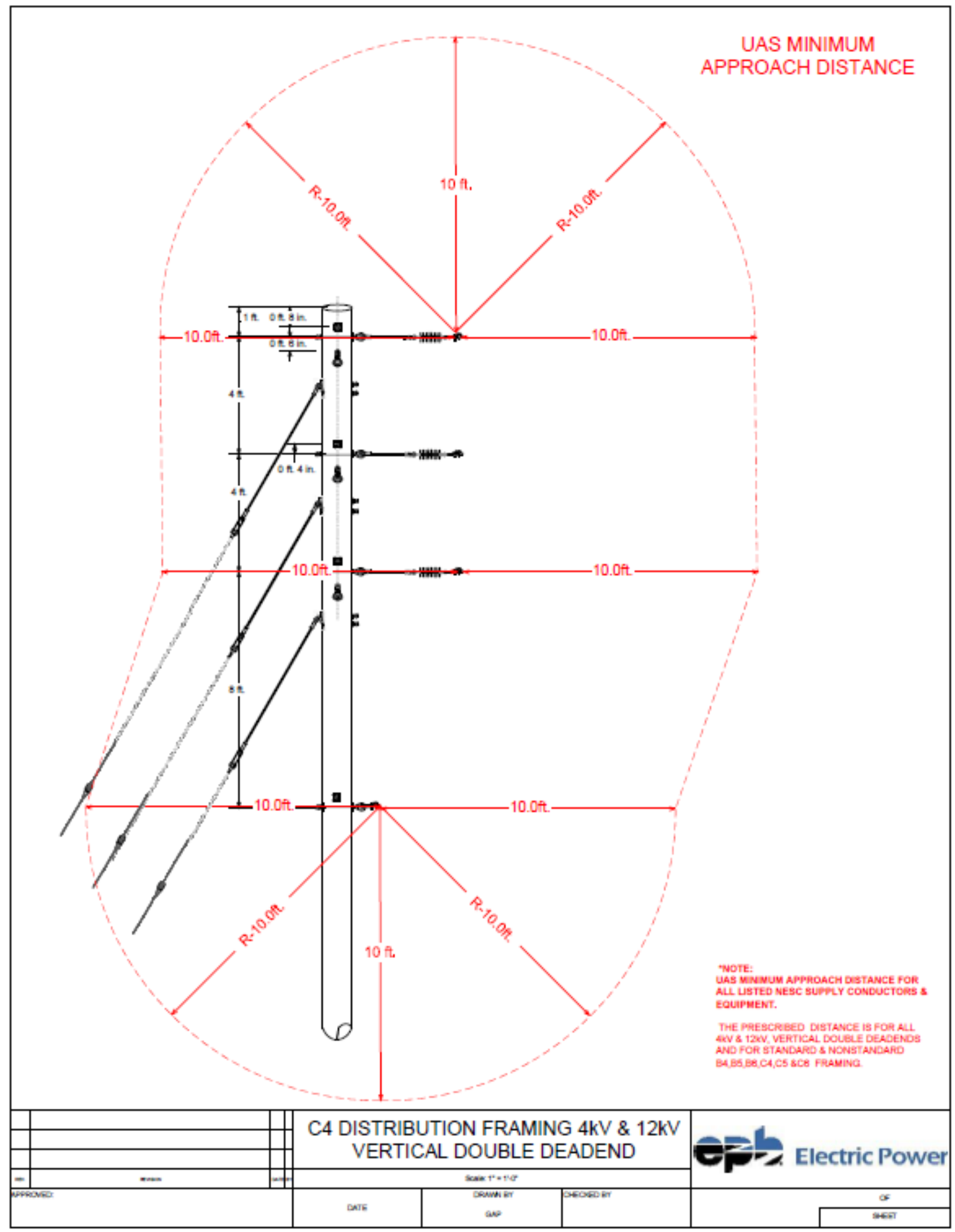

Figure 5. C4 distribution framing $4 \mathrm{kV}$ and $12 \mathrm{kV}$ vertical double dead end; lateral view. (Electric Power Board, 2016). 


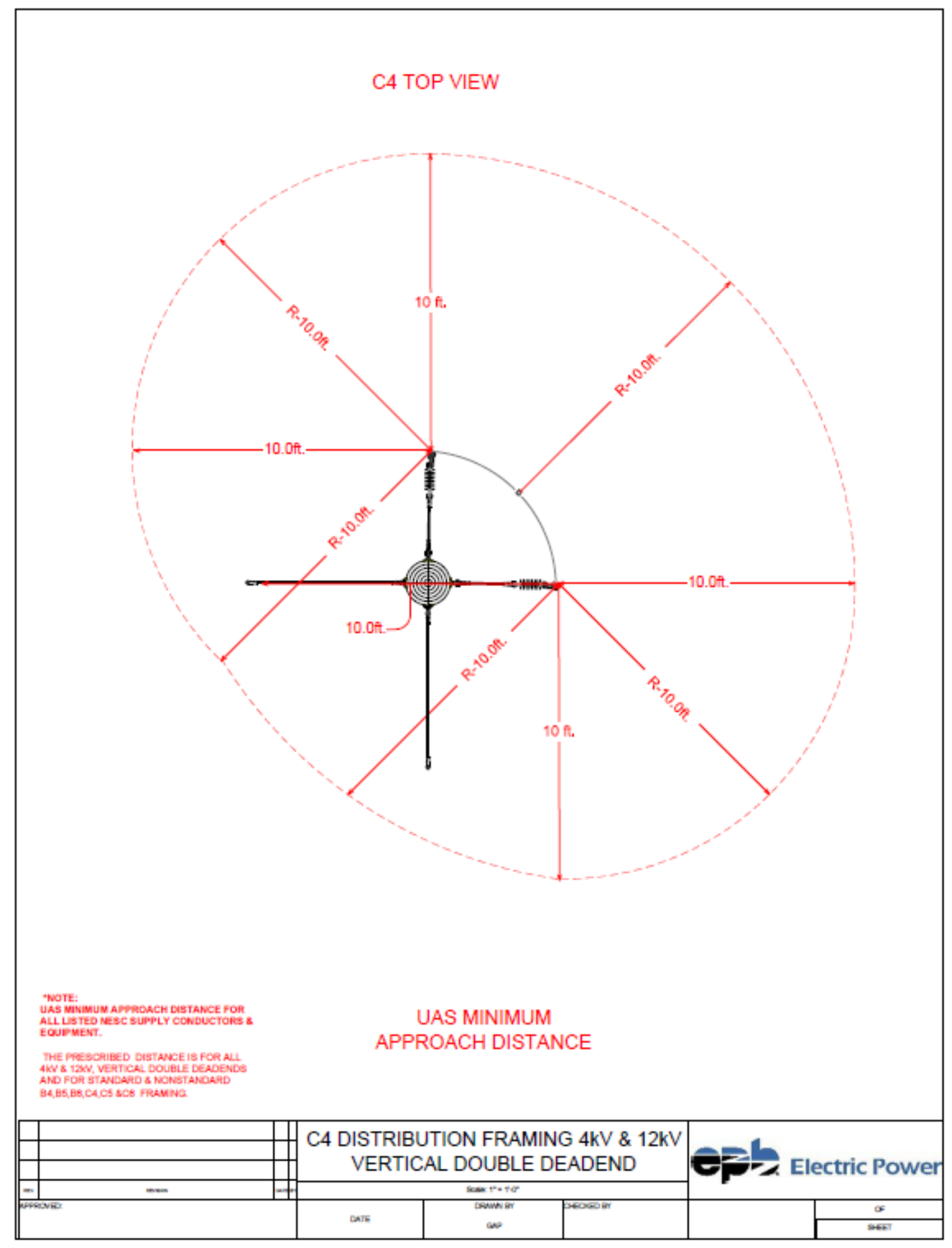

Figure 6. C4 distribution framing $4 \mathrm{kV}$ and $12 \mathrm{kV}$ vertical double dead end; top view. (Electric Power Board, 2016). 


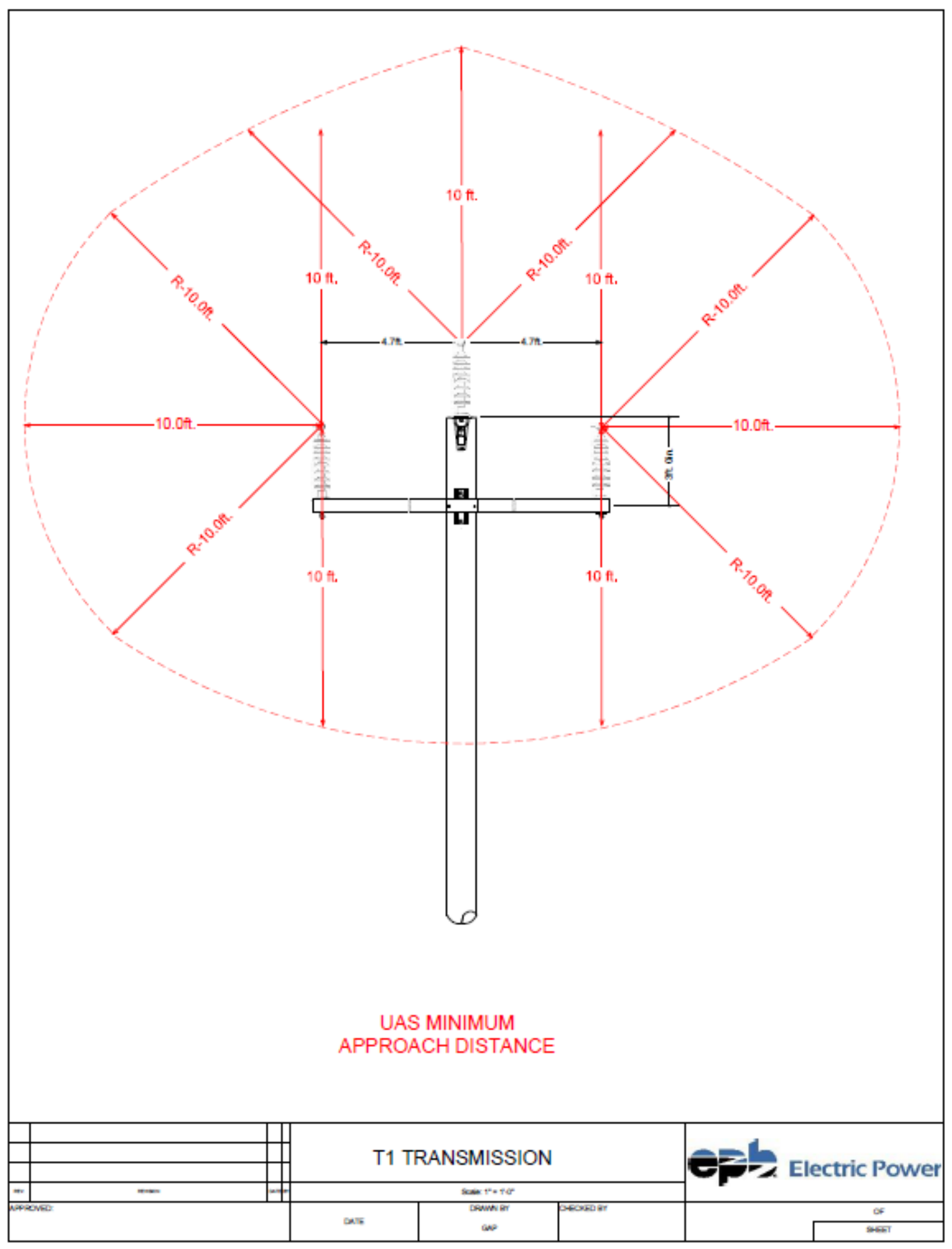

Figure 7. T1 transmission. (Electric Power Board, 2016). 


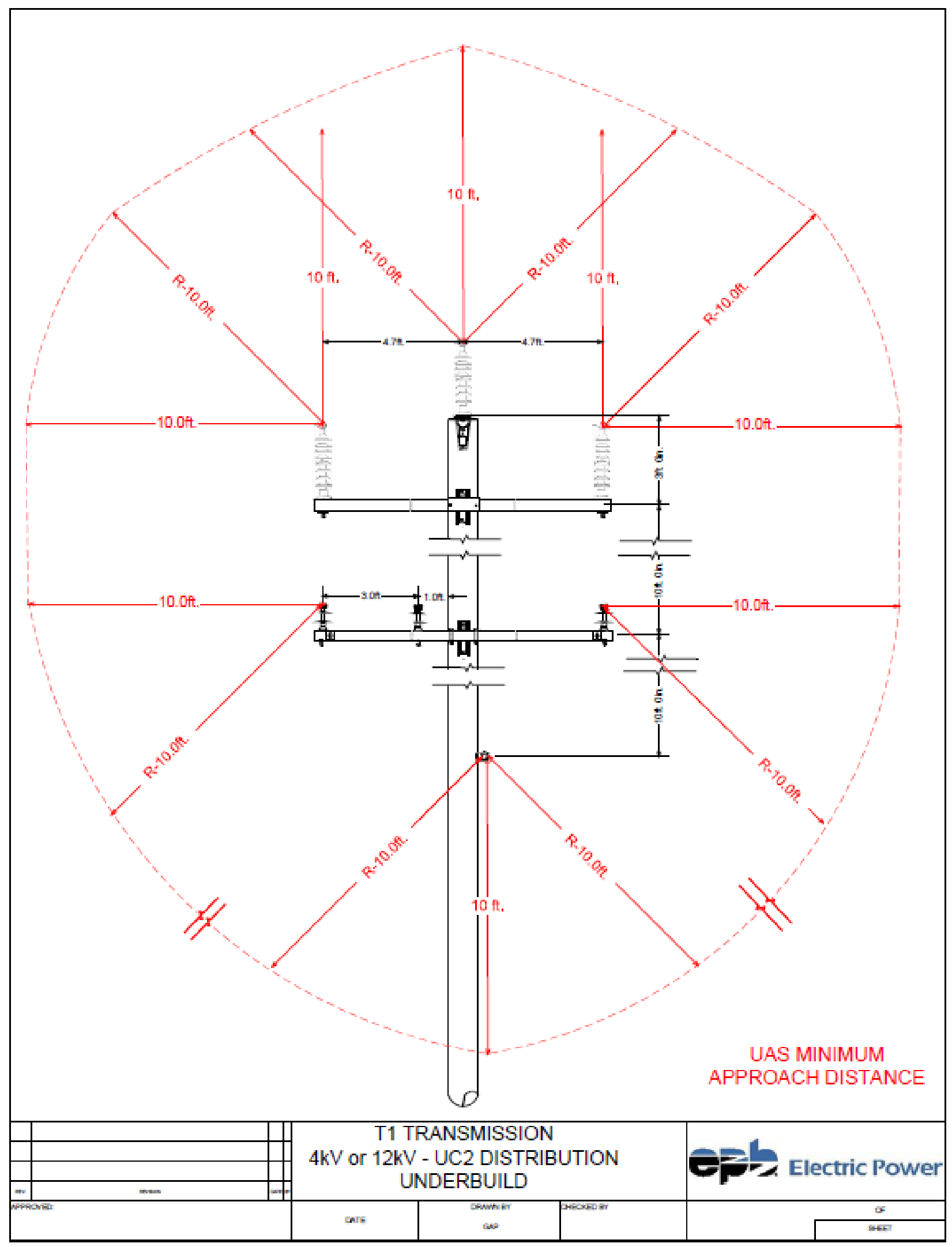

Figure 8. T1 transmission 4 kV or 12 kV UC2 distribution underbuild. (Electric Power Board, 2016). 


\subsubsection{Effect of Electromagnetic Interference on Unmanned Aerial Systems}

When operating close to energized systems, UASs can be affected by electromagnetic interference (EMI), especially when high voltages are involved. Unlike certified manned aircraft, UASs are not required to implement standard engineering practices such as shielding to minimize risk from EMI, and to date such practices have seldom been used as they tend to add mass and thus reduce flight time. With hundreds of UAS makes and models on the market, sensitivity to EMI can vary widely; further, the sensor package may very well be affected by EMI to a greater extent than the aircraft. Generally speaking, EMI should not be a factor for flights greater than $30 \mathrm{ft}(10 \mathrm{~m})$ from energized equipment; however, flights at 6-12 ft (2-4 m) have been observed to experience EMI issues. It should be noted that for each combination of UAS, sensor, and infrastructure, electromagnetic (EM) fields may have unique characteristics that could impact the mission profile. (Olsen, 2016)

In the event of a compass error on the ground, the UAS should be moved away from the energized system (e.g., power lines and wind turbines) before takeoff. In the event of an in-flight compass error, the UAS should be moved to a safe distance from the electric infrastructure and landing procedures executed.

Note: For wind turbine operations, underground power conduits, live with a large voltage of electricity, usually follow the access road up to the turbine. Moving the UAS perpendicular to the access road commonly solves these errors. (EdgeData, 2016)

The next stage of research by the Electric Power Research Institute (EPRI) regarding UAS testing will focus on UAS performance in electrical environments. It is critical that electric utilities fully understand the limitations of a UAS platform and CS when operated in high electric and magnetic fields. (Electric Power Research Institute (EPRI), 2016)

\subsubsection{Procedures While Operating Unmanned Aerial Systems Near Wind Infrastructure}

Professional UAS crew members are the key to safe and successful UAS work in support of wind infrastructure. UAS crews need to be properly trained and conduct appropriate safe work practices when operating near wind infrastructure. Any flight operation requires thorough observation of recognized safety practices and proper enforcement of procedures by trained crew members.

This section provides safety guidelines for persons associated with wind infrastructure UAS operations and suggests ways to avoid hazards and reduce the risk of accidents while operating near and around wind infrastructure (see also Appendix L). The information contained in this section is based on helicopter safety operating procedures provided by EdgeData. EdgeData serves the wind energy market assisting in repairs, upgrades and other information necessary to improve performance and extend wind turbine blade life.

\subsubsection{Positioning}

The wind turbine should be stopped by a certified wind turbine technician with the emergency brake applied before the inspections begin. (EdgeData, 2016)

\subsubsection{Proximity}

Lateral proximity to the wind turbine should be greater than $30 \mathrm{ft}(10 \mathrm{~m})$. Because of unexpected control signal loss or turbulence, which could be from the wind turbine itself, maintaining a distance of more than $30 \mathrm{ft}$ provides adequate time for evasive action. (EdgeData, 2016) 


\subsubsection{Flight Path}

The easiest flight path for a manual UAS inspection is the "ALF" method, which stands for $\underline{\text { Ascend, }}$ Lock On, and $\underline{\mathbf{F}}$ all. The UAS ascends the turbine blade until hub height; locks on to the blade with the preferred sensor package; and, finally, falls down the blade to fully capture it lengthwise (Figure 9). (EdgeData, 2016)

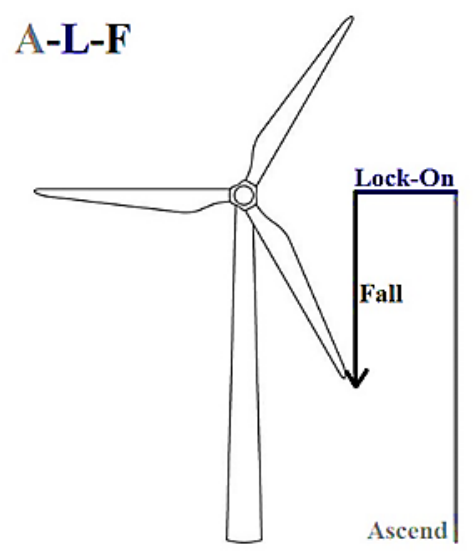

Figure 9. Ascend, lock-on, and fall (ALF) for unmanned aerial system wind infrastructure operations. (EdgeData, 2016).

\subsubsection{Danger Zones}

Being aware of danger zones is essential for safe operation around wind infrastructure. For example, the area in front of the leading edge of a wind turbine blade is a danger zone. If the UAS loses stability, the UAS in "attitude" mode can easily and quickly be pushed into the wind turbine blade without counter inputs on the controls from the UAS operator. Knowing the direction of the wind relative to the UAS and wind turbine structure is essential for safe UAS operations around wind infrastructure. (EdgeData, 2016)

\subsubsection{Bladepoint}

"Bladepoint" is the position of the UAS in reference to an aerodynamic design feature of most wind turbine blades. Essentially, these blades are most commonly not "flat" like an airplane wing. They are curved to increase their efficiency (Figure 10). Because of this, knowing you are in the danger zone known as bladepoint is important for safe operation. What's important to know here is that the UAS can be moving closer to the blade as it descends without lateral movement, but that may not be apparent from the ground.

Note: Verbally calling out to all crew members when the UAS is operating at bladepoint is a good general practice. 


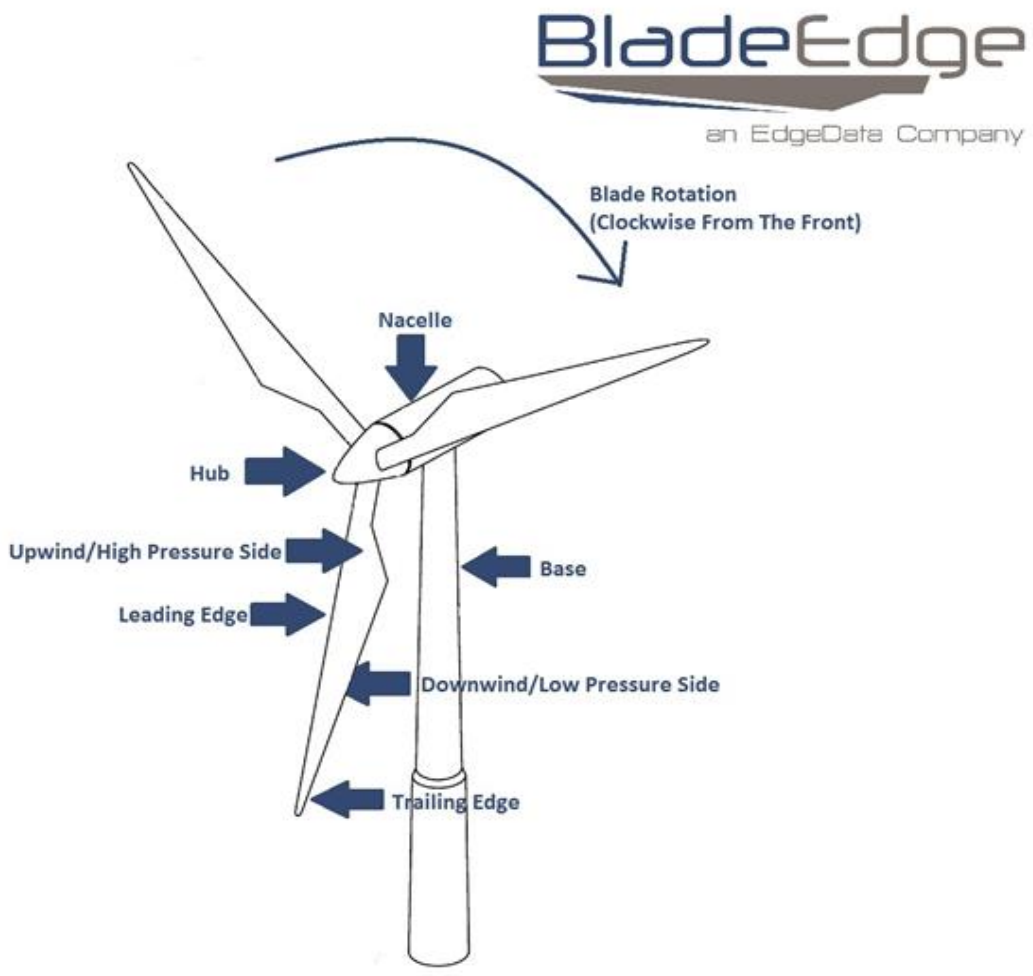

Figure 10. Wind turbine anatomy. (EdgeData, 2016).

\subsubsection{Exit Zones}

The single greatest threat to UAS operation near wind infrastructure is physical contact with the wind turbine. To safely operate, maintain continuous knowledge of the UAS's "exit zone." This is the direction in which control inputs would immediately move the UAS away from the structure in the event of an emergency. (EdgeData, 2016)

\subsubsection{Performance}

Wind gusts over the rotor disk of a hovering UAS multi-copter can cause the UAS to momentarily, but sharply, rise, significantly increasing danger. The area directly below a blade is considered a danger zone for this reason. Being prepared to use the predetermined exit zone and quickly decrease hover power while operating directly below a wind turbine blade is advised. (EdgeData, 2016)

Note: While these work practices are specifically recommended for use when operating near wind infrastructure, they also may have applicability to other UAS work environments.

\subsubsection{Procedures While Operating Unmanned Aerial Systems Near Nuclear Power Plants}

UAS operations at or near nuclear power plants should only be conducted after the proper coordination with the appropriate nuclear facility authorities and should be flown for official business only. Manned aircraft are already advised not to linger around sensitive infrastructure such as hydroelectric dams; power plants, including nuclear power plants; and refineries. UAS operators would be expected to avoid these 
facilities at the same levels. FAA NOTAMs advise pilots to avoid the airspace above, or in proximity to, nuclear power plants. UAS operators must follow the same NOTAMs and other flight restrictions that may prohibit overflights of certain facilities.

Even though nuclear power plants are built to withstand a multitude of possible malicious and/or unintended calamities, such as direct hits by commercial airliners and severe weather, and although UASs are much smaller than manned aircraft, they could potentially affect the lesser components of a nuclear power plant such as the plant's electric transmission lines should a mishap occur.

The nuclear industry has a very rich safety culture. Safety is part of everything that particular industry does. Therefore, the nuclear power industry has adopted a "safety first" approach for the implementation of its UAS programs. Nuclear facility operators currently operate UASs under FAA exemptions for the purposes of inspection, security, etc.

Nuclear power plants also have their own privacy worries as more UASs are used across the country as they could potentially be used to conduct nefarious activities such as intelligence gathering upon the nuclear facilities' apparatus and operations. For example, in October and November 2014 security breaches occurred at 13 different nuclear plants in France when UASs flew over restricted airspace. ${ }^{4}$ Although we are unaware of any unauthorized UAS flights over US nuclear plants, the incidents in France have raised noteworthy concerns within the US nuclear energy community.

\subsubsection{Unmanned Aerial System Applications at Electric Power Plants}

Whether it be hydroelectric, nuclear, or thermal, all power plants comprise a wide range of components that may be concentrated or spread throughout a particular facility. UAS applications can be used to support various work tasks within the plant site, ranging from recurring inspections to maintenance surveillance. A list of some of the UAS applications at a typical electric power plant follows.

- Surveys of pipe and pipe hanger supports

- Survey grade mapping

- Inventories of solid fuels, such as coal piles

- Inspections of ash ponds and other water features

- Inspections of exterior structures such as stacks

- Inspections following leaks or other mechanical failures to determine whether it is safe for personnel to approach

- Inspections of T\&D lines

(National Rural Electric Cooperative Association - NRECA, 2016)

\subsubsection{Overview: Visual Line of Sight UAS Operations}

The remote PIC and person manipulating the controls must be able to see the UAS at all times during flight. Therefore, the UAS must be operated closely enough to the CS to ensure visibility requirements are met during UAS operations. This requirement also applies to the VO, if used during the aircraft operation.

However, the person maintaining VLOS may have brief moments in which he or she is not looking directly at or cannot see the UAS but still retains the capability to see the UAS or quickly maneuver it

\footnotetext{
${ }^{4}$ French authorities revealed that unidentified drones had breached restricted airspace over 13 of France's 19 nuclear power plants between early October and late November 2014. The drones were believed to have been sophisticated civilian devices costing several thousand dollars, and the intrusions were seemingly coordinated and generally occurred at night.
} 
back to VLOS. These moments can be the result of actions taken for safe operation (e.g., looking at the controller to see battery life remaining) or for operational necessity.

For example, a remote PIC stationed on the ground using a UAS to inspect a rooftop may lose sight of the aircraft for brief periods while inspecting the farthest point of the roof. As another example, a remote PIC conducting a search operation around a fire scene with a sUAS may briefly lose sight of the aircraft while it is temporarily behind a dense column of smoke. However, it must be emphasized that even though the remote PIC may briefly lose sight of the sUAS, he or she always has the see-and-avoid responsibilities set out in Part 107, §§ 107.31 and 107.37.

For operational necessity, the remote PIC or person manipulating the controls may intentionally maneuver the sUAS so that he or she loses sight of it for brief periods of time. Should the remote PIC or person manipulating the controls lose VLOS of the sUAS, he or she must regain VLOS as soon as practicable.

The circumstances that would prevent a remote PIC from fulfilling those responsibilities will vary, depending on factors such as the type of sUAS, the operational environment, and the distance between the remote PIC and the sUAS. For this reason, there is no specific time interval that interruption of VLOS is permissible, as it would have the effect of potentially allowing a hazardous interruption or prohibiting a reasonable one. If VLOS cannot be regained, the remote PIC or person manipulating the controls should follow predetermined procedures for a loss of VLOS.

These procedures are determined by the capabilities of the sUAS and may include immediately landing the sUAS, entering hover mode, or initiating an RTB/return-to-home sequence. Thus, the VLOS requirement would not prohibit actions such as scanning the airspace or briefly looking down at the sUAS CS. (FAA, 2016)

\subsubsection{Overview: Beyond Visual Line of Sight and Night Unmanned Aerial System Operations}

BVLOS would allow the modeling of power lines over longer corridor stretches. In January 2015, Xcel Energy became the first utility company to use drones in BVLOS inspections of more than 320,000 miles of electricity and natural gas infrastructure. In partnership with Flot Systems, Xcel launched the program following FAA regulations for UASs that were in place at that time. (UAS Vision, 2015)

Although most current UAS applications are carried out in VLOS missions, there are limits to VLOS inspections. It is expected that long-term UAS application by the electric utility industry will substantially benefit from BVLOS operations in the not-so-distant future. Developing BVLOS capabilities should allow for large-scale inspection missions, wide area incident response, and gathering of high quality data with low risk to personnel. Longer UAS flights can cut the time, and thus the costs, for inspections of electric utility infrastructure, which typically are accomplished using manned helicopters. UASs can provide better images and data.

Currently, FAA restrictions would prevent electric utilities using UASs for long distance inspections of power lines. However, FAA is providing waivers on BVLOS operations and companies are already acting on that option. Among them is Sharper Shape, a Palo Alto, California, company that has already conducted miles-long inspections of power lines in Europe.

Sharper Shape, in concert with EEI, Minnkota Power Cooperative, Montana-Dakota Utilities, Xcel Energy, a flight operations company called SkySkope, and others, filed waiver requests with FAA within hours of the agency's release of Part 107. Sharper Shape believes its BVLOS flights can travel up to 20 miles in rural and lower-population suburban areas compared to about 1,500 ft under Part 107. 
Currently, FAA must grant special exemptions for night operations. Via the FAA Extension, Safety, and Security Act of 2016, Congress authorized FAA to begin development of new rules specifically to benefit the electric power industry and other operators of critical infrastructure. Under this new legislation, FAA will begin to develop rules enabling BVLOS flights, night flights, and other changes expected to streamline the permitting of UAS flights and improve commercial viability and safety while facilitating inspection of critical infrastructure. However, any such new rules are not expected to become part of formal regulations until the 2018 timeframe or beyond. That said, many operators under Part 107 are expected to apply for waivers to a number of Part 107 regulations, such as flying at BVLOS distances; some such waivers are likely to be granted in advance of more formal regulation changes that arise from the 2016 act. (Olsen, 2016)

\subsection{UNMANNED AERIAL SYSTEM ELECTRIC UTILITY MISSION PLANNING}

The electric power T\&D network is a critical national infrastructure asset that requires routine and, sometimes, emergency maintenance. Using UASs near transmission lines raises additional concerns that must be addressed as a part of effective UAS electric utility mission planning. To achieve the goal of successful UAS use by the electric utility industry will require the development of a robust mission profile and contingency planning to mitigate the chances of issues arising, thus ensuring that the impact of potential incidents is kept to an absolute minimum. This planning should be carried out with particular concern for the following.

\subsubsection{Aircraft Marking and Painting}

Painting the aircraft with bright colors is beneficial in two ways. Along with distinguishing the aircraft's orientation at greater distances, the bright colors also create better contrast for overall visibility. This concept applies to both sunny and overcast weather conditions. Easier detection of the aircraft reduces eye fatigue for the crew member tasked with maintaining visual sight of the aircraft. (Lone Star UAS Center Excellence and Innovation, 2016)

High visibility colors such as bright florescent green or orange paint schemes would greatly aid crew members with the visual tracking of the UAS during flight operations; greatly assist with "see and avoid" of other aircraft; and contribute to locating the UAS should a mishap occur.

\subsubsection{Aircraft Speed}

UASs are required to maintain a maximum ground speed of $100 \mathrm{mph}$ ( 87 knots) or less. There are many different types, also known as categories or classes, of sUASs and different ways to determine ground speed. Therefore, this guidance will only touch on some of the possible ways for the remote PIC to ensure that the sUAS does not exceed a ground speed of $100 \mathrm{mph}$ during flight operations. Some of the possible ways to ensure that $100 \mathrm{mph}$ is not exceeded are as follows.

- Installing a GPS device on the sUAS that reports ground speed information to the remote PIC, who takes into account the wind direction and speed, crosswind, wind shear, etc. and calculates the sUAS's airspeed for a given direction of flight.

- Timing the ground speed of the sUAS when it is flown between two or more fixed points, taking into account wind speed and direction between each point, then noting the power settings of the sUAS to operate at $100 \mathrm{mph}$ or less ground speed.

- Using the sUAS manufacturer design limitations (e.g., installed ground speed limiters). (FAA, 2016) 


\subsubsection{Altitude and Altimeter}

sUASs are limited by Part 107 to a maximum altitude of $400 \mathrm{ft}$ AGL or, if higher than $400 \mathrm{ft}$ AGL, remain within $400 \mathrm{ft}$ of a structure. To comply with the maximum altitude requirements of Part 107, as with determining ground speed, there are multiple ways to determine a sUAS's altitude above the ground or structure. Some possible ways for a remote PIC to determine altitude are as follows.

- Installing a calibrated altitude reporting device on the sUAS that reports the sUAS altitude above mean sea level (MSL) to the remote PIC, wherein the remote PIC subtracts the MSL elevation of the CS from the sUAS reported MSL altitude to determine the sUAS AGL altitude.

- Installing a GPS device on the sUAS that also has the capability of reporting MSL altitude to the remote PIC.

- With the sUAS on the ground, pace off $400 \mathrm{ft}$ from the sUAS to get a visual perspective of the sUAS at that distance, wherein the remote PIC and VO maintain that visual perspective or closer while the sUAS is in flight.

- Using the known height of local rising terrain and/or structures as a reference. (FAA, 2016)

\subsubsection{Autopilot}

UASs should possess an autopilot (AP) that provides for heading, altitude, and speed, allowing for safe RTB and obstacle avoidance. Recent UAS technological advancements have increased the capacity of autonomous operations, and improvements in this technology are continuously under development. Programming prebuilt flight paths before mission initiation potentially assists in ensuring data from the needed geographic areas are collected and enables assigned staff to maximize their time in the field.

\subsubsection{Communications}

Effective communication is vital to ensuring mission status and, ultimately, mission success. The following should be considered regarding communications.

- Use transmit and receive radio communications able to communicate on aviation bands; crews should have air band radios during flight operations to communicate with area ATCs and manned aircraft if needed.

- Before flight operations crews should review all communication requirements to make any needed adjustments, and they should modify communication requirements during flight operations as required.

- "Deconfliction" should be accomplished through the local Common Traffic Advisory Frequency (CTAF) when possible.

- Use intra-organization radios and/or aviation bands for other entities, general public.

- Ensure communications checks are accomplished before launch.

- Use brevity; be clear, be concise, be direct. The following is an example of an appropriate radio call:

Crossville Traffic, small unmanned aircraft operations under way 5 miles northwest of airfield at 200 feet and below, Crossville Traffic." (Note: For training purposes only.)

- Implement redundant communications if possible.

- If a communications failure occurs in VMCs, the remote PIC should continue the flight and land as soon as practicable as long as they maintain a good visual of the UAS. 
- Security Requirements

○ Encrypted Aircraft Control Signal Frequencies

- Encrypted Datalink Frequencies

\subsubsection{Communications Links}

In the digital communication age, simply because a transmitter and receiver are on the same frequency does not necessarily mean that they will work together, or link. Even if the transmitter and receiver are on the same channel, the device must use the same manufacturer's protocol to "talk" to one another.

The UAS operator's manual should include a datalink section to verify the link, or "handshake," connection of the flight controller device and the UAS. If the UAS loses transmission of its signal, it should be identified on the UAS by the LED status light indications appropriate to the platform. In this eventuality, many UASs will automatically initiate RTB profiles. The following are typical "lost link" procedures.

- The UAS failsafe RTB should activate automatically if the remote controller signal is lost for more than $3 \mathrm{~s}$; RTB site should be located inside the approved flight operating area.

- The UAS is programmed to climb to a preassigned RTB altitude [e.g., factory set to $65 \mathrm{ft}$ (20 m) for DJI platforms).

- The UAS will hover at RTB preprogrammed location for $5 \mathrm{~s}$, then auto-land.

- The RTB process may be interrupted and the remote PIC may regain control of the UAS if the control link is reestablished.

\subsubsection{Communication Control Link}

A control link is used to guide or control the UAS while in operation and should be considered an essential part of the communications equipment needed to safely fly a UAS. A control link may consist of a transceiver, a communication/navigation data link transceiver, and antennas.

\subsubsection{Communications for Emergencies}

In the event of an emergency, the remote PIC should notify his/her management; engage first responders; and notify other stakeholders, as required. When making a notification of an emergency, the following information should be provided.

- Location and time of incident

- Type of emergency

- Nature and number of injuries, if any

- Extent of assistance required for aid/mitigation

- Type of UAS with full tail number (N-Number)

- Possibility of damage or fire to UAS

- Other pertinent factors as required

Once the UAS is recovered and the power is turned off, any recorded data on the incident, such as a secure digital (SD) card, should be secured as soon as possible by the remote PIC for forwarding to the organization's management and/or authorities for review. 
The flight operations documentation should be secured. As the situation permits, crew members should complete the post-flight documentation, describing the nature and details of the emergency. In the event of an emergency involving a suspected serious injury or fatality, an organizational procedure on how to deal with the public, media inquiries, etc. should be in place.

\subsubsection{Communications: Loss of GPS Signal During Flight and Potential Consequences}

If for some reason the GPS signal fails, use extreme caution as the positional data for the UAS will not be accurate. When the GPS signal strength is insufficient or if GPS signal is lost, it will typically be identified on the UAS by a sensor light indicator. The following are actions that may be taken should a GPS signal fail.

- Assume manual control of the UAS

- Maneuver and climb the UAS to reacquire GPS signal

- If GPS signal cannot be acquired, determine whether safe UAS control can be maintained

- If safe flight cannot be maintained, land as soon as possible

(Avion Solutions Inc./Avion Unmanned, 2016)

\subsubsection{Documentation}

Documentation is more than just good record keeping. It is a culture of compliance regarding following all required laws, permits, and regulations at the federal, state, and local levels. It is obtaining appropriate approvals. It is obtaining and maintaining certification and training and keeping it current. It is references for planning and safety for the proper execution of flight operations. The following delineate either legal requirements or best practices and should be considered foundational before conducting flight operations.

- Aircraft Registration (N-Number). A sUAS must be registered, as provided for in 14 CFR Part 47 or Part 48, before being operated under Part 107. Part 48 is the regulation that establishes the streamlined online registration option for sUASs that will be operated only within the territorial limits of the United States. The online registration web address is http://www.faa.gov/uas/registration/. Guidance regarding sUAS registration and marking may be found at http://www.faa.gov/licenses_certificates/aircraft_certification/ aircraft registry/. Alternatively, operators can elect to register sUASs under Part 47 in the same manner as manned aircraft. (FAA, 2016)

- The N-Number should be placed on both sides of the UAS in a location that allows for the largest possible lettering as practical, using uppercase Roman lettering.

- The ground CS should also be marked with the N-Number of the UAS it is supporting. The ground CS will be marked in a manner similar to the UAS, using uppercase Roman lettering, as large as practical. (Avion Solutions Inc./Avion Unmanned, 2016)

- Aviation Charts. Charts should be consulted, especially for reference to alert areas, caution areas, controlled airspace, danger areas, high traffic airspace, military operation areas (MOAs), National Security Areas (NSAs), prohibited airspace, restricted airspace, special use airspace (SUA), TFRs, uncontrolled airspace, and warning areas.

- Battery Logbook. A logbook that would enable the UAS operator to keep track of battery parameters such as voltage measures before and after a flight mission should be maintained. 
- COWs/COAs. A COW or a COA is an authorization issued by the air traffic organization to a public operator for a specific UAS activity. After a complete application is submitted, FAA conducts a comprehensive operational and technical review. If necessary, provisions or limitations may be imposed as part of the approval to ensure the UAS can operate safely with other airspace users. In most cases, FAA will provide a formal response within 60 days from the time a completed application is submitted. To better support the needs of its customers, FAA deployed a web-based application system, the UAS COA Online System (https://ioeaaa.faa.gov/oeaaa/Welcome.jsp), which provides applicants with an electronic method of requesting a COW. Applicants will need to obtain an account to access the online system. (FAA, 2016; Commercial or Government Weather Forecasting Service Reports)

- Contingency Plan Checklist (see Appendix D)

- Drone NOTAM (DROTAM). Aviation charting website SkyVector (https://skyvector.com) has added a useful new feature - graphical depictions of drone NOTAMs, which it calls "DROTAMs" - that shows dimensions of drone/UAS airspace and information about activity times and operating altitudes. DROTAMs are available as a graphical layer on any kind of chart available from SkyVector. [Aviation International News (AIN), 2016]

- Emergency Procedures. An emergency can be either a distress or urgency condition. Distress is defined as a condition of being threatened by serious and/or imminent danger and requiring immediate assistance. Urgency is defined as a condition of being concerned about safety and requiring timely but not immediate assistance; a potential distress condition. (FAA, 2016)

- Manned Aircraft Avoidance

○ Forced Landing

○ Lost Communications Landing Procedures

- Radiofrequency Interference and Awareness

- Emergency Contact List (see Appendix D)

- $\quad$ FAA (see Chapter 3)

- FAA Advisory Circular 107-2, "sUAS Maintenance and Inspection Best Practices” (see Appendix J)

- FAA Medical Certificate

- FAA Part 107 (see paragraph 3.2)

- FAA Remote Pilot in Command (PIC) Certificate. Part 107 establishes a remote PIC position. A person operating a sUAS must either hold a remote pilot airman certificate with a sUAS rating or be under the direct supervision of a person who does hold a remote pilot certificate (i.e., remote PIC).

- FAA Section 333 Exemption. Beginning in 2012, before issuance of the new Part 107 regulations, FAA began issuing commercial UAS operators COWs or COAs under Section 333 of the FAA Modernization and Reform Act of 2012. Operators who have been granted a COA or COW can fly commercially under limited operational and environmental conditions. To some extent, the Section 333 provision was enacted to enable initial and limited commercial operations to commence in advance of the formal regulation changes recently authorized under Part 107, and most Section 333 
petitions granted have limitations similar to those outlined in the basic Part 107 regulations, though differences could have been requested and approved. Operations can and will continue under both sets of regulations for some time. However, there are key differences; for example, under Section 333 the operator of the aircraft must be an FAA licensed pilot, and a separate VO is required to help the pilot see and avoid other aircraft. Another key difference is that Section 333 authorizations are given for the specific commercial applications (e.g., agriculture or cinematography) that were requested in the Section 333 petition by the operator; thus not all Section 333 operators are authorized to fly inspections of infrastructure. See http://www.suasnews.com/faa-drone-333-exemption-holders/. (Olsen, 2016)

- Flight Logbook (see Appendix K)

- Flight Manual. The aircraft flight manual is useful for guidance in performing flight operations, both normal and extreme), maintenance, and system limits

- Flight Plan. Specified information relating to the intended flight of an aircraft that is filed orally or in writing (Jeppesen Sanderson, Inc., 1983)

- Insurance Policy

- Internet Map Programs (e.g., Google Maps, https://www.google.com/maps/)

- Maintenance Logbook. Document used for recording maintenance actions

- Manufacturer User Guide

- Mishap Notification Procedures (see Appendix O)

- Mission Plan (see Appendix C)

- Mission Planning Weather Forecast (see Appendix D)

- Mission Planning Considerations for Using sUASs Near Energized Infrastructure. (See paragraph 4.2.3.3 in this manual.)

- Mission Profile. Graphical depiction of flight route including, but not limited to, altitudes, distances, mission waypoints, flight borders, location of CS, time, etc. (see Appendix D)

- National Weather Service. Agency of the US government that is tasked with providing weather forecasts (including aviation weather), warnings of hazardous weather, and other weather-related products to organizations and the public for the purposes of protection, safety, and general information. (Wikipedia, 2016)

- NOTAM. A NOTAM is a notice filed with an aviation authority to alert aircraft pilots of potential hazards along a flight route or at a location that could affect the safety of the flight. NOTAMs are unclassified notices or advisories distributed by means of telecommunication that contain information concerning the establishment, conditions or change in any aeronautical facility, service, procedure or hazard, the timely knowledge of which is essential to personnel and systems concerned with flight operations. NOTAMs are created and transmitted by government agencies and airport operators under guidelines specified by Annex 15: Aeronautical Information Services of the Convention on International Civil Aviation (CICA). The term "NOTAM" came into common use rather than the 
more formal "Notice to Airmen" following the ratification of CICA, which came into effect on April 4, 1947. Notices to Airmen were normally published in a regular publication by each country's air authorities (e.g., in Flight Magazine in the UK). A number of developments and amendments to CICA have resulted in the more automated system available today. (Flight Magazine, 1921)

- Notifications (see Appendix B)

- Operator's Manual

- $\quad$ ORM Process (see paragraph 4.4.6 in this manual)

- Pilot Logbook (see Appendix K)

- Safety Plan Checklist (see Appendix D)

- UAS Flight Operations-Execution Checklist. Consult with the aircraft manufacturer for the approved checklist or improvements to the checklist whenever appropriate. (see Appendix G)

- UAS Pre-Flight Checklist (see Appendix E)

- UAS Post-Flight Checklist (see Appendix I) and Reporting

- Work Order (see Appendix C)

- Weather Depiction Charts: Weather analysis, portraying areas of precipitation and obstructions to vision, cloud cover, and cloud heights. (Jeppesen Sanderson, Inc., 1983)

\subsubsection{Fuel Planning}

One of the top hazards of flight is mismanagement of fuel. To avoid or ameliorate this hazard, all aircraft should carry sufficient usable fuel and/or battery life, considering all meteorological factors and mission requirements. One rule of thumb is that at mission end $20 \%$ of the fuel, beyond that required for the mission, should remain for contingencies. Another is to maintain at least a $5 \mathrm{~min}$ power reserve or the manufacturer recommended reserve, whichever is greater.

\subsubsection{Hand Signals}

High noise environments and long distances may require a means of nonverbal communication to be able to conduct operations. Therefore, standardized hand signals should be understood and, when situations dictate, used. Commonly used hand signals for aviation operations may be reviewed in Appendix H.

\subsubsection{Human Factors}

The environment plays a role in the UAS PIC's concentration, more so as the day progresses. Being acclimated or having the proper attire to fly the aircraft in cold or hot conditions reduces pilot fatigue and subsequent incidents or accidents due to human error. Knowing the terrain and other obstacles in the flight operation area ensures that the pilot can correctly identify potential hazards and anticipate future events. Manned aviation pilots and UAS pilots alike must use SA to accomplish the scope of the tasks at hand. (Lone Star UAS Center Excellence and Innovation, 2016) 
In addition to the above and per FAA Part 107, "A person may not operate a sUAS if he or she knows or has reason to know of any physical or mental condition that would interfere with the safe operation of a sUAS."

Before each flight, the remote PIC should ensure that all personnel on the assigned crew are physically and mentally able to perform the tasked flight operations. The following IMSAFE checklist is provided as a resource to analyze crew members for their fitness.

- Illness: Are you, as the remote PIC, MPO, VO, etc. suffering from any illness or any symptom of illness that might affect you in flight?

- Medication: Are you currently taking prescription or over-the-counter drugs that might affect your performance?

- Stress: Are there any psychological or emotional factors that might affect your judgment or performance?

- Alcohol: What was your alcohol intake within the last 8 to $24 \mathrm{~h}$ ?

- $\quad$ Fatigue: Have you had sufficient sleep and rest in the recent past?

- $\quad$ Eating: Are you adequately nourished? (FAA, 2016)

\subsubsection{Judgment}

Although the choice of whether or not to fly is normally dictated by weather and mission considerations, sound judgment plays a most important role. There are occasions when VFRs may be legally followed by applying the appropriate visibility and cloud clearance criteria. That prerogative should be exercised with reasonable restraint. The established weather criteria are minimums. The remote PIC should allow a greater margin of safety when operational requirements permit and when reduced visibility or cloud conditions make flight under VFRs questionable. (Integrated Publishing, Inc.)

\subsubsection{Lighting}

Aircraft lighting is for both safety and navigation. The lighting allows for more rapid location of the UAS visually, and depending on the lighting configuration, the lights will indicate the direction in which the aircraft is travelling.

Navigation lights, also known as running lights, are colored sources of illumination on aircraft used to signal a craft's position, heading, and status. Typically, their placement is mandated by international conventions or civil authorities. Because they indicate the craft's relative position, they are often called "position lights." Aircraft lighting (if mounted) includes the following.

- Navigation Lights. Navigation lights should be used during all times when flight operations are being conducted except when the use of such lights would adversely affect ground operations. They should consist of a red light mounted on the left, or port side, of the aircraft and a green on the right, or starboard side. In a situation where the paths of two aircraft cross, these lights assist each crew in determining the other craft's direction and who has the right-of-way. When two aircraft have crossing paths, each sees a red or green running light. The aircraft on the port side, which must yield the rightof-way, sees the red light on the other, while the aircraft on the starboard side, which has the right-of- 
way, sees the green on the other. Note: UAs are required to always give the right-of-way to manned aircraft.

- Strobe Lights. On manned aircraft primarily, strobe lights flash a high-intensity burst of white light to help other crews recognize the aircraft's position in low-visibility conditions. They also may be known as "anticollision lights." Anticollision lights should be used immediately before engine start and at all times when the aircraft engines are in operation, except when the use of such lights would adversely affect ground operations. (Wikipedia, 2016)

High visibility lighting in combination with bright paint schemes greatly aid crew members with visual tracking of UASs during flight operations, greatly assist with seeing and avoiding other aircraft, and contribute in locating UASs should mishaps occur.

\subsubsection{Mishaps}

If a hazard is identified, all UAS crew members should have the authority to take corrective actionsespecially if it is believed the hazard could result in an accident or injury. Moving the UAS away from people on the ground is the highest priority. A rapid descent, achieved by dramatic decrease of power, followed by a sharp increase before impacting the ground, could help an operator regain sufficient enough control of the UAS, changing an unsalvageable impact into a hard landing.

Notification of a hazard or resulting mishap should be communicated immediately to other crew members. In the event of a mishap involving UAS work, the safety of the crew and all participating and nonparticipating personnel should be paramount. The loss of a UAS platform or any other materials is secondary to concern for the safety of personnel.

In case of a UAS mishap, the remote PIC is responsible for safe custody of the UAS until the aircraft has been taken into custody by proper authority. Per Part 107, any operation that results in serious injury, loss of consciousness, or property damage of at least $\$ 500$ should be reported to FAA within 10 days. (See Appendix O, "FAA Accident Reporting and Regional Operations Centers Telephone List.")

If the mishap occurs within controlled airspace, the remote PIC should notify the control tower, local CTAF, or the flight following agency of the situation. In the event of a UAS mishap involving known or suspected damage, human factors, or landings of an emergency nature, the remote PIC should notify his/her management and first responders and other stakeholders, as required. When making a notification of a mishap, the following information should be provided.

- Location and time of incident

- Type of emergency

- Nature and number of injuries, if any

- Extent of assistance required for aid/mitigation

- Type of UAS with full tail number (N-Number)

- Possibility of damage or fire to UAS

- Other pertinent factors as required

Once the UAS is recovered and the power is turned off, any recorded data on the incident, such as an SD card, should be secured by the remote PIC for forwarding to the organization's management and/or appropriate authorities for review as soon as possible. 
Flight operations documentation. As the situation permits, crew members should complete the post-flight documentation stating the nature and details of the mishap. In the event of a mishap involving a suspected serious injury or fatality, an organizational procedure on how to deal with the public, media inquiries, etc. should be in place.

\subsubsection{Mission Brief}

In addition to having a weather brief, scheduling a mission brief before flight operations is always an effective tool for coordination among crew members. A positive mission brief is one that is interactive and establishes open communications. This open discussion helps identify potential problems with the mission and create new actions for mitigating these issues. In addition, mission briefs outline the expectations of the flights and specify the duties and responsibilities of each crew member. Mission briefs should include a discussion of the emergency procedures for the mission. The briefing establishes a "team concept" among crew members and enhances the safety culture of the operational environment. (Lone Star UAS Center Excellence and Innovation, 2016)

\subsubsection{Navigation}

The VFR Raster Charts or Sectional Aeronautical Charts are the primary navigational reference media used by the VFR pilot community. These charts will display all public and private airports and different type of airspace such as controlled airspace and SUA. If you plan to operate near an airport, ensure that you are coordinating with the airport's tower and abide by its directives. ${ }^{5}$ Maintain SA with incoming or outgoing air traffic from airport runway approach and departure routes. These charts are provided for free on the FAA website. Other websites such as SkyVector, https://skyvector.com/, provide pilots with nationwide views of the Sectional Aeronautical Charts. SkyVector has recently added a UAS NOTAM layer system called DROTAMs. DROTAMs provide general aviation pilots SA of UAS activity through their flight paths. Check your FAA authorizations for NOTAM publishing requirements during your UAS operations. Plan ahead and follow a checklist for your pre-flight briefing. (Lone Star UAS Center Excellence and Innovation, 2016)

The Chart Supplement, formerly known as the Airport/Facility Directory, contains general information a pilot needs to know about specific airports. The Chart Supplement includes the airport identifier, the class of airspace, runway information, fuel services, communication radio frequencies, weather data sources, and other airport-specific information. Communicate with nearby pilots via radio frequencies over a VHF radio. Frequencies around local airspace can be found on the Sectional Aeronautical Charts and within Chart Supplements. Visit the FAA website to learn more about airports around your flight operation. (Lone Star UAS Center Excellence and Innovation, 2016)

TFRs define a certain area of airspace where air travel is limited because of a temporary hazardous condition, such as a wildfire or chemical spill; a security-related event, such as the United Nations General Assembly; or other special situations. The text of the actual TFR contains the details about the restriction, including the size, altitude, time period that it is in effect, and what types of operations are restricted and permitted. To view the list of active TFRs visit http://tfr.faa.gov/tfr2/list.html. (FAA, 2016)

\footnotetext{
${ }^{5}$ Per FAA Part 107, never fly within 5 miles of an airport without contacting airport authorities and the airport's traffic control facility.
} 


\subsubsection{Navigation Compass}

A compass is used as direction and heading indicator and should be considered an essential part of the navigation equipment needed to safely fly a UAS. One of the top hazards involving flight is failure to maintain direction control.

\subsubsection{Navigation Global Positioning System Module}

A navigational GPS keeps the UAS stable while it is in flight. A GPS module measures the UAS's location by measuring how long a signal takes to travel from a satellite. A GPS module is also able to give an estimation of the UAS's altitude. However, GPS modules are rather inaccurate and will only give a position to within $15 \mathrm{ft}(5 \mathrm{~m})$. Another feature of the GPS module is that it enables a UAS to autonomously fly to "way-points," so it can potentially fly on its own from takeoff to landing. (DroneTrest, 2015)

\subsubsection{Notifications}

Ensure that landowners and associated stakeholders are provided accommodations through adequate prior notification of UAS flight operations. Note that the operator must gain the consent of any person who might be in the UAS overflight zone (see Appendix B, "Unmanned Aerial System Operations-Public Notification").

\subsubsection{Notices to Airmen ${ }^{6}$}

A NOTAM is a notice filed with an aviation authority to alert aircraft pilots of potential hazards along a flight route or at a location that could affect the safety of the flight. (Chambers, 2010)

- NOTAMs warn other airspace users of RPAS operation. The airspace is not reserved for UAS operation. Other airspace users are still allowed to fly in the airspace concerned and the UAS pilot is responsible for separation.

- NOTAMs should have the following minimum information:

○ Dates during which the project will be executed

- Area of operation

- Registration number of the aircraft

- Maximum flight altitude AGL

To issue a NOTAM, access the Lockheed-Martin flight services website, or call the NOTAM number (877-487-6867) and provide the following information.

- Who is submitting the NOTAM and contact information

\footnotetext{
6 "Operation near airports, in certain airspace, in prohibited or restricted areas, or in the proximity of certain areas designated by a Notice to Airmen (NOTAM). Though many sUAS operations will occur in uncontrolled airspace, there are some that may need to operate in controlled airspace (i.e., IFR). Operations in Class B, Class C, or Class D airspace, or within the lateral boundaries of the surface area of Class $\mathrm{E}$ airspace designated for an airport, are not allowed unless that person has prior authorization from air traffic control. ... FAA has the authority to approve or deny aircraft operations based on traffic density, controller workload, communication issues, or any other type of operations that could potentially impact the safe and expeditious flow of air traffic in that airspace. Those planning sUAS operations in controlled airspace should contact FAA as early as possible." (FAA, 2016)
} 
- Current date and time

- Aircraft type: UAS make/model; also size and weight if possible

- FAA approved COA/COW number

- Dates and times (Zulu $\left.{ }^{7}\right)$ of fights (beginning and ending)

- Flight altitude (zero to $400 \mathrm{ft}$ AGL)

- Affected Air Route Traffic Control Center (ARTCC) if any

- Flight operations area to include distance and direction from the nearest airport or navigational aid, and the distance radius of the COA boundary center point

FAA will provide a NOTAM number that will be used by the UAS crew when flying the UAS.

\subsubsection{Operator's Manual}

Reading the operator's manual is crucial to familiarizing oneself with the UAS platform. The operator's manual for an aircraft provides technical specifications and procedures that are valuable to the pilot. When developing a pre-flight checklist, reference material from the operator's manual. These manuals are typically included when purchasing the UAS. If you are missing the operator's manual, contact the manufacturer or search for the manual online. Most manufacturers will have the UAS and its components readily available online at their websites. (Lone Star UAS Center Excellence and Innovation, 2016)

\subsubsection{Payload and Weight}

A key factor in the type of UAS to be used is its payload capacity. Per FAA Part 107, a sUAS must weigh less than $55 \mathrm{lb}(25 \mathrm{~kg})$, including its payload. If multiple sensors are to be used, for example thermal and visual sensors used to survey transformers and connections for problems, a larger UAS platform may need to be considered to allow for heavier payloads and longer flight and loiter times. Multiple sensor payloads offer increased capability in a single flight but may require an FAA waiver if the UAS proposed for use does not conform to the Part 107 weight restriction. Longer flight ranges will also require use of secure communication links to control the UAS at extended distances.

Once the payload is determined, and it falls within the acceptable flight weight, it must be balanced. Balance is key to flight stability, and stability is essential for safe operations. As the technology advances, payload capacities are being upgraded across a wide spectrum of products (e.g., sensors) at a rapid pace. The payload also influences flight time. Typically, the larger the payload, or sensor, the shorter the flight time.

To carry multiple aerial sensors, greater payload capacity is required, which typically means a larger and more powerful UAS.

\subsubsection{Personnel}

Crew assigned may vary due to the complexity of missions assigned. Crew members may also perform dual duties and serve in multiple roles. The crew might include

- remote PIC (required)

- SME (optional)

\footnotetext{
7 "Zulu" time is more commonly known as Greenwich Mean Time (GMT) or, time at the "Zero Meridian."
} 
- UAS MPO (optional)

- UAS VO (optional)

All crew members should be current on training requirements before initiating flight operations. The remote PIC should have performed three flight events with launch and recovery in the UAS model within the preceding 90 days to be eligible for a flight mission. If crew-member currency is not maintained, the remote PIC should display proficiency to the organization's authority before operating a UAS outside of a training environment. Failure to prove proficiency should result in UAS crew-member flight responsibilities being removed (i.e., "down" status) either on a temporary or permanent status.

\subsubsection{Privacy Concerns}

Privacy concerns and the public perception of intrusion into private "space" is an issue yet to be fully overcome with regard to UAS use. An attitude has already developed among many as a result of early uses or misuses, of UASs. ${ }^{8}$ This subject is of such prominence, we have dedicated an entire chapter to the topic (see Chapter 7, "Privacy and Proper Unmanned Aerial System Operational Etiquette").

To ensure professional conduct of UAS crew members, strict procedures regarding privacy should be applied. Crew members found to be collecting data not related to the nature of their tasked mission (e.g., images for pleasure or personal use, purposefully invading privacy) should be disqualified from operating as crew members until the employer can determine that the contractor or employee can be trusted to ensure the public's privacy.

\subsubsection{Post-Flight Analysis}

Closing of a flight plan is the responsibility of the remote PIC. The remote PIC should ensure that the proper agency is notified of the flight's termination And that closeout reports are completed and distributed to the proper entities. The following are some of the items that need to be addressed in such reports.

- Furnish only factual information that would normally be available to air traffic facilities; the report should not contain any conjectures, assumptions, or hearsay.

- Any abnormal, erratic, or other kind of unusual performance of an aircraft or its power plant, including material failures, should be reported through appropriate channels.

- Reports of Violations of Flying Regulations. Each fact must be supported by testimony, documentary, or real evidence. Statements of the remote PIC should be included along with maintenance log book action forms, flight schedules, and other documentary evidence.

Depending upon the type of mission conducted the amount of data collected may be enormous, requiring extensive processing, analysis, storage, and validation.

\footnotetext{
${ }^{8}$ US Drone Test Case: In July 2015, a roofer took legal action against a neighbor for shooting down his $\$ 1,800$ drone with a shotgun. This case could shape the property rights law of who owns the air with regard to UAS overflight. After a year of counter argument, a decision on which court jurisdiction should hear the complaint is expected within the next few weeks and this could set new precedents for US law. Experts are watching the case closely as the drone industry highlights the lack of regulation governing lower altitude airspace not just in the United States but, globally. If the case is heard in a district court, it will not be binding in other federal court jurisdictions but will be influential in other courts. However, if it is appealed and sent to a higher court, it could create a precedent for the country. (Reuters, 2016)
} 


\subsubsection{Public Access}

When deciding whether to allow public access to company equipment, any probability of risk must be considered. Any doubt should be resolved by limiting or denying public access and strictly enforcing the decision once it has been made.

\subsubsection{See and Avoid}

UAS operations should remain clear of other aircraft. A remote PIC has a responsibility to operate the sUAS so it remains clear of and yields to all other aircraft. This is traditionally referred to as "see and avoid." To satisfy this responsibility, the remote PIC must know the location and flight path of his or her UAS at all times. The remote PIC must be aware of other aircraft, persons, and property in the vicinity of the operating area and maneuver the sUAS to avoid a collision and prevent other aircraft from having to take action to avoid the sUAS. (FAA, 2016)

The see-and-avoid concept applies to visual flight conditions. Because pilots are responsible for their own separation from other aircraft, conditions must exist that permit ample opportunity to see and avoid other air traffic and maintain obstruction clearance.

Onboard sense and avoid ${ }^{9}$ technology for UASs to avoid hazards and potential air collisions may be the next phase in the evolution of this technology.

\subsubsection{Sensors Used-Systems Integration}

The UAS's operational manual should be checked for any applicable payloads or sensors. Within the 3-D Robotics Solo owner's manual, the manufacturer states that the Wi-Fi connection on the GoPro payload needs to be off. In the case of Solo and GoPro, the Solo's wireless communication frequency and the GoPro camera's built-in Wi-Fi frequency are both 2.4 GHz. Devices that are Wi-Fi-enabled, such as the popular line of GoPro cameras, can interfere with the aircraft's Command and Control (C2) link. Some $\mathrm{C} 2$ interference symptoms include, but are not limited to, loss of flight authority, erratic flight behavior, and aircraft crash. Reference should be made to the specific UAS manual for proper use of the payload. (Lone Star UAS Center Excellence and Innovation, 2016)

\subsubsection{Situational Awareness}

SA refers to the ability of UAS pilots and other crew members to identify, process, and comprehend critical information about their surroundings at a given point in time. Pilot SA is key to the successful operation of UAs. Common factors contributing to loss of SA include repetition, stress, and unfamiliarity in new situations. From aircraft operating limits to the environment, a UAS pilot has as many items to consider as a manned aircraft pilot. Understanding the local traffic patterns of general aviation in the operating area allows the UAS pilot to safely "deconflict" in the event that a manned aircraft approaches his/her flight area. An additional layer of SA consists of interacting on communication frequencies, checking NOTAM reports, and/or receiving various informational feeds from FAA. (Lone Star UAS Center Excellence and Innovation, 2016)

A prominent lesson learned from recent (2016) EPRI UAS testing confirmed the importance of SA in UAS operations. Inspections on electric test lines quickly showed that it is very difficult for a UAS operator to maintain SA when flying to structures one or two spans away from where the operator is standing. The small size and long distances make it very difficult to accurately judge distances and

\footnotetext{
9 "Sense and avoid" technology is viewed by FAA as essential for the full integration of UASs into NAS.
} 
clearance, even though the UAS is still in the line of sight. (Electric Power Research Institute (EPRI), 2016)

An operational application of SA is ensuring that sound flight principles and procedures are followed for all operations regardless of mission urgency. For example, always clear turns (visually or through a sensor camera) when obstructions or other hazards are present, always announce actions verbally, and always maintain positive control of the UAS. (Avion Solutions Inc./Avion Unmanned, 2016)

\subsubsection{Training}

Crew member training is key to maintaining safe UAS operations in NAS. Training of new crew members should be conducted and documented for reference. Crew members should regularly train on the best and safest use of the UAS platform in various environments and under various scenarios. The ultimate goal is to have all assigned crew members coordinate more effectively and efficiently with one another as a team. Assigned personnel who train together tend to work well together and communicate more effectively. Team training is a major contributor to the overall safe completion of assigned flight operations.

\subsubsection{General Training}

Before conducting UAS flight operations, remote PICs should demonstrate the ability to safely operate and control the UAS platform in a manner consistent with the way the UAS will be operated in normal and emergency maneuvers. VOs should be required to demonstrate the ability to capably perform the roles and responsibilities required of the VO during UAS flight operations before commercial/public UAS flight operations.

- All flight training should be conducted in an approved, dedicated training area.

- All personnel unrelated to the training event should be a safe distance away from the flight operations in the event that the UAS operator experiences difficulties during flight instruction.

- All UAS flight training should be conducted during dedicated training sessions.

- All flight crew training should be conducted with an instructor in close proximity to the students and in a position to secure the controls as necessary for safe UAS recovery.

- All UAS emergency procedure training should be conducted during initial UAS operator training and performed regularly to maintain proficiency.

- The manufacturer's user guides and UAS checklists should be referred to for UAS specific emergency procedures.

- Training hours and currency should be logged and maintained.

Every 12 months each crew member should receive recurring training consisting of the following topics.

- Aeromedical Standards and Regulations

- Aircraft Operations

- Airspace 
- FAA Regulations

- Emergency Procedures

- New and Updated Equipment

- UAS Maintenance

- UAS Safety

- Utility-Specific Operations

- Weather

\subsubsection{Remote Pilot in Command Training}

The remote PIC should complete UAS operator training before operating a UAS in NAS. UAS operator training must include, but should not be limited to, the following topics.

- Aircraft Components

- Aircraft Systems

- Airspace

- Aerodynamics

- FAA Regulations

- Flight Operations

- Flight Basics

- Emergency Procedures

- Mission Scenarios

- MPO Responsibilities

- Privacy

- Safety

- SME Responsibilities

- Software

- VO Responsibilities

- Weather

UAS flights for currency or training should be conducted during a dedicated training session in a dedicated training area free of nonparticipants and hazards. All currency and training flights should be documented and maintained by the organization.

Training scenarios should simulate real-world scenarios that UAS crew members are likely to encounter or consist of situations that UAS operators are not likely to encounter but which should elicit a predictable, trained response (e.g., emergencies, mishap drills). Training scenarios should be briefed and debriefed as closely as possible to a real-world operation or event to include crew-member roles, checklists, emergency procedures, equipment, hazards, etc. The following are examples of scenario training events. 
- Downed Electric Transmission Tower Response in Inaccessible Terrain. The UAS operator should fly and inspect an area beyond an obstruction to simulate a downed electric transmission tower in rough terrain. Mission focus should be on maintaining VLOS of the UAS while collecting data necessary to provide an assessment on the damage. A VO and MPO may be required depending upon the scenario proposed. Crew members may be required and placed near the target to practice internal communications.

- Power Line and Pole Inspections. The UAS operator may be tasked to fly the length of a suspended power line while a VO is positioned to assist in maintaining separation between the UAS and the targeted power line. The MPO would control the sensors for data collection as required. The UAS operator could then perform an orbit of transformer equipment and/or power pole maintaining VLOS on the UAS while taking directional instructions from the MPO viewing through the payload sensor system.

- See and Avoid. The UAS operator, MPO, and VO may initiate a team power line and pole inspection training mission, which is interrupted by another UAS. During mission planning, the crew is briefed on the threat through the Contingency Plan Checklist and Safety Plan Checklist before conducting the training so that all players are aware of the hazard and the requirement for see and avoid action.

(Avion Solutions Inc./Avion Unmanned, 2016)

\subsubsection{Visual Observer Training}

The VO should complete sufficient training to communicate to the UAS operator any information required to remain clear of conflicting traffic, terrain, and obstructions; maintain proper cloud clearances; and provide navigational awareness. This training, at a minimum, should include knowledge of the following.

- Appropriate sections of the Federal Aviation Regulations (in 14 CFR)/Aeronautical Information Manual (FAR/AIM series; https://www.faa.gov/air_traffic/publications/media/aim.pdf)

- Air traffic and radio communications, including the use of approved ATC/pilot phraseology

- VO responsibility to assist the UAS remote PIC in complying with the requirements of

○ FAR 91.3, Responsibility and authority of the pilot in command (PIC)

- FAR 91.13, Careless or reckless operation

- FAR 91.17, Alcohol or drugs

- FAR 91.25, Aviation Safety Reporting Program: Prohibition against use of reports for enforcement purposes

○ FAR 91.101, Applicability

- FAR 91.103, Preflight action

○ FAR 91.111, Operating near other aircraft

- FAR 91.113, Right-of-way rules: Except water operations. This rule does not apply to sUASs as it does to manned aircraft. sUAS operators shall not expect manned aircraft to see the sUAS and maneuver following this rule. sUAS operators will maneuver as needed to remain well clear of manned aircraft at all times.

○ FAR 91.115, Right-of-Way Rules: Water Operations 
- FAR 91.119, Minimum Safe Altitudes: General

- FAR 91.155, Basic VFR weather minimums-Only those minimums that will apply to sUAS ops as identified in the COA-Class G, E, D, below 1,200 AGL

(Avion Solutions Inc./Avion Unmanned, 2016)

\subsubsection{Traffic Management}

In planning and conducting flight paths, all entities operating UASs should select and adhere to those tracks and altitudes that completely minimize the possibility of UASs falling into congested areas in the event of electronic or material malfunction, including malfunctions that could lead to loss of control, and that minimize danger to personnel and property and personnel on the surface. Aerobatics should not be performed. Because one of the top hazards to flight is improper level off, flight levels (FLs) should be determined as a part of route planning. As indicated previously, manned aircraft have the right-of-way; however, due consideration should be given to avoiding all other aircraft, including UAs such as park flyers.

Ground traffic management plans are required for all activities in or around a roadway that may affect operating conditions of the roadway. This includes any visual distraction that could be caused by a UAS.

\subsubsection{Weather}

Weather is an important factor that influences aircraft performance and flying safety. Atmospheric pressure and density, wind, and uneven surface heating are factors that affect sUAS performance and must be considered before flight. (FAA, 2016)

The operator's SA should be extended to the surrounding weather patterns. Depending on the season and geographical location, these conditions will change over time. Wind speeds, cloud ceilings, and temperature are likely to change several times in a given day. 14 CFR 91.155, Basic VFR weather minimums, should be consulted for standards on flight visibility and distance from clouds. Popular sources for finding weather information in the aviation industry are the local METAR (Meteorological Terminal Aviation Routine) or Terminal Aerodrome Forecast reports, advisories, and other weather forecast data at http://aviationweather.gov. Choosing the right time to fly will increase cost-effectiveness and minimize grounded time. (Lone Star UAS Center Excellence and Innovation, 2016)

UAS flight operations must be conducted during daylight hours within the local flying area in VMCs. Commercial weather forecasting services may be used. Weather minimums must be followed.

When conducting operations in more extreme weather conditions, the following steps are recommended.

- Calibrate sensors to the external temperature before operations.

- During cold weather operations be aware system parts may become brittle. Adjust equipment after allowing to warm indoors.

- To maximize discharge levels and power draw, keep batteries warm until required for operations.

- Remote areas operations may require a generator or power converter to recharge equipment. 


\subsubsection{Wind}

UASs are especially sensitive to wind conditions while at altitude. ${ }^{10}$ When planning for recurring missions or surveys, historical wind data should be part of scheduling. Weather patterns and trends can, to a certain degree, be predicted from a weather analysis. For instance, the average wind speed for south Texas is generally lower in the fall months compared to the spring months. It might be beneficial for annual surveys or inspections to occur in the fall in this case. Overall, the lower winds during certain seasons may optimize flight time. Raw weather data collected from the FAA-approved weather stations may be downloaded from the Iowa State University Department of Agronomy website. (Lone Star UAS Center Excellence and Innovation, 2016)

An anemometer should be considered a critical part of the CS equipment. The CS or the UAS itself should possess an instrument to measure wind speed to help better determine aircraft capability and application. A wind sock should also be considered a critical part of the CS equipment. The CS should possess an instrument to measure wind direction to help better determine aircraft takeoff and landing capability and application.

Do not hesitate to postpone flight operations until the winds are suitable. Making the right decision about the wind before or during flight operations could help prevent unnecessary harm to people and/or property.

\subsubsection{Fire}

The Fire Potential Index (FPI) is a planning and decision support tool that incorporates weather and fuel information to rate the overall fire threat at the district level. The system merges weather forecasts with assays of the moisture level in vegetation, similar to USGS fire potential tools (https://firedanger.cr.usgs.gov/firepotential.php). Table 3 describes the index.

Table 3. Fire Potential Index (San Diego Gas and Electric, 2016)

\begin{tabular}{lcl}
\hline Index Category & Color Designation & \multicolumn{1}{c}{ Description } \\
\hline Normal & Green & The burn environment is not conducive for a large wildfire \\
Elevated & Yellow & $\begin{array}{l}\text { The burn environment has become conducive for a large } \\
\text { wildfire }\end{array}$ \\
Extreme & Red & $\begin{array}{l}\text { The burn environment has become conducive for a catastrophic } \\
\text { wildfire }\end{array}$ \\
\hline
\end{tabular}

UAS flights are prohibited in locations where the FPI is designated as "Extreme" or whenever the National Weather Service has issued a Red Flag Warning (also known as a "Fire Weather Warning") for the area of operations. Red Flag Warnings notify firefighters and land management agencies that conditions are advantageous/auspicious/favorable for large, rapidly spreading wildfires. (Note: Conditions for Red Flag Warnings are unique to each locale.)

\subsubsection{Worksite Survey}

Researching the area is vital to safe UAS operations, successful mission completion, and good public relations. The following should be a part of such worksite surveys prior to initiating missions.

\footnotetext{
${ }^{10}$ Per FAA Part 107, sUAS should only be operated at a wind speed of $25 \mathrm{mph}$ or the operator manual aircraft capability (whichever is lower).
} 
- Identify potential sources of risk and develop mitigation actions.

- Visit potential launch and landing zones for the mission.

- Acquire land use agreements from land owners if private property is needed for launch or landing.

- Identify obstacles or buildings that may cause loss of visual or digital links, and take appropriate actions.

- Reach out to various stakeholders and ATC centers in the area to make the UAS operational presence known. (Crop-dusters, for example, may not always check NOTAMs or respond to radio calls.) Be proactive in informing local users of the airspace that you are in the area with radio calls, NOTAMs, and, if necessary, physical meetings with local organizations. (Lone Star UAS Center Excellence and Innovation, 2016)

\subsection{SAFETY REQUIREMENTS FOR UNMANNED AERIAL SYSTEM WORK ON ELECTRIC UTILITIES}

"When they don't fly safely, they'll know there will be consequences."

—Michael P. Huerta, Administrator, Federal Aviation Administration

Incorporating a safety culture into operations applies to more than just the crew members involved. The application of personal and team management concepts helps enhance the safe operation of the UAS, both on the ground and in the air. One important concept of crew resource management is that crew members are teams, not a collection of competent individuals. Developing a team under this approach fosters crew effectiveness and reduces stress. These principles should be a part of a UAS company philosophy. Remember: "See something, say something." (Lone Star UAS Center Excellence and Innovation, 2016)

The remote PIC has overall responsibility for the safe, orderly flight of the UAS. At the end of the day, the aircraft is expendable, but people are not. The only way to mitigate risk is to plan for the occurrence of a failure. One of the primary concerns associated with UAS operations for the electric utilities industry is the safety of the public and its own employees. Electric service providers desiring to use UASs to support electric power utility work will need to be able to demonstrate that their aircraft (or their contracted UAS providers) comply with the standards described in the remainder of this section.

\subsubsection{Airframe Safety}

Among the top hazards involving flight are inadequate pre-flight preparation and/or planning and improper operation of flight controls. Even if the UAS manufacturer has a written pre-flight inspection procedure, it is recommended that the remote PIC ensure that the following inspection items are incorporated into the pre-flight inspection procedure required by FAA Part 107 to help determine that the sUAS is in a condition for safe operation overall airworthiness. The pre-flight inspection should include a visual or functional check of the following items.

- UAS components

- Airframe structure (including undercarriage), all flight control surfaces, and linkages

- Registration markings (for proper display and legibility) 
- Moveable control surfaces, including airframe attachment points

- Servomotors, including attachment points

- Propulsion system, including power plants, propellers, rotors, ducted fans, etc. (For safety, rotors or fans may be shrouded to prevent entanglement.)

- Energy supply [confirm all systems (e.g., aircraft and control unit) have an adequate energy supply for the intended operation and are functioning properly]

- Avionics, including control link transceiver, communication/navigation equipment, and antennas

- Compass (calibrate UAS compass before any flight)

- Control link transceiver, communication/navigation data link transceiver, and antennas

- Display panel, if used (confirm functioning properly)

- Ground support equipment, including takeoff and landing systems (check for proper operation)

- Control link functionality established between the aircraft and the flight control surfaces

- Flight control surfaces using the CS

- Onboard navigation and communication data links

- Flight termination system, if installed

- Fuel type and quantity

- $\quad$ Aircraft and CS battery levels

- Secure attachment of all equipment, including cameras and sensors

- Communications with the UAS, including that the UAS has acquired GPS location from at least four satellites

- UAS propellers; inspect for any imbalance or irregular operation

- Controller operation

If required by the flight path, walk through and verify any noted obstructions that may interfere with the UAS. At a controlled low altitude, fly within range of any interference and recheck all controls and stability. If available, whenever a UAS is started, personnel should be on hand with adequate fire extinguishing equipment. (FAA, 2016) Note: These operating limitations are intended, among other things, to support the remote PIC's ability to identify hazardous conditions relating to encroaching aircraft or persons on the ground and to take the appropriate actions to maintain safety. (FAA, 2016) 
Additional safety considerations include the following.

- No emergency parachute use [parachute use could be a hazard for some industries (e.g., electric)].

- The person manipulating the flight controls cannot operate a UAS and drive a moving vehicle in a safe manner and remain in compliance with FAA Part 107. (FAA, 2016)

The following is one example of a manufacturer using a built-in safety feature. AirRobot Inc., the manufacturer of the AR200 sUAS, has taken certain design steps to ensure the aircraft is properly prepared for flight. The AR200 propeller locks are designed to turn and lock. AirRobot has designed a red safety clip to be placed over the propeller locks. If the locks are engaged correctly, the safety clip will be secured to the propeller and the propeller lock; otherwise the safety clip will not be attached and will alert crew members that the propeller's locks are not engaged when going through the checklist. Even though the safety clip is minimal to the integrity of the locking mechanisms, the safety clips are required for the verification of the locking mechanisms of all eight of the AR200's propellers. (Lone Star UAS Center Excellence and Innovation, 2016)

\subsubsection{Battery Safety}

Lithium-ion (Li-ion) batteries are common in UASs. "A lithium polymer battery, or more correctly lithium-ion polymer battery (abbreviated variously as LiPo, LIP, Li-poly, and others), is a rechargeable battery of lithium-ion technology in a pouch format. Unlike cylindrical and prismatic cells, LiPos come in a soft package or pouch, which makes them lighter but also less rigid." (Wikipedia, 2017) The difference between a lithium battery and a Li-ion battery is that most Li-ion batteries are rechargeable.

Li-ion batteries can be dangerous under some conditions and can pose a safety hazard because they, unlike other rechargeable batteries, contain a flammable electrolyte and are kept pressurized. In 2013, at least four aircraft suffered electrical system problems stemming from Li-ion battery use, and in at least two instances the batteries started fires. (CNN, 2013) (BBC, 2013) Therefore, it is extremely important that all $\mathrm{Li}$-ion batteries be handled in accordance with the manufacturer's recommendations.

Even when fires have not resulted from Li-ion battery use, Li-ion batteries have been known to show signs of battery fatigue, including overheating and bloating of the battery cells. Misused or faulty batteries can lead to inconsistent power supply to the system. The aircraft may also experience erratic flight, loss of control authority, or premature landing due to improper amperage or low voltage spikes. A battery log will enable the operator to keep track of battery parameters like voltage before and after the mission. All batteries should be maintained by following guidelines in the UAS operator's manual. (Lone Star UAS Center Excellence and Innovation, 2016)

\subsubsection{Safe Battery Charging}

Li-ion batteries offer good charging performance at cooler temperatures and may even allow fast charging within a temperature range of $41^{\circ} \mathrm{F}$ to $113{ }^{\circ} \mathrm{F}\left(5^{\circ} \mathrm{C}\right.$ to $\left.45^{\circ} \mathrm{C}\right)$. Consumer-grade lithium-ion batteries should not be charged at temperatures below $32^{\circ} \mathrm{F}\left(0^{\circ} \mathrm{C}\right)$. (Sony, 2016) Current-generation cells typically can be fully charged in 45 min or less. If overheated or overcharged, Li-ion batteries may suffer what is known as "thermal runaway," and cell rupture, and as mentioned previously, in extreme cases combustion can occur. (Donal P. Finegan, 2015) Therefore, batteries should not be left unattended when charging. After flight operations are complete, batteries should be allowed to cool for about $20 \mathrm{~min}$ before being connected to a charging station. 


\subsubsection{Safe Battery Transportation}

Most people are unaware that Li-ion batteries are dangerous goods that can pose a safety risk. Concerns are so great that there are in fact regulations for their safe transport, and the International Civil Aviation Organization (ICAO) Council Air Navigation Commission has even taken the extreme step of prohibiting Li-ion batteries as cargo on passenger aircraft. [International Air Transport Association (IATA), 2016].

However, for the purposes of field use, Li-ion batteries can be transported in stainless steel or plastic battery boxes capable of containing any free liquid. The battery holder should be securely fastened and the battery protected in such a manner as to prevent damage and short circuits. If possible, tape over the battery terminals and cables before transport. (US Army, 2007)

\subsubsection{Safe Battery Use, Storage, and Disposal}

When dealing with any power storage device, safety is key. First, one needs to reduce the probability of an unsafe event, and second, take steps to reduce the severity of the event, should one occur. Keep new batteries in their original battery packaging until ready for use. Keep original battery packaging to use for expended batteries.

Safety devices are incorporated into the battery cell modules and battery packs to protect against abnormal conditions. These safety devices are used to manage both heat and gas generation, which are consequences of battery use. (Roth, 2016) The remote PIC should land as soon as possible if a low battery is detected during flight operations.

To reduce the risks associated with Li-ion batteries, battery packs should contain fail-safe circuitry that disconnects the battery when its voltage is outside the safe range of $3-4.2 \mathrm{~V}$ per cell. When stored for long periods of time, the small current draw of the protection circuitry may drain the battery below its shut-off voltage; normal chargers may then be useless.

Typically the safety devices work well, and battery leaks and explosions are rare, but if you suspect that you have a malfunctioning battery, exercise caution. Do not connect it to a power source. If the battery is swollen, it should be assumed to be in a dangerous state resulting from built-up gasses. Handle the battery with care as it could catch fire or explode. Try to carefully remove it from the device housing. If you are able to do so, place it in a safe, cool container. Do not place it in a hot location such as a vehicle until the vehicle is cooled. Then dispose of the battery at an authorized commercial or government battery disposal facility. If you are unable to remove the battery, seek assistance from the manufacturer or an electronics store. (Tanous, 2014)

To avoid malfunctioning batteries

- Use the appropriate power charger.

- Do not leave the device plugged in to a power source all the time.

- Keep the device (or battery) stored in a cool, dry environment.

- Replace the battery if it becomes exhausted or damaged.

At the end of serviceable life, batteries should be disposed of at an authorized commercial or government collection facility. 


\subsubsection{Coordination}

To ensure public safety, airspace coordination requirements (e.g., deconfliction of rural agriculture with utility flight operations, notification of landowners and other sUAS stakeholders under and/or near flight paths, as required) are essential to the successful use of UASs by electric power utilities. It is important to maintain the confidence of other airspace users, landowners, and FAA that the utility UASs will be used in a professional and safe manner. Successes in initial UAS application in a VFR environment will enable the expansion of UAS use into more complex applications such as BVLOS, IRF, and night operations. It is essential that the electric power utilities build a reputation for well-managed, minimally intrusive UAS mission use.

- Precoordination should be accomplished with ATC authorities exercising jurisdiction over the affected airspace.

- Details on specific industries' inspection/search/survey program requirements should be publicized to other airspace users (i.e., agriculture, infrastructure, utilities).

\subsubsection{Wildlife}

Since 1990, about 160,000 incidents of wildlife striking civil aircraft have occurred, according to a report by the US Department of Agriculture and FAA. (Yerak, 2015) To reduce the chance of a bird strike and the possibility of disturbing or damaging activities on the ground, never operate a UAS to harass, herd, or alter the normal behavior of domestic animals or wildlife. To do so could potentially result in both civil and criminal penalties.

\subsubsection{Crew Rest and Endurance}

There are numerous factors that can influence individual performance (e.g., time, weather, workload). All these factors should be continually weighed against mission requirements. When the risk becomes too significant, it is time to reassess the execution of the mission. People are not expendable and should be viewed as an organization's most valuable asset.

Studies have shown that as continuously awake time increases, performance efficiency begins to drop. After 18 hours, performance efficiency rapidly declines to $75 \%$ of effectiveness, or less. The loss of effectiveness is manifested by lapses in attention, increased reaction time, slowed information processing, decreased vigilance, and increased error frequency. Accident rates for just about every type of human activity increase after 18 hours of wakefulness, particularly during the nighttime "circadian trough," when sleep would normally occur. (US Navy, 2016)

It is very important that remote PICs be able to recognize the signs of fatigue in themselves and their crews. Failure to maintain proper crew rest lowers effectiveness and could result in mishaps. UAS crew members should also be aware that weather conditions, such as extreme heat or cold, can play a major factor in increasing fatigue through dehydration or body chill.

Proper management of crew endurance ensures overall aviation safety, mission accomplishment, and crew-member efficiency. There should be constant contact between crew members to ensure the effects of fatigue are noted. If a crew member is unable to perform his/her duties due to fatigue, or other factors, the remote PIC should be the final decision maker on whether the mission should be performed/completed. The following guidelines may be used to set crew endurance limits for the safe execution of flight operations. 
- Maximum duty period of 10 hours

- Minimum 10 hours rest between duty days

- Maximum 12 consecutive duty days

(Avion Solutions Inc./Avion Unmanned, 2016)

\subsubsection{Emergency Procedures}

Specific UAS emergency procedures should be identified in the manufacturer's documentation or in the UAS operations checklist. The remote PIC should abort a flight in the event of an emergency that would pose a threat to other aircraft or personnel/equipment on the ground.

\subsubsection{Hazards}

Hazards may be permanent or temporary. Hazards may be natural or man-made. Hazards may be readily visible or invisible. Some potential hazards to consider may include, but are not limited to, other aircraft, EMI, foot and vehicular ground traffic, obstructions, terrain, towers, and dynamic weather conditions. The remote PIC should avoid all hazards, regardless of their nature and characteristics, as is reasonably possible. The 10 most frequent cause factors for general aviation accidents are as follows.

- Inadequate pre-flight preparation and/or planning

- Failure to obtain and/or maintain flying speed

- Failure to maintain direction control

- Improper level off

- Failure to see and avoid objects or obstructions

- Mismanagement of fuel

- Improper in-flight decisions or planning

- Misjudgment of distance and speed

- Selection of unsuitable terrain

- Improper operation of flight controls (FAA, 2016)

\subsubsection{Local Emergencies and Emergency Response}

Keep well away from emergency response efforts such as those associated with fires, car wrecks, or other disasters. FAA may issue flight restrictions in the vicinity of disaster areas. Unauthorized UAS operations may prevent other aircraft from performing life-saving missions and increase the risk of midair collisions. Anyone, including hobbyists and recreational fliers, who interferes with disaster response efforts is subject to civil penalties of up to $\$ 32,140$ per violation and possible criminal prosecution. UAS operators are responsible for checking applicable flight restrictions before operating and must not interfere with any aircraft assisting in hurricane disaster response operations, regardless of whether a flight restriction is in place. UAS operators may obtain information about posted flight restrictions by using the FAA B4UFLY mobile app or by checking the FAA website: https://pilotweb.nas.faa.gov/PilotWeb/. UAS or drone operators supporting disaster response operations must be approved by FAA before operating. The following are the steps for approval. 
1. The operator must secure support from a governmental entity, and the operation must directly contribute to the response, relief, or recovery effort.

2. After completing step 1, the operator must contact the FAA Systems Operations Support Center (SOSC) at 202-267-8276 for assistance.

3. After calling SOSC, the operator must also send the request via email to 9-ator-hq-sosc@ @aa.gov.

\subsubsection{Operational Risk Management}

One of the top hazards to flight is improper in-flight decisions or planning. ORM is a systematic decisionmaking process used to identify hazards that endanger the public or assigned resources and make informed decisions to manage them. Its purpose is to increase operational readiness by anticipating hazards and reducing the potential for loss, thereby increasing the probability for success. Below is a brief description of the ORM process.

- ORM uses a five-step process.

- Identify hazards

○ Assess hazards

○ Make risk decisions

○ Implement controls

○ Supervise

The ORM process is used on three levels based upon time and available assets.

- Time-critical: A quick mental review of the five-step process when time does not allow for any more (i.e., in-flight mission/situation changes).

- Deliberate: Experience and brain-storming are used to identify hazards and are best done in groups (i.e., aircraft moves, fly on/off).

○ In-depth: More substantial tools are used to thoroughly study the hazards and their associated risk in complex operations (i.e., payload detachment).

- The ORM process is guided by the following four principles.

- Accept risk when benefits outweigh the costs.

○ Accept no unnecessary risk.

- Anticipate and manage risk by planning.

- Make risk decisions at the right level.

(US Navy, 2016)

\subsubsection{Safety Risk Assessment}

When conducting a risk assessment, identify the present risks and look for ways to mitigate the hazards they create. Pre-flight familiarizations, inspections, and actions can be accomplished as part of an overall safety risk assessment. FAA encourages the remote PIC to complete the overall safety risk assessment as 
a method of compliance with the prohibition on operations over certain persons and the requirement to remain clear of other aircraft. Flight operations should be conducted at least $500 \mathrm{ft}$ from all nonparticipating persons, structures, vehicles, and vessels unless

- Barriers or structures are present that sufficiently protect nonparticipating persons from the UAS and/or debris in the event of a mishap. If a situation arises where nonparticipating persons leave such protection and are within $500 \mathrm{ft}$ of the aircraft, flight operations must be terminated immediately in a manner ensuring the safety of nonparticipating persons.

- The owner/controller of any structures, vehicles, and/or vessels has granted permission for operating closer to those objects, and the operator has made a safety assessment of the risk of operating closer to those objects and determined that it does not present an undue hazard.

\subsubsection{Risk Mitigation}

Knowing the risk factors that can affect a successful operation is important. These risks range from the people involved to issues with the aircraft or the environment. Higher risk situations include taking off with a known problem, unstable approach when landing the aircraft, and deviating from standard operating procedures. Similar to manned-aircraft pilots, UAS pilots see an increased workload during critical phases of flight, notably during takeoff, approach, and landing. Understanding the risks of flight is the first step to mitigating mishaps associated with these risks. (Lone Star UAS Center Excellence and Innovation, 2016)

All of these risks are inherent but can be mitigated by proper planning, communication, and SA. If applicable, file a NOTAM and/or DROTAM to inform other pilots about any UAS activity that is conducted within the airspace. NOTAMs/DROTAMs provide information considered useful to pilots for hazards, military exercises, airport notifications, and other UAS activity. Check for current NOTAMs in the mission area by visiting the FAA NOTAM search website at https://pilotweb.nas.faa.gov/PilotWeb/. (Lone Star UAS Center Excellence and Innovation, 2016)

Crews should also review the causal factors, results, and lessons learned from other aircraft mishaps. Knowing the recommended corrective actions and preventive measures from other mishaps assists with contingency and safety planning and the ultimate mitigation of risk of accidents. Crews should not hesitate to recommend and promulgate recommended risk reduction procedures to enhance overall safe operations.

Wind impacts and other data found in weather forecasts should be considered for proper flight planning. The aircraft operating manual should provide the wind limitation for safe flights. As part of the weather brief, checking the wind helps mitigate risks of the aircraft operating beyond the recommended conditions. Do not hesitate to postpone operations until the winds are suitable; making the right decision helps prevent unnecessary harm to people and property. (Lone Star UAS Center Excellence and Innovation, 2016)

Risk mitigation is crucial for the well-being of the crew members. Be aware of potential health issues and ensure that crew members are physically equipped for the environment in which you are operating. Heat exhaustion can be prevented by drinking fluids and staying out of direct sunlight as much as possible. When a crew member is suffering from heat exhaustion, the individual in question may not be aware of his/her condition. The PIC and crew members should look for early signs of danger such as heavy sweating or breathing, noticeable fatigue, and/or a distant glance from fellow crew members possibly suffering heat exhaustion. When the weather is cold, crew members should take steps to prevent hypothermia by wearing proper clothing and staying as dry as possible. Onset signs of hypothermia include fatigue, slower breathing, loss of coordination, and confusion. Again, the PIC and crew members 
should look for signs of distress in other team members. (Lone Star UAS Center Excellence and Innovation, 2016)

In the event that an emergency does occur, ensure that your company has the proper emergency procedures in place. For immediate, severe emergencies where every second is critical, call 911 immediately and provide first aid, as applicable. Consider all possible emergency scenarios, and plan for each situation accordingly. All crew members should have a compact emergency card containing phone numbers of all authorities to contact during an emergency. Examples include local law enforcement, emergency services, and ATC authorities. Operations in rural areas may not have the same emergency procedures as an urban area due to variance in communication and emergency response times at different locations. Always plan for any situation, and contact FAA for incidents and accidents that involve major damage, injury, or loss of property and life (see Appendix O, "FAA Accident Reporting and Regional Operations Centers Telephone List"). (Lone Star UAS Center Excellence and Innovation, 2016)

For further validation of flight procedures, it is recommended that companies go to a credentialing program to validate the ability to safely and effectively operate in NAS. Credentialing programs such as the National Unmanned Aircraft Systems Credentialing Program (NUASCP) provide organizations assistance in demonstrating safe operations and enhanced safety management systems. NUASCP provides third-party vetting of organizations that includes a thorough documentation review, oral examination, and live-flight audit for all pertinent flight procedures, including launch and recovery. The auditors will then provide useful feedback on operational and safety enhancements for compliant and safe operations. With the proper procedures in place, your company can fly safely in NAS with confidence. (Lone Star UAS Center Excellence and Innovation, 2016)

\subsubsection{Task Management}

Remote PICs should conduct their flights in such a manner as to avoid all unacceptable risks as determined by following the ORM process. Flight maneuvers that should be avoided during missions include, but are not limited to, spirals, stalls, flight through turbulence and smoke, etc. Each remote PIC must exercise prudent judgment and take proper action when dictated by emergencies that endanger life or property. It is the responsibility of the remote PIC and assigned crew to aviate, navigate, and communicate, in that priority, throughout all aspects of both routine and unusual circumstances. Maintaining stable flight during the operation should be the rule.

\subsection{UNMANNED AERIAL SYSTEM FLIGHT OPERATION EXECUTION FOR ELECTRIC UTILITIES}

Just like a manned-aircraft PIC, the remote PIC of a sUAS is directly responsible for, and is the final authority as to, the operation of that UAS. The remote PIC will have final authority over the flight. Additionally, a person manipulating the controls can participate in flight operations under certain conditions. It is important to note that a person may not operate or act as a remote PIC or VO for more than one UA at the same time. (FAA, 2016)

- One of the top hazards to flight is improper operation of flight controls. Ensure that all control links between the CS and the sUAS are working properly. For example, before each flight, the remote PIC must determine that the sUAS flight control surfaces necessary for the safety of flight are moving correctly through manipulation of the sUAS CS. If the remote PIC observes that one or more of the flight control surfaces is not responding correctly to CS inputs, then the remote PIC may not conduct flight operations until correct movement of all flight control surfaces is established. 
- Ensure there is sufficient power to continue controlled flight operations to a normal landing. One of the ways that this could be done is by following the sUAS manufacturer's operating manual power consumption tables. Another method would be to include a system on the sUAS that detects power levels and alerts the remote pilot when remaining aircraft power is diminishing to a level that is inadequate for continued flight operation.

- Ensure that any object attached to or carried by the sUAS is secure and does not adversely affect the flight characteristics or controllability of the aircraft.

- Ensure that all necessary documentation is available for inspection, including the remote PIC's remote pilot certificate, aircraft registration (if required), and COW (if applicable).

- Ensure the mission execution is in compliance with sound flight principles and safe practices during all flight operations.

Being adaptable and flexible are essential to safe, successful flight operations. The PIC and crew should be adaptive and agile enough to make on-the-spot corrections, alter a course of action based on new information, maintain constructive behavior under pressure, and adapt to internal and external environmental changes such as aircraft drift or drag. The success of UAS missions directly depends upon the remote PIC's ability to alter behavior and manage assigned resources to meet situational demands.

\subsection{UNMANNED AERIAL SYSTEM OPERATIONAL FLIGHT MINIMUMS—PRINCIPAL "TAKE-AWAYS"}

- For commercial or public use, public notification of UAS operations should be made.

- SA-know your surroundings; when able, check with local authorities before you fly.

- Obtain emergency contact information (e.g., local law enforcement, fire, rescue) as a contingency for all aspects of the proposed UAS work.

- Complete a pre-flight checklist ensuring proper coordination has been accomplished and the UAS is aviation worthy and in good working order.

- $\quad$ The remote PIC or VO may not operate more than one UAS at the same time.

- Be aware of FAA airspace restrictions (https://www.faa.gov/uas/where to fly/airspace restrictions/).

- The current FAA regulation ruling for sUASs applies to aircraft up to $55 \mathrm{lb}$.

- Stay within the UASs' designated flight envelope of air speed, load factor, and altitude.

- Stay within the operational altitude of less than $400 \mathrm{ft}$ AGL for UASs. The absolute ceiling for sUAS operations is $400 \mathrm{ft}$ AGL. Current UAS models being sold can reach a ceiling of 4,000 ft AGL. New UAS technology has demonstrated that future UAS models will be able to reach an altitude greater than $15,000 \mathrm{ft}$. As the technology progresses, it is expected that the absolute ceilings of UAS platforms will increase.

- Fly VLOS: UASs are intended to be operated within VLOS but may be capable of BVLOS operations. Current technology allows remote UAS operations up to 6 miles from an operator. New UAS technology has demonstrated internet-enabled remote control up to 13,000 miles from the 
operator. Currently, remote PICs must be able to maintain unassisted sight of aircraft during all flight operations (e.g., not through binoculars or a monitor); this is to ensure proper separation from other aircraft traffic, personnel, or property.

- Visibility distance: Unaided line of sight to maximum mission flight distance-VFR

- Minimum visibility, from the location of the CS, may not be less than 3 statute miles.

- Minimum distance from clouds being no less than $500 \mathrm{ft}$ below a cloud and no less than $2,000 \mathrm{ft}$ horizontally from the cloud.

- The UAS should not be operated at a distance where it cannot, under its own power, return to the origination point.

- Wind: $25 \mathrm{mph}$ or aircraft capability (whichever is lower).

- Precipitation: Per aircraft capabilities.

- Hours of sUAS Flight Operations: Daylight only; 30 min before sunrise to sunset.

- Avoid flying near other aircraft; manned aircraft have right-of-way.

- Avoid flying over groups or public gatherings, including stadium events, and targeted infrastructure (i.e., bridges and overpasses when the focus is power lines).

- Never fly within 5 miles of an airport without contacting airport authorities and the airport's traffic control facility.

- Keep well away from emergency response efforts such as fires, car wrecks, or other disaster areas. In the case of the latter, the FAA may issue flight restrictions in the vicinity of disaster areas.

- PICs and flight crews should not fly under the influence.

- MAD: Varies by industry (e.g., electric utilities unofficially recommend $40 \mathrm{ft}$ from power lines); no overflight of the public or populated areas (e.g., farms, roadways, stadiums).

- Return-to-Base (RTB): Return leg of charted route configured to avoid obstacles; if UAS is capable, set AP RTB function.

- Complete a post-flight checklist ensuring all documentation is created and that post-flight coordination requirements have been met. 



\section{UNMANNED AERIAL SYSTEM TYPES FOR ELECTRIC UTILITIES}

\subsection{CONSIDERATIONS FOR SELECTING A UNMANNED AERIAL SYSTEM COMMERCIAL OPERATOR}

Some electric cooperatives and power companies may choose to use an outside service for their UAS needs. This may be due to the costs of maintaining an in-house capability; better capabilities of the UAS commercial operator regarding platform use and data processing; and/or lack of desire by the utility to assume the potential increase in liability of operating a UAS capability should something go awry. Beyond the usual good business practices for selecting a contractor, there are several factors that should be considered when evaluating potential UAS operators. These include the following.

- FAA Airspace Authorization. If the operator will be flying for you under a Section 333 exemption, ask to see a copy of the actual exemption, which will outline, among other things, the types of commercial applications authorized. For a more complete due diligence, you can also get this directly from FAA. If the operator will be flying under Part 107, ask to see the Remote Pilot Certificate for each crew member who will be operating the aircraft, and check that the operator ensures adequate crew training. In addition, ask the operator to assess the locations of the infrastructure to be inspected; UAS flights conducted in populated areas or certain types of airspace will require special FAA permissions or more likely be prohibited. If the operator claims any special exemptions or waivers, ask for written FAA documentation.

- Insurance. Aviation insurance is a specialized field. General business insurance policies typically do not cover aircraft operations, including UAS, or damages or injuries caused by such aircraft. Have your insurance specialist review the insurance coverage of the UAS operator.

- Sensor and Data Processing Capabilities. Many different sensors are now available for use by UASs, from simple digital video cameras to multispectral, hyperspectral, ultraviolet (UV), or thermal cameras to lidar systems. Each of these sensor types can detect different properties; for example, UV sensors can detect corona emanating from energized systems. Be sure the UAS operator understands your infrastructure inspection needs, uses a UAS with sensors appropriate to those needs, and can demonstrate post-flight sensor data processing capabilities to provide the inspection outcomes for which you are looking. Data processing platforms are undergoing huge transformations, and some vendors are offering value-added services for managing sensor data and processing it into meaningful information for the electric industry, especially for maintenance of transmission line corridors.

(Olsen, 2016)

While UAS service providers are responsible for their equipment and the conduct of their employees, a utility company that outsources UAS work will ultimately be responsible for the UAS program it incorporates. It is strongly recommended that utility companies protect themselves by researching a thirdparty provider thoroughly and ensuring that the provider has aviation standards compatible with industry standards. (Hendrix, 2016) (See Appendix M, "FAQs Regarding Unmanned Aerial System Use for the Electric Utility Industry," for specific questions to consider when selecting a UAS commercial operator.

\subsection{CONSIDERATIONS BEFORE PURCHASING AN UNMANNED AERIAL SYSTEM}

\subsubsection{Unmanned Aerial System Ease of Use}

If your organization is in the market for a UAS, it should be understood that much like learning to ride a bicycle or driving a car, it requires a certain level of training to develop the skills needed to fly a UAS. For many a UAS may be hard to control. For example, a quadcopter UAS would simply be impossible to 
fly without a computerized flight controller device, which allows for its stability in flight. It should also be understood that like different makes and models of automobiles, every UAS flies slightly differently depending on how the airframe is configured and the flight controller is set up. For example, some flight controllers may be set for speed and agility flying (i.e., quadcopters), while others might be geared more toward endurance and stability (i.e., fixed-wing). Regardless of the ease of use, the type of UAS selected should first and foremost be based upon the business application and/or mission requirements.

\subsubsection{Investment}

Cost vs. UAS ease of use is directly proportional. In other words, as cost goes up for a UAS platform, typically its ease of use also increases. If considering the investment of both money and time in the operation and maintenance of a UAS or a fleet of UAS platforms, dedicated research on the particular UAS required for the work needs to be conducted before the purchase. The following section discusses factors that should be considered before purchase.

\subsubsection{Insurance Considerations}

Incidents involving UAS operations could result in multi-million-dollar claims against a business, the operators, and possibly even the manufacturers (Table 4). Injuries involving UAS operations have already occurred. A collision involving a UAS striking the engine of an airliner could cause $\$ 10 \mathrm{M}$ in physical damage alone. An insurance considerations and risk management checklist is shown in Figure 11. (Transport Risk Management, Inc., Unmanned Risk Management, 2016).

Numerous insurance companies provide cost quotes for insuring UASs and UAS work. They may be found online and can offer coverage for use of unowned UAs and unowned UASs, including liability insurance for physical damage to the UAS and for loss of life or bodily injury or property damage to others. The following are just a few examples of the types of coverage offered.

- Aerial Photo

- Agriculture and Crop Spraying

- Construction

- Emergency Response

- Exploration

- $\quad$ Fire and Rescue

- $\quad$ Fixed Wing

- Law Enforcement

- Multi Rotor

- News Gathering

- Personal Use

- Predator Control

- Power Line or Pipeline Patrol

- Real Estate

- Search and Rescue 
- Security

- Single Rotor

- Surveillance

- $\quad$ Traffic Patrol

Table 4. Top Causes of Loss: Aviation Claims (\$1M+) (Transport Risk Management, Inc., Unmanned Risk Management, 2016)

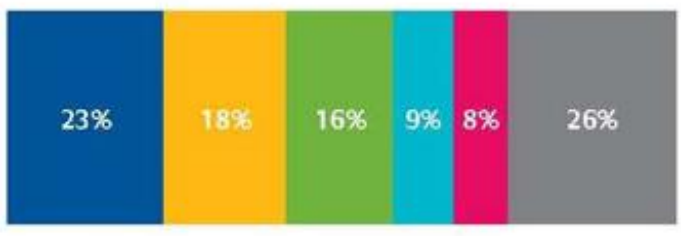

No. of Claims

Plane crash 23\%

Ground handling $18 \%$

Mechanical failure $16 \%$

Hard landing 9\%

Damage by foreign object $8 \%$

Other 26\%

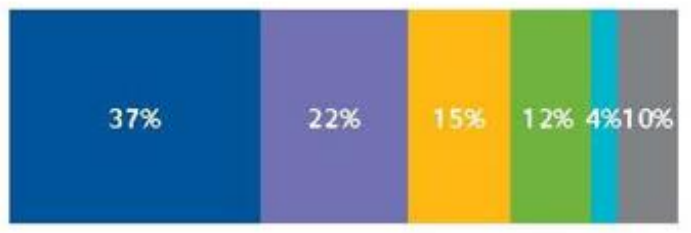

By value

Plane crash $37 \%$

Over/undershot runway/taxiway $22 \%$

Ground handling $15 \%$

Mechanical failure $12 \%$

Hard landing $4 \%$

Other $10 \%$

Source: Global Claims Review, Allianz Global Corporate \& Specialty. Data based on accident years 2009-2013

If the UAS work is outsourced, the work may be covered by a primary contractor's liability insurance or that of the organization hiring the contractor. Ensure you have the policy number readily available in the event of a mishap. 


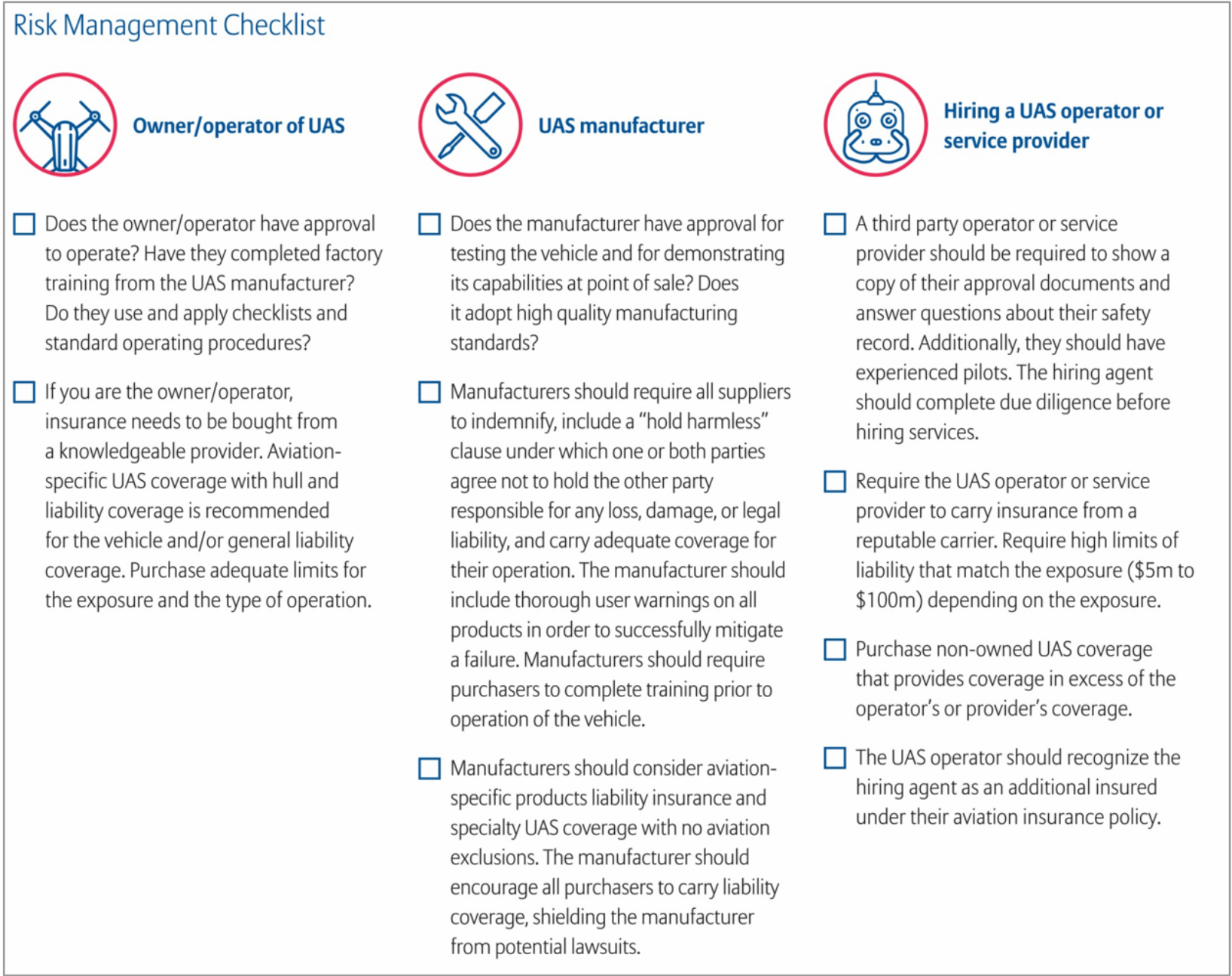

Figure 11. Insurance considerations and risk management checklist. (Transport Risk Management, Inc., Unmanned Risk Management, 2016) 


\section{UNMANNED AERIAL SYSTEM-MOUNTED SENSORS AND APPLICATIONS FOR ELECTRIC UTILITIES}

Remote sensing images and video in various forms offer an unsurpassed benefit that UASs could deliver to the electric utility industry. Sensor and data processing platforms are currently undergoing huge transformation. UASs can be equipped with a wide variety of sensors that can be used to collect data for analysis, allowing the utilities to observe their T\&D networks from above. A UAS with a payload of sensors could maneuver within close proximity of the targeted infrastructure to acquire detailed imagery and potentially detect abnormal, or even dangerous, conditions that could result in power generation or distribution problems. The following are some of the problems that could be targeted.

- Arcing electric equipment

- Cracked insulators

- Cracked and broken utility poles

- Corrosion of equipment, towers and other infrastructure

- Degraded or Ineffective Conductor Connectors

- Encroaching vegetation

- $\quad$ Sagging power lines

The electric utility industry could also use UAS-mounted sensors for some of the following applications.

- Corridor mapping of easements and rights-of-way

- Generation of system model of the grid using 3-D mapping

- Preventive maintenance prioritization

- Thermography for solar panels

- Turbine blade inspection for wind farms

- Vegetation management

With specific regard to the sensors, UASs can carry infrared cameras, still cameras, or video cameras that can provide varying degrees of resolution. In many circumstances, the collected data will require postprocessing, which is an added cost in time and money due to manning and equipment requirements. This in itself is an important consideration when determining the type of UAS platform and sensor package to be used. Conversely, other sensors allow for real-time analysis. These types of sensors would be particularly important to use during emergency and/or time-sensitive operations, but again, the speed of analysis most probably will come with a monetary price.

EPRI is performing tests and demonstrations on the applicability of UAS technology for support to the electricity transmission industry. Early EPRI research focused on UAS controls, platforms, and sensors. Tests were staged to assess various UAS platforms in realistic electric utility transmission applications. Some of the EPRI testing lessons learned regarding sensors follow.

- High-quality imagery is more useful than video. Staged defects on the test circuit provided many opportunities to test the imaging systems. While transmission structures are typically large, the inspection points are quite small in comparison. Still images proved more useful in performing a good inspection. (Electric Power Research Institute (EPRI), 2016) 
- Point-of-view is challenging. Many UAS platforms only provide imaging and views looking laterally or down. A complete inspection of a transmission structure may require a more adjustable view. (Electric Power Research Institute (EPRI), 2016)

Finally, and with specific regard to sensor operators and data custodians, training should be conducted on an annual basis to ensure crew members, specifically MPOs, are current on the proper collection, handling, and storage of data with regard to local, state, and federals laws and regulations.

\subsection{APPLICATIONS FOR SENSORS}

Currently, there is no single or combined sensor technology configuration that has been set as the standard for all tasks required by the industry. Additionally, there is no formally accepted process for selecting the best aerial platform for the sensor payload that is to be carried. Below is a list of UAS applications and what they might target for the electric utilities industry.

- Visual Inspection-HD imagery to detect equipment problems sagging lines, cracked insulators, broken cross arms, etc.

- Thermal Inspection - detection of hot spots and identification of equipment problems.

- Infrastructure Inspection-identification of transmission and distribution line issues.

- Vegetation Management—prioritization of easement clearing.

\subsubsection{2-D Imaging}

2-D aerial imagery can be used for site surveying, including surveys of vegetation encroachment, to create accurate geospatial mapping solutions. In some cases, it can provide high resolution digital elevation models, digital surface models, and orthomosaic images, ${ }^{11}$ which can be used to complete specific tasks. The data are collected by the UAS using specialized cameras, and that data can then be processed using tools that turn the images collected into 3-D-type models that can be explored on the computer as if the viewer were on-site. One common example is to use this technology to look at trees along power lines to see whether there are areas that need attention. (Charlie Toms, 2016)

\subsubsection{Forward-Looking Infrared}

Forward-looking infrared uses a thermographic camera that senses infrared radiation and can provide useful temperature-based information. In the electric utility industry, one popular application for this is to spot splices or insulators with excessive heat signatures, which could indicate problems. (Charlie Toms, 2016)

\subsubsection{High Definition Cameras}

HD digital cameras and video cameras are the collection sensors most readily available to the UAS user. It is possible to record video or still images using HD cameras mounted in stabilized gimbals attached to the UAS. These stabilized cameras provide high quality images and video. In most cases, it is also possible to view what the UAS camera is seeing in real-time through monitors on the ground. This is

\footnotetext{
11 “' 'Orthomosaic image' refers to an aerial photograph geometrically corrected, or 'orthorectified,' such that the scale is uniform. The photo has the same lack of distortion as a map. Unlike an uncorrected aerial photograph, an orthophotograph can be used to measure true distances because it is an accurate representation of the Earth's surface, having been adjusted for topographic relief, lens distortion, and camera tilt. Orthophotographs are commonly used in Geographic Information Systems as 'map accurate' background images.” (Wikipedia, 2017)
} 
useful for the remote PIC but can also be shared with others using monitors, laptops, or even tablets, so they can make live assessments or provide feedback safely from the ground. This is often referred to as "first-person view." Currently, there is a lack of automated systems that can scan video and bring any potential issues to the attention of an operator. Video must be viewed in either real-time or afterwards in an office, and this can be time-consuming. Systems that can automatically identify anomalies are under development and would enhance the usefulness of video. (Charlie Toms, 2016)

\subsubsection{Hyperspectral Imaging}

"Hyperspectral imaging ... collects and processes information from across the EM spectrum. The goal of hyperspectral imaging is to obtain the spectrum for each pixel in the image of a scene, with the purpose of finding objects, identifying materials, or detecting processes." (Wikipedia, 2016)

\subsubsection{Light Detection and Ranging}

Lidar, which is popularly used to make high-resolution maps, also has applications in geodesy, geomatics, archaeology, geography, geology, geomorphology, seismology, forestry, atmospheric physics, airborne laser swath mapping, and laser altimetry. What is known as lidar is sometimes simply referred to as laser scanning or 3-D scanning, with terrestrial, airborne, and mobile applications. (National Oceanic and Atmospheric Administration (NOAA), 2016)

Lidar generates "point cloud data," which is a set of points in a 3-D coordinate system, typically to depict the external surface of an object, which can potentially be measured in inches. Because of the way lidar works, it generates very large amounts of data compared to digital imagery. The large volume of data lidar produces necessitates an updated approach to data management and processing. Currently, lidar sensors are typically flown by manned helicopters for the utilities at a considerable cost.

\subsubsection{Multispectral Imaging}

Multispectral imaging uses special cameras or filters that capture image data at specific frequencies across the EM spectrum. "The wavelengths may be separated by filters or by the use of instruments that are sensitive to particular wavelengths, including light from frequencies beyond the visible light range, such as infrared. Spectral imaging can allow extraction of additional information the human eye fails to capture with its receptors for red, green, and blue. It was originally developed for space-based imaging" but is being adapted for ground and airborne applications for industry. (Wikipedia, 2016)

\subsubsection{Pan-Sharpened Imaging}

"Pan-sharpened imaging is a process of merging high-resolution panchromatic and lower resolution multispectral images to create a single high-resolution color image. Google Maps and nearly every map creating company use this technique to increase image quality. Pan sharpening produces a high-resolution color image from three or more low-resolution multispectral satellite bands plus a corresponding highresolution panchromatic band: low-resolution color bands + high-resolution grayscale band = highresolution color images. ... One of the principal reasons for configuring satellite sensors this way is to keep satellite weight, cost, bandwidth, and complexity down." (Wikipedia, 2016)

\subsubsection{Synthetic Aperture Radar}

Synthetic Aperture Radar (SAR) is a form of radar that is used to create images of objects such as landscapes - these images can be either 2- or 3-D representations of the objects. "SAR uses the motion of the radar antenna over a targeted region to provide finer spatial resolution than is possible with 
conventional beam-scanning radars. SAR is typically mounted on a moving platform such as an aircraft or spacecraft and has its origins in an advanced form of side-looking airborne radar. The distance the SAR device travels over a target in the time taken for the radar pulses to return to the antenna creates the large "synthetic" antenna aperture (the "size" of the antenna). As a rule of thumb, the larger the aperture is, the higher the image resolution will be, regardless of whether the aperture is physical (a large antenna) or synthetic (a moving antenna) - this allows SAR to create high resolution images with comparatively small physical antennas." (Wikipedia, 2016)

\subsubsection{Ultraviolet Sensors}

For the electric utility industry, corona discharges and arcing are common phenomena in power transmission line external insulation. Such discharges may indicate a serious defect that negatively influences the properties of the associated conductors. Without detection and repair, this deficiency could result in serious impairment to electric transmission along the affected line. UV imagery technology has been widely used to detect the corona/arcing discharge throughout the electric utility industry. (Lan Chen, 2013) By mounting UV sensors on UASs, the industry now has another tool to quickly detect defects within the T\&D system.

\subsubsection{Thermal Infrared Imaging and Infrared Thermography}

Thermal infrared (TIR) sensors are used to collect data on hot spots to identify potential equipment problems. Such cameras are typically applied for geological measurements, outdoor surveillance, and UAS applications. TIR cameras convert the energy in the infrared wavelength into a visible light display. All objects above absolute zero emit TIR energy, so thermal cameras can passively see all objects, regardless of ambient light. Infrared thermography, thermal imaging, and thermal video are examples of infrared imaging science. "Thermographic cameras usually detect radiation in the long-infrared range of the EM spectrum (roughly 9,000-14,000 nanometers or 9-14 $\mu \mathrm{m}$ ) and produce images of that radiation, called 'thermograms.' Because infrared radiation is emitted by all objects with a temperature above absolute zero according to the black body radiation law, thermography makes it possible to see one's environment with or without visible illumination. The amount of radiation emitted by an object increases with temperature; therefore, thermography allows one to see variations in temperature. When viewed through a thermal imaging camera, warm objects stand out well against cooler backgrounds; humans and other warm-blooded animals become easily visible against the environment, day or night. As a result, thermography is particularly useful to the military, commercial industry, and other users of surveillance cameras." (Wikipedia, 2016)

\subsection{DATA COLLECTION AND ANALYSIS CONSIDERATIONS}

To be useful to operations or engineering personnel, collected data must be stored, easily retrieved, and analyzed. In the case of a large utility, such a system is likely to already be in place, especially if a manned aerial inspection program is already in place. However, electric cooperatives and smaller utilities may not have systems in place to support the large amounts of data that would be produced by UAS work. One recommendation to assist management of the large data that would be collected is to process the data on-site. If the UAS crew collecting data takes the time to properly label and store data as they conduct the operation, it could potentially save large amounts of time and help make the data processing tasks go more smoothly. What should be avoided is long hours trying to analyze, edit, and organize large volumes of data. In some instances, contracted out data management services should be considered as a cost- and time-saving option. (Charlie Toms, 2016)

Consideration should also be given to data security. Loss or even theft of the data being collected is a realistic possibility. Valuable recorded data could be lost during UAS flight operations if the UAS is 
transmitting information back to a CS. Collected UAS data could potentially be obtained by an antagonist through a cyberattack after the data have been stored.

On a very basic level, UAS technology will provide users real-time or near-real-time data for analysis and use. However, due to the extraordinary volume of data that can be collected, high-level automation technology will be needed to handle the enormous scale of data analysis, collection, processing, storage, validation, and retrieval required, as well as a data repository for the massive volumes of collected data, to fully exploit the capabilities of UAS technology.

\subsection{INTERNET OF THINGS, UNMANNED AERIAL SYSTEMS, AND THE ELECTRIC UTILITY INDUSTRY}

To date, a variety of line and vegetation management trials of UASs - or more generally mobile platforms - for visual inspection have been conducted by public, private, and academic sector organizations for utilities. These typical situations rely on a camera that is used to inspect the status of the asset.

While these trials are noteworthy, it is the need for a wide variety of appropriate sensing technologies for monitoring the modern grid that the ORNL UASRC is addressing. As part of this research and development, advanced sensors and communication components are being integrated into sensor modules that are then coupled to UAS platforms. This combination of advanced sensors and secure communications, integrated into UAS platforms, provides utilities with capabilities to enhance system operation in a cost-effective manner. (Fuhr, 2015) 



\section{PRIVACY AND PROPER UNMANNED AERIAL SYSTEM OPERATIONAL ETIQUETTE}

UAS flight crew members are responsible for protection of citizens' civil rights and their reasonable expectations of privacy. In recognition of this responsibility and its importance, a number of organizations, agencies, and associations are working on formalizing best practices and UAS etiquette recommendations. The remainder of this chapter will be devoted to a discussion of the current status of these efforts, including recommendations for UAS users.

In 2016, the National Telecommunications and Information Administration (NTIA ${ }^{12}$ ) initiated a multistakeholder engagement process to develop and communicate best practices, address accountability, and transparency issues regarding commercial and private UAS use in NAS, and to provide guidance to UAS operators on ways to balance their rights as UAS users and other people's rights to privacy. The stakeholders included representatives from industry, civil society, academia, and other interested US government agencies. The multi-stakeholder group released its recommended voluntary best practices on May 18, 2016; many of them are included in the privacy and best practices below. To see the full report, go to https://www.ntia.doc.gov/other-publication/2016/multistakeholder-process-unmanned-aircraftsystems.

Building off the NTIA-led multi-stakeholder process, the Commercial Drone Alliance, Association of Unmanned Vehicle Systems International, Small UAV Coalition, US Chamber of Commerce, Wireless Association, ${ }^{13}$ National Association of Realtors, National Society of Professional Surveyors, and MAPPS $^{14}$ announced a broad educational effort to raise awareness of privacy best practices and some of the ways they can be incorporated into various operations for users of UAS technology. (The White House, 2016)

It is essential that the electric power industry build a reputation for well-managed, minimally intrusive UAS use. A reputation of professionalism will support future, more complex applications of this new industrial tool. Any adverse incidents such as unprofessional and unsafe use have the potential to jeopardize the public trust, thus hindering future expansion of the far-reaching UAS capabilities. The following list of privacy and UAS etiquette best practices should be considered when operating UASs.

- Aircraft Noise Abatement. UAS noise could create a public relations problem. Operators should review their operating practices on a continuing basis with a view toward minimizing this nuisance to the public.

- Prohibited Operation Over Persons. Part 107 prohibits a person from flying a sUAS directly over a person who is not under a safe cover such as a protective structure or a stationary vehicle that would

\footnotetext{
${ }^{12}$ The National Telecommunications and Information Administration (NTIA) is the executive branch agency that is principally responsible for advising the president on telecommunications and information policy issues. NTIA's programs and policy making focus largely on expanding broadband Internet access and adoption in America, expanding the use of spectrum by all users, and ensuring that the Internet remains an engine for continued innovation and economic growth.

${ }^{13}$ The Wireless Association, originally known as the Cellular Telephone Industries Association, is an international industry trade group representing all wireless communication sectors including cellular, personal communication services, and enhanced specialized mobile radio. Founded in 1984, it is primarily involved in lobbying the US government and was instrumental in the passage of both the Electronic Communications Privacy Act and the Telecommunications Disclosure and Dispute Resolution Act.

${ }^{14}$ MAPPS is the only national association of firms in the surveying, spatial data, and geographic information systems field in the United States. MAPPS member firms are engaged in surveying, photogrammetry, satellite and airborne remote sensing, aerial photography, hydrography, aerial and satellite image processing, GPS, and GIS data collection and conversion services.
} 
protect the person from harm if the sUAS were to crash into that structure or vehicle. However, a sUAS may be flown over a person who is directly participating in the operation of the sUAS, such as the remote PIC, other persons manipulating the controls, a VO, or crew members necessary for the safety of the sUAS operation, as assigned and briefed by the remote PIC. There are several ways that the sUAS remote PIC can comply with these requirements, including the following.

- Selecting an operational area (site) that is clearly unpopulated/uninhabited. If selecting a site that is populated/inhabited, the PIC should have a plan of action that ensures persons remain clear of the operating area, remain indoors, or remain under safe cover that would protect them from harm until such time as the sUAS flight has ended.

- Establishing an operational area that the remote PIC has taken reasonable precautions to keep free of persons not directly participating in the operation of the sUAS.

- Choosing an operating area that is sparsely populated or, ideally, clear of persons if operating a sUAS from a moving vehicle.

- Having a plan of action that ensures the sUAS remains clear of persons who may enter the operating area.

- Adopting an appropriate operating distance from persons not directly participating in the operation of the sUAS. (FAA, 2016)

- Prohibited Maneuvers. The following maneuvers should be prohibited when flying in support of commercial energy companies.

○ Maneuvers solely for "thrill" purposes

- Flying directly over a substation.

$\circ$ Flying within $5 \mathrm{ft}$ of energized power lines

- Flying in a known active bird nesting area, disrupting or giving the appearance of disrupting wildlife

- Protecting civil rights and reasonable expectations of privacy.

- Ad hoc unplanned operations should not be conducted except for emergency response to utility outages and/or manmade/natural disasters; if used, the application of the UAS emergency response work should be tightly controlled and regulated.

- All data collected (e.g., images and video) should be protected and maintained in strict compliance with organizational security policies and procedures.

- Avoid gathering personal data if at all possible, and don't keep it for longer than required by the mission.

- When asked by a member of the public to delete personal data about him or her that you've gathered, do so, if at all possible.

- Whenever possible, the UAS crew should divert sensors from occupied structures and uninvolved persons to minimize inadvertent, unapproved data collection. 
- Public Relations. Any UAS flight open to misinterpretation by the public should be avoided. The following are examples of flights that would be considered controversial.

- Flights of a routine business nature for which commercial or other public transportation could be more economically substituted.

- Flights coinciding with major sports events or civic celebrations within the operating area.

Note: The best practices do not apply to news gatherers and news reporting organizations, which are protected by US law and the First Amendment to the Constitution. These organizations should operate under the ethics rules and standards of their organizations and according to existing federal and state laws. (The White House, 2016)

In summary, all UAS operators and assigned crew members should make every effort not to invade the public's privacy in the execution of UAS work. All federal, state, and local regulations should be adhered to, and as required, the public should be notified before UAS operations. 



\section{CONCLUSION}

In conclusion, how the electric utility industry will fully integrate UAS work to support its present and future requirements is still evolving. However, it is clear that UAS work will play some part of any future work for the industry. In some cases, it may be determined that a UAS may not be the optimal aerial platform for every application. This may be due to cost, flight time, operational support, payload, a combination of these factors, or some other unforeseen requirements or factors. The data analytics and management portion of UAS data collection is an enormous issue unto itself, with the prospective use of lidar collection outstripping the capabilities of most utilities. Thus, contracting UAS work, the operational support it requires, and the follow-up data analysis and management may be the preferred approach by many utilities.

The economics on a case-by-case basis will drive the decision of whether to select manned or unmanned data collection technologies. Using a UAS has the advantages of lower cost to operate with an overall increase in safety compared to a manned platform tasked with the same requirements. However, the growing need for increasing amounts of real-time data, BVLOS, and night-time and emergency operations may require larger UAS platforms with multi-sensor payloads, thus increasing UAS costs.

As a cautionary note, some lessons learned by the US Department of Defense (DoD) over the past two decades should be considered for future utility industry UAS operations. While specific requirements are dissimilar, military commanders' insatiable demand for drones to satisfy their infinite tasking requirements resulted in only about half of their requirements being fulfilled. (HQS USAF, 2016) As DoD budgets plateaued, manpower requirements to both operate and support these programs became unsustainable. The bottom line for the DoD example is that current military programs using UASs cannot be sustained or afforded if they remain on their current paths. So drastic adjustments in both cost and staffing are being made.

It is believed that electric utility crews, engineers, and planners will require a similar demand outcome once UASs are fully integrated into the rebuilding, maintenance, and repair of the national grid. However, the industry has the benefit of learning from the DoD lesson. Technological innovations such as the following will be needed to enable UASs to be fully integrated, economical, and capable tools for the electric utility industry.

- Big data capture, analysis, management, and storage — data analytics

- Higher levels of autonomy UASs, sensors, and related subsystems (e.g., communications and navigation)_-adaptability, self-launch, and recovery UASs

- Improvements in resilient and secure communication links, capabilities, and efficiencies-BVLOS

- Increased precision of measurements - sensors

- Smaller platforms with higher endurance and payload capacity_electronics, materials, and power

- Smaller, more effective payload capabilities - modular payloads, sensors

- More efficient and effective propulsion technologies for smaller systems - energy storage, hybrid engines, new fuels, etc. 
The good news is UASs are flexible and can be flown with different sensors that can be configured to detect a variety of potential targets. However, it will require an investment in time, money, skills, and software to fulfill current and future needs. The technology used in UASs for electric utilities and aerial imaging processing is progressing rapidly with the quality of data improving and the speed with which the data are collected increasing. This ensures the relevance of the technology to the industry for the foreseeable future.

The electric utility industry still has quite a way to go before fulling incorporating UASs as a regular part of operations by a professional workforce, but the potential is great and the future bright. This best practices manual and others like it will contribute to safe and proper operations of UAS work, and it is anticipated that its application will have a long-lasting, positive societal impact through the professional and safe application of UAS technology by industry. 


\section{REFERENCES}

Academy of Model Aeronautics. (2014). Academy of Model Aeronautics, AMA Document \#550. "Radio Controlled Model Aircraft Operation Utilizing “First Person View” Systems, Revision, January.

AUVSI. (2016, September 27). http://www.auvsi.org/blogs/auvsi-news/2016/09/27/small-uas-rule-agood-first-step-but-more-work-remains-industry-reps-tell-congress. Retrieved from http://www.auvsi.org/: http://www.auvsi.org/

Aviation International News (AIN). (2016, March 21). http://www.ainonline.com/. Retrieved from http://www.ainonline.com/aviation-news/general-aviation/2016-03-21/skyvector-publishesdrone-notams-graphical-format: http://www.ainonline.com/

Avion Solutions Inc./Avion Unmanned. (2016). Unmanned Aircraft Systems (UAS) Standard Operating Procedures (SOP). Huntsville, AL: Avion Solutions Inc./Avion Unmanned.

BBC. (2013, January 9). http://www.bbc.com/news/business-20950287. Retrieved from http://www.bbc.com/: http://www.bbc.com/

Chambers, D. (2010, February 10). Wikipedia. Retrieved from NOTAM: https://en.wikipedia.org/wiki/NOTAM\#cite_note-1

Charlie Toms, J. W. (2016, May). Opportunities for Unmanned Aircraft Systems (UAS) Use by Electric Utilities. National Rural Electric Cooperative Association - NRECA, Tech Surveillance, 13. Retrieved November 4, 2016

Chen, L. M. (2003). Aerial Surveillance System for Overhead Power Line Inspection. Logan, Utah: Center for Self-Organizing and Intelligent Systems (CSOIS) Department of Electrical and Computer Engineering College of Engineering, Utah State Universtiy .

CNN. (2013, January 8). http://edition.cnn.com/2013/01/07/travel/dreamliner-fire/index.html. Retrieved from http://edition.cnn.com/: http://edition.cnn.com/

Dictionary.com. (2016, September 1). Dictionary.com. Retrieved from Dictionary.com Web Site: http://www.dictionary.com/browse/anemometer

Donal P. Finegan, M. S. (2015, April 28). https://www.ncbi.nlm.nih.gov/pmc/articles/PMC4423228/. Retrieved from https://www.ncbi.nlm.nih.gov/: https://www.ncbi.nlm.nih.gov/

DroneTrest. (2015, November 13). http://www.dronetrest.com/t/beginners-guide-to-drone-autopilots-andhow-they-work/1380. Retrieved from http://www.dronetrest.com/: http://www.dronetrest.com/

Duvignau, R. (2014, December 27). http://www.newsweek.com/drones-threat-nuclear-plants-294458. Retrieved from http://www.newsweek.com/: http://www.newsweek.com/drones-threat-nuclearplants-294458

EdgeData. (2016). Safety Practices and Procedures While Operating sUAS Near Wind Infrastructure. Grand Forks, ND: University of North Dakota. Retrieved October 31, 2016

Electric Power Board. (2016). Unmanned Aerial Systems (UAS) Operators Concept of Operations. Chattanooga, TN: Electric Power Board.

Electric Power Research Institute (EPRI). (2016). Lessons Learned from UAS Research - An EPRI Perspective. Palo Alto, CA: EPRI.

FAA. (2016, June 21). Advisory Circular 107-2. Retrieved February 10, 2017, from Federal Aviation Administration: https://www.faa.gov/documentlibrary/media/advisory_circular/ac_107-2.pdf 
FAA. (2016, August 29). Federal Aviation Administration (FAA). Retrieved from FAA Web site: http://www.faa.gov/news/updates/?newsId=86305

FAA. (2016, June 21). Federal Aviation Administration (FAA). Retrieved from FAA Web Site: http://www.faa.gov/uas/media/Part_107_Summary.pdf

FAA. (2016, October 11). http://tfr.faa.gov/tfr2/list.html. Retrieved from http://tfr.faa.gov/: http://tfr.faa.gov/

FAA. (2016, October 11). https://www.faa.gov/air_traffic/publications/media/aim_basic_4-03-14.pdf. Retrieved from https://www.faa.gov/: https://www.faa.gov/

FAA. (2016, September 13). https://www.faa.gov/air_traffic/publications/media/aim_basic_4-03-14.pdf. Retrieved from https://www.faa.gov/: https://www.faa.gov/

FAA. (2016, September 13). https://www.faa.gov/air_traffic/publications/media/aim_basic_4-03-14.pdf. Retrieved from https://www.faa.gov/: https://www.faa.gov/

FAA. (2016, October 10). https://www.faa.gov/regulations_policies/handbooks_manuals/aviation/instrument_procedures_h andbook/media/Appendix_A.pdf. Retrieved from https://www.faa.gov/: https://www.faa.gov/

FAA. (2016, June 28). Operation and Certification of Small Unmanned Aircraft Systems; Final Rule. Retrieved from Federal Register: https://www.gpo.gov/fdsys/pkg/FR-2016-06-28/pdf/201615079.pdf

Flight Magazine. (1921, January 27). https://www.flightglobal.com/pdfarchive/view/1921/1921\%20\%200059.html. Retrieved from https://www.flightglobal.com/: https://www.flightglobal.com/

Fuhr, P. (2015, November). Unmanned Aerial Systems (UAS) for Grid Visibility (GridViz). Oak Ridge, Tennessee, US.

Guggenmoos, S. (2011, March 7). Vegetation Management Terms. Retrieved January 20, 2017, from Transmission \& Distribution World: http://tdworld.com/insights/vegetation-management-terms.

Hendrix, J. (2016). Recommendations for Ensuring Safe UAS Operations Within the Utilities Industry . AUV Flight Services.

HQS USAF. (2016, August 23). RPA Program Update and Way Ahead. Power Point Presentation. Columbus, Ohio, US: HQS USAF.

Integrated Publishing, Inc. (n.d.). Instrument Flight Rules Workbook. Retrieved February 11, 2017, from http://navyflightmanuals.tpub.com/P-305/Weather-Criteria-P-3050122-122.htm

International Air Transport Association (IATA). (2016, October 13). http://www.iata.org/whatwedo/cargo/dgr/Pages/lithium-batteries.aspx. Retrieved from http://www.iata.org/: http://www.iata.org/

Jeppesen Sanderson, Inc. (1983). Aviation Fundamentals. Jeppesen Sanderson, Inc.

Lan Chen, L. L. (2013). The Ultraviolet Detection of Corona Discharge in Power. Beijing, China : Jibei Electric Power Maintence Company, Jibei Electric Power Company, Limited.

Lone Star UAS Center Excellence and Innovation. (2016). Test Site Support for Unmanned Aircraft System. Texas A\&M University-Corpus Christi, Texas A\&M Engineering Extension Service and the Integrative Center for Homeland Security (TEEX/ICHS). Corpus Christi, TX: Texas A\&M University-Corpus Christi. Retrieved October 11, 2016

Merriam-Webster. (2016, October 20). http://www.merriam-webster.com/dictionary/waypoint. Retrieved from http://www.merriam-webster.com/: http://www.merriam-webster.com/ 
MyFirstDrone. (2015, October 19). http://myfirstdrone.com/tutorials/buying-guides/want-to-buy-a-drone5-things-you-should-know-before-you-buy/. Retrieved from http://myfirstdrone.com/: http://myfirstdrone.com/

National Association of Tower Erectors. (2016). Unmanned Aerial Systems Operations Around Vertical Communications Infrastructure. WATERTOWN, SD: NATE.

National Oceanic and Atmospheric Administration (NOAA). (2016, August 30). http://oceanservice.noaa.gov/facts/lidar.html. Retrieved from http://oceanservice.noaa.gov/: http://oceanservice.noaa.gov/

National Rural Electric Cooperative Association - NRECA. (2016). Technology Advisory - The Potential for Utilities to Use Unmanned Aerial Systems. Arlington, VA: February.

Olsen, D. (2016). UAS Inspections of Electrical Power Industry Systems - UND Best Practices Recommendations. University of North Dakota, Unmanned Aircraft Systems Center of Excellence, John D. Odegard School of Aerospace Sciences. Grand Forks, ND: University of North Dakota. Retrieved October 5, 2016

Reuters. (2016, September 21). http://in.reuters.com/article/property-drones-rights-idINKCNI1RIR3. Retrieved from http://in.reuters.com/: http://in.reuters.com/

Roth, D. D. (2016, October 13). https://www.electrochem.org/dl/interface/sum/sum12/sum12_p037_044.pdf. Retrieved from https://www.electrochem.org/: https://www.electrochem.org/

San Diego Gas and Electric. (2016). Small Unmanned Aircraft System (sUAS) Aviation Operations Manual. El Cajon, California: San Diego Gas and Electric.

Sony. (2016, October 13). https://web.archive.org/web/20090411024100/http://www.sony.com.cn/products/ed/battery/downl oad.pdf. Retrieved from https://web.archive.org/: https://web.archive.org/

Tanous, J. (2014, August 19). https://www.tekrevue.com/swollen-battery/. Retrieved from https://www.tekrevue.com/: https://www.tekrevue.com/

The White House. (2016, September 1). The White House. Retrieved from The White House Web Site: https://www.whitehouse.gov/the-press-office/2016/08/02/fact-sheet-new-commitmentsaccelerate-safe-integration-unmanned-aircraft

Transmission \& Distribution World. (2011, March 7). http://tdworld.com/insights/vegetationmanagement-terms. Retrieved from http://tdworld.com/: http://tdworld.com/

Transport Canada. (2016, September 26). https://www.tc.gc.ca/eng/civilaviation/standards/generalrecavi-uav-4161.html\#toc1_0. Retrieved from https://www.tc.gc.ca/: https://www.tc.gc.ca/

Transport Risk Management, Inc., Unmanned Risk Management. (2016, Ocotber 19). Unmanned Aerial Systems - UAS Insurance Considerations. Unmanned Aerial Systems - UAS Insurance Considerations. USA: Transport Risk Management, Inc., Unmanned Risk Management.

Transpower New Zealand Limited. (2016). Utilising Remotely Piloted Aircraft Systems on the Transpower Network. Wellington, New Zealand: Transpower. Retrieved from http://tphub.transpower.co.nz/activity/gm72/Administration/Forms/Default.aspx.

UAS Vision. (2015, February 5). http://www.uasvision.com/2016/02/05/xcel-energy-to-conduct-blospower-line-inspections/. Retrieved from http://www.uasvision.com/: http://www.uasvision.com/

US Army. (2007, October). http://www.carson.army.mil/dac/documents/Cert/COAST\%20GUARD\%20UNIT\%20MOVEMEN 
T\%20FIELD\%20GUIDE\%202007.pdf. Retrieved from http://www.carson.army.mil/:

http://www.carson.army.mil/

US Army Corps of Engineers. (2016, November 2).

http://www.iwr.usace.army.mil/Portals/70/docs/iwrreports/2015-R-01.pdf. Retrieved from

http://www.iwr.usace.army.mil/: http://www.iwr.usace.army.mil/

US Navy. (2016, August 31). Naval Air Training and Operating Procedures Standardization (NATOPS)

Fundamentals. Retrieved from NATOPS GENERAL FLIGHT AND OPERATING

INSTRUCTIONS OPNAV INSTRUCTION 3710.7U Web Site: http://www.public.navy.mil/airfor/vaw120/Documents/OPNAVINST_3710.7U\%20(IC\%2045).p df

USA Today. (2016, August 31). http://www.usatoday.com/story/money/columnist/2016/08/30/utilitiesdrone-plans-cleared-takeoff/88621556/. Retrieved from http://www.usatoday.com/: http://www.usatoday.com/

Utility Dive. (2015, March 5). http://www.utilitydive.com/news/faa-authorizes-comed-to-use-drones-forpower-line-inspections/371469/. Retrieved from http://www.utilitydive.com/: http://www.utilitydive.com/

Weiker, P. (2013, November 1). https://books.google.com/books?id=pXIiAgAAQBAJ\&pg=PA214\#v=onepage\&q\&f=false. In P. Weiker, A Systems Approach to Lithium-Ion Battery Management (p. 214). Retrieved from https://books.google.com/: https://books.google.com/

Wikipedia. (2016, September 27). https://en.wikipedia.org/wiki/Catenary. Retrieved from https://en.wikipedia.org/wiki/: https://en.wikipedia.org/wiki/

Wikipedia. (2016, September 13). https://en.wikipedia.org/wiki/First-person_view_(radio_control). Retrieved from https://en.wikipedia.org/: https://en.wikipedia.org/

Wikipedia. (2016, September 13). https://en.wikipedia.org/wiki/Flight_control_surfaces. Retrieved from https://en.wikipedia.org/: https://en.wikipedia.org/

Wikipedia. (2016, September 13). https://en.wikipedia.org/wiki/Flight_envelope. Retrieved from https://en.wikipedia.org/: https://en.wikipedia.org/

Wikipedia. (2016, August 30). https://en.wikipedia.org/wiki/Hyperspectral_imaging. Retrieved from https://en.wikipedia.org/: https://en.wikipedia.org/

Wikipedia. (2016,September 22). https://en.wikipedia.org/wiki/Inertial_measurement_unit. Retrieved from https://en.wikipedia.org/: https://en.wikipedia.org/

Wikipedia. (2016, September 13). https://en.wikipedia.org/wiki/Military_operations_area. Retrieved from https://en.wikipedia.org/: https://en.wikipedia.org/

Wikipedia. (2016, August 30). https://en.wikipedia.org/wiki/Multispectral_image. Retrieved from https://en.wikipedia.org/: https://en.wikipedia.org/

Wikipedia. (2016, September 13). https://en.wikipedia.org/wiki/National_Security_Area. Retrieved from https://en.wikipedia.org/: https://en.wikipedia.org/

Wikipedia. (2016, October 10). https://en.wikipedia.org/wiki/National_Weather_Service. Retrieved from https://en.wikipedia.org/wiki/: https://en.wikipedia.org/wiki/

Wikipedia. (2016, October 12). https://en.wikipedia.org/wiki/Navigation_light. Retrieved from https://en.wikipedia.org/wiki/: https://en.wikipedia.org/wiki/ 
Wikipedia. (2016, September 13). https://en.wikipedia.org/wiki/NOTAM. Retrieved from https://en.wikipedia.org/: https://en.wikipedia.org/

Wikipedia. (2016, September 15). https://en.wikipedia.org/wiki/Pansharpened_image. Retrieved from https://en.wikipedia.org/: https://en.wikipedia.org/

Wikipedia. (2016, September 13). https://en.wikipedia.org/wiki/Radio-controlled_aircraft\#Ready_to_fly. Retrieved from https://en.wikipedia.org/: https://en.wikipedia.org/

Wikipedia. (2016, September 13). https://en.wikipedia.org/wiki/Restricted_airspace. Retrieved from https://en.wikipedia.org/: https://en.wikipedia.org/

Wikipedia. (2016, September 13). https://en.wikipedia.org/wiki/Rotorcraft. Retrieved from https://en.wikipedia.org/: https://en.wikipedia.org/

Wikipedia. (2016, August 30). https://en.wikipedia.org/wiki/Synthetic_aperture_radar. Retrieved from https://en.wikipedia.org/: https://en.wikipedia.org/

Wikipedia. (2016, August 30). https://en.wikipedia.org/wiki/Thermography. Retrieved from https://en.wikipedia.org/: https://en.wikipedia.org/

Wikipedia. (2016, September 13). https://en.wikipedia.org/wiki/Uncontrolled_airspace. Retrieved from https://en.wikipedia.org/: https://en.wikipedia.org/

Wikipedia. (2016, September 13). National Airspace System. Retrieved from Wikipedia: https://en.wikipedia.org/wiki/National_Airspace_System

Wikipedia. (2016, September 13). Park flyer. Retrieved from Wikipedia: https://en.wikipedia.org/wiki/Park_flyer

Wikipedia. (2016, September 13). Prohibited airspace. Retrieved from Wikipedia: https://en.wikipedia.org/wiki/Prohibited_airspace

Wikipedia. (2016, August 31). Situation awareness. Retrieved from Wikipedia : https://en.wikipedia.org/wiki/Situation_awareness

Wikipedia. (2016, September 13). Special use airspace. Retrieved from Wikipedia: https://en.wikipedia.org/wiki/Special_use_airspace

Wikipedia. (2016, August 31). Wikipedia. Retrieved from Wikipedia Web Site: https://en.wikipedia.org/wiki/Operational_risk_management

Wikipedia. (2016, September 1). Wikipedia. Retrieved from Wikipedia Web Site: https://en.wikipedia.org/wiki/Avionics

Wikipedia. (2016, August 31). Wikipedia . Retrieved from Wikipedia Web Site: https://en.wikipedia.org/wiki/Visual_meteorological_conditions

Wikipedia. (2017). Lithium polymer battery. Retrieved February 1, 2017, from Wikipedia: https://en.wikipedia.org/wiki/Lithium_polymer_battery

Wikipedia. (2017, February 9). Orthophoto. Retrieved February 11, 2017, from Wikipedia: https://en.wikipedia.org/wiki/Orthophoto

Willis, H. L. (2001). Aging Power Delivery Infrastructures. New York: Marcel Dekker, Inc.

Yerak, B. (2015, December 15). Wildlife and planes don't mix, government report shows. Chicago Tribune, p. 1. 



\section{APPENDIX A. DEFINITIONS}

The following terms are defined as they apply to unmanned aerial system flight operations.

Absolute Ceiling: Maximum height at which a particular airplane can operate. (Jeppesen Sanderson, Inc., 1983)

Acrobatic Flight: Maneuvers a pilot intentionally performs, involving abrupt altitude change and abnormal attitude or acceleration. (Jeppesen Sanderson, Inc., 1983)

Aerial Work: Means an aircraft operation in which an aircraft is used for specialized services such as agriculture, construction, photography, surveying, observation and patrol search and rescue, aerial advertisement, etc. (Transport Canada, 2016)

Aircraft: Any contrivance now known or hereafter invented, used, or designed for navigation of or flight in the air. (Jeppesen Sanderson, Inc., 1983)

Airport: Defined area on land or water, including any buildings and installations, normally used for aircraft takeoff, parking, and landing. (Jeppesen Sanderson, Inc., 1983)

Airport Advisory Area: Area within 5 statute miles of an uncontrolled airport where a flight service station is located. (Jeppesen Sanderson, Inc., 1983)

Airspeed: The speed of an aircraft relative to the air. (Jeppesen Sanderson, Inc., 1983)

Airworthy: Aircraft status indicating that it is suitable for safe flight. (Jeppesen Sanderson, Inc., 1983)

Alert Area: Alert areas are depicted on aeronautical charts to inform nonparticipating pilots of areas that may contain a high volume of pilot training or an unusual type of aerial activity. Remote pilots in command should be particularly alert when flying in these areas. All activity within an alert area must be conducted in accordance with CFRs, without waiver, and pilots of participating aircraft as well as pilots transiting the area must be equally responsible for collision avoidance. Alert areas contain special hazards that remote PICs must take into consideration when entering the areas. (FAA, 2016)

Altimeter: Instrument that measures altitude using air pressure change with height, using sealed thinwalled metallic bellows as its sensitive element. (Jeppesen Sanderson, Inc., 1983)

Altitude: Height expressed in units of distance above a reference plane, usually above mean seal level or ground. (Jeppesen Sanderson, Inc., 1983)

Anemometer: Any instrument for measuring the speed of wind. (Dictionary.com, 2016)

Attitude: Airplane's position determined by the inclination of the axes in relation to the horizon. (Jeppesen Sanderson, Inc., 1983)

Autopilot: Units and components used to automatically control the aircraft. (Jeppesen Sanderson, Inc., 1983)

Avionics: Avionics are the electronic systems used on aircraft, artificial satellites, and spacecraft. Avionic systems include communications, navigation, the display and management of multiple systems, and the hundreds of systems that are fitted to aircraft to perform individual functions. (Wikipedia, 2016) 
Axis: Theoretical line extending through the center of gravity of an airplane in each major plane: these are the longitudinal, lateral, and vertical axis. (Jeppesen Sanderson, Inc., 1983)

Balance: Condition of the aircraft load relative to the aircraft's center-of-gravity. (Jeppesen Sanderson, Inc., 1983)

Buddy-Box System: A two-tier system, with one transmitter operating as the master controller while a second transmitter is linked or slaved to it allowing dual control of an aircraft. A switch provides instantaneous transfer of control from one transmitter to the other. This system is a means of achieving a position transfer of control from one pilot to another. (Academy of Model Aeronautics, 2014)

Category: Describes the certification, ratings, privileges, and limitations of airmen. Examples include: airplane, rotorcraft, glider, and lighter-than-air. Also refers to aircraft based on intended use or operating limitations. Examples include: transport, normal, utility, acrobatic, limited, restricted, and provisional. (Jeppesen Sanderson, Inc., 1983)

Catenary: This wire curve that approximates the natural path of a wire strung between two points. Thus, the use of "catenary" to describe electric power lines. (Wikipedia, 2016)

Caution: An operating procedure, practice, or condition that may result in damage to equipment if not carefully observed or followed. (US Navy, 2016)

Caution Area: An area of defined dimensions within which the military training activities conducted, though not hazardous, are of interest to nonparticipating pilots. (Jeppesen Sanderson, Inc., 1983)

Certificate of Waiver (COW) or Certificate of Authorization (COA): A COA is an authorization issued by the Air Traffic Organization to a public operator for a specific UAS activity. After a complete application is submitted, FAA conducts a comprehensive operational and technical review. If necessary, provisions or limitations may be imposed as part of the approval to ensure the UAS can operate safely with other airspace users. In most cases, FAA will provide a formal response within 60 days from the time a completed application is submitted. To better support the needs of its customers, FAA deployed a web-based application system. The UAS COA Online System provides applicants with an electronic method of requesting a COA or COW. Applicants need to obtain an account to access the online system. (FAA, 2016)

Chart: Graphic representation of a section of the earth's surface specifically designed for navigational purposes (also called a map). (Jeppesen Sanderson, Inc., 1983)

Checklist: List of items requiring the airman's attention for various flight operations. (Jeppesen Sanderson, Inc., 1983)

Checkpoint: Geographical reference point used for checking the position of an aircraft in flight. As generally used, it is a well-defined reference point easily seen. Its exact position is known or plotted on the navigational chart, and was selected in pre-flight planning for use in checking aircraft position in flight. (Jeppesen Sanderson, Inc., 1983)

Class "G" Airspace: This class of airspace is uncontrolled airspace is mostly used for a small layer of airspace near the ground, but there are larger areas of Class $G$ airspace in remote regions of US flight operations may be conducted under instrument flight rules or visual flight rules (VFRs). Air traffic control has no authority but VFR minimums are to be known by pilots. Traffic information may be given as far as 
is practical in respect of other flights. Note: The United States does not use the International Civil Aviation Organization Class F airspace designation. (FAA, 2016)

Class of Aircraft: Classification of aircraft within a category, differentiating between single-engine and multi-engine and land and water configurations. (Jeppesen Sanderson, Inc., 1983)

Clearance (instrument flight rules): Authorization to follow a specified flight outline. Clearances are issued by the control agency within which the flight will operate, and are used to prevent collisions between aircraft. (Jeppesen Sanderson, Inc., 1983)

Cloud: A visible cluster of minute water and/or ice particles existing in the atmosphere. (Jeppesen Sanderson, Inc., 1983)

Compass: An instrument which indicates direction, measured clockwise from magnetic north. (Jeppesen Sanderson, Inc., 1983)

Command and Control Link: Means the data link between the UAS and the control station for the purposes of managing the flight. Note: These links are the wireless means of connecting one location to another for the purpose of transmitting or receiving data. (Transport Canada, 2016)

Control Station: An interface used by the remote pilot in command or the person manipulating the controls to control the flight path of the sUAS. (FAA, 2016)

Controlled Airspace: This airspace of defined dimensions within which air traffic control services are provided. The level of control varies with different classes of airspace. Controlled airspace usually imposes higher weather minimums than are applicable in uncontrolled airspace. It is the opposite of uncontrolled airspace. (FAA, 2016)

Course: Direction toward the destination as charted. A true course is measured from true north; magnetic course is measured from magnetic north. (Jeppesen Sanderson, Inc., 1983)

Crew Member: Means a person assigned to duties essential to the operation of the unmanned air vehicle system during flight time. (Transport Canada, 2016)

Crosswind: A wind blowing across the line of flight of an aircraft. (Jeppesen Sanderson, Inc., 1983)

Danger Area: A specified area within or over which there may exist activities constituting a potential danger to aircraft. (Jeppesen Sanderson, Inc., 1983)

Danger Tree: Any tree on or off the right of way that could contact electric supply lines. (Transmission \& Distribution World, 2011)

Daylight Operations: Part 107 prohibits operation of a sUAS at night, which is defined in part 1 as the time between the end of evening civil twilight and the beginning of morning civil twilight, as published in the Air Almanac, converted to local time. In the continental United States, evening civil twilight is the period of sunset until $30 \mathrm{~min}$ after sunset and morning civil twilight is the period of $30 \mathrm{~min}$ before sunrise until sunrise. In Alaska, the definition of civil twilight differs and is described in the Air Almanac. The Air Almanac provides tables which are used to determine sunrise and sunset at various latitudes. (FAA, 2016) 
Drag: The force opposing the movement of the airplane through the air. Induced drag - the part of the total drag on an airplane produced by the flow of air over lifting surfaces. Parasite drag - drag produced by attachments to the aircraft and no-lift devices such as landing gear and struts. (Jeppesen Sanderson, Inc., 1983)

Drift: Defection of an airplane from its intended course by action of the wind. (Jeppesen Sanderson, Inc., 1983)

Drone NOTAM (DROTAM): Aviation charting website SkyVector has added a useful new featuregraphical depictions of drone NOTAMs, which it calls "DROTAMs" - that show dimensions of drone/UAS airspace and information about activity times and operating altitudes. DROTAMs are available as a graphical layer on any kind of chart available from SkyVector. (Aviation International News (AIN), 2016)

Final Approach: A flight path of a landing aircraft in the direction of landing. (Jeppesen Sanderson, Inc., 1983)

First-Person View (FPV): Also known as remote-person view or simply video piloting, FPV is a method used to control a radio-controlled vehicle from the driver's or remote pilot in command's viewpoint. Most commonly it is used to pilot a radio-controlled aircraft or other type of UAS. The vehicle is either driven or piloted remotely from a first-person perspective via an onboard camera, fed wirelessly to video FPV goggles or a video monitor. More sophisticated setups include a pan-and-tilt gimbaled camera controlled by a gyroscope sensor in the pilot's goggles, and with dual onboard cameras enabling a true stereoscopic view. (Wikipedia, 2016)

Flare Out: To level off just above the landing area by decreasing the rate of decent and airspeed. (Jeppesen Sanderson, Inc., 1983)

Flight Control Surface: Aircraft flight control surfaces allow a remote pilot in command to adjust and control the aircraft's flight attitude. The development of effective flight controls is what allowed stable flight. (Wikipedia, 2016)

Flight Envelope: In aerodynamics, the flight envelope, service envelope, or performance envelope of an aircraft refers to the capabilities of a design in terms of airspeed and load factor or altitude. The term is somewhat loosely applied, and can also refer to other measurements such as maneuverability. When a plane is pushed, for instance by diving it at high speeds, it is said to be flown "outside the envelope," something considered rather dangerous. (Wikipedia, 2016)

Flight Plan: Specified information relating to the intended flight of an aircraft that is filed orally or in writing. (Jeppesen Sanderson, Inc., 1983)

Flight Termination System: Means the system that, upon initiation, terminates the flight of a UAS in a manner so as not to cause significant damage to property or severe injury to persons on the ground. (Transport Canada, 2016)

Flight Time: The time from the moment the aircraft first moves under its own power for the purpose of flight until the moment it comes to rest at the next point of landing. (Jeppesen Sanderson, Inc., 1983)

Fly-away: Means an interruption or loss of the Command and Control link where the pilot is unable to affect control of the aircraft and the aircraft is longer following its preprogrammed procedures resulting in the UAS not operating in a predictable or planned manner. (Transport Canada, 2016) 
Glide: Sustained forward flight in which speed is maintained only by the loss of altitude. (Jeppesen Sanderson, Inc., 1983)

Gross Weight: The total weight of the UAS ready for flight. This weight consists of aircraft basic empty weight, fuel, cargo, and removable equipment.

Ground Speed: The speed of the aircraft relative to the ground. (Jeppesen Sanderson, Inc., 1983)

Handover: Means the act of passing pilot-in-command responsibilities from one control station or pilot to another. (Transport Canada, 2016)

Hazard Tree: A structurally unsound tree that could strike electric supply lines when it fails. (Transmission \& Distribution World, 2011)

Heading: The direction in which the nose of the airplane points during flight. Corrections made to compensate for wind will cause differences to arise between track and heading. If no change is made in heading to compensate for wind, differences will arise between track and course as the aircraft drifts. (Jeppesen Sanderson, Inc., 1983)

In-Flight Emergency: An in-flight emergency is an unexpected and unforeseen serious occurrence or situation that requires urgent, prompt action. In case of an in-flight emergency, the remote pilot in command (PIC) is permitted to deviate from any rule of Part 107 to the extent necessary to respond to that emergency. A remote PIC who exercises this emergency power to deviate from the rules of Part 107 is required, upon FAA request, to send a written report to the FAA explaining the deviation. Emergency action should be taken in such a way as to minimize injury or damage to property. (FAA, 2016)

IFR Conditions: Weather conditions below the minimum prescribed for flight under visual flight rules. (Jeppesen Sanderson, Inc., 1983)

Inertial Measurement Unit: An electronic device that measures and reports a body's specific force, angular rate, and sometimes the magnetic field surrounding the body using a combination of accelerometers and gyroscopes and sometimes also magnetometers. Inertial measurement units are typically used to maneuver aircraft, including unmanned aerial systems (UASs). (Wikipedia, 2016)

Instrument Flight Rules: When weather conditions are below the minimums prescribed for visual meteorological conditions, pilots must fly in accordance with instrument flight rules (IFRs). Pilots may elect to fly an IFR flight plan during visual flight rule conditions. (Jeppesen Sanderson, Inc., 1983)

International Civil Aviation Organization (ICAO): An international body in the field of aeronautics. ICAO standards and recommended practices are not binding: final decision rest with the sovereign state. (Jeppesen Sanderson, Inc., 1983)

Knot: A unit of speed equal to 1 NM per hour. (Jeppesen Sanderson, Inc., 1983)

Landing: The act of terminating flight and bringing an airplane to rest. (Jeppesen Sanderson, Inc., 1983)

Landing Gear: The under structure which supports the weight of the stationary airplane. (Jeppesen Sanderson, Inc., 1983)

Log: To make a flight-by-flight record of all operations of an airplane, engine, or remote PIC, listing flight time, area of operation, and other pertinent information. (Jeppesen Sanderson, Inc., 1983) 
Lost Link: Means the loss of Command and Control link contact with the unmanned air vehicle such that the pilot can no longer manage the aircraft's flight. (Transport Canada, 2016) In this eventuality, many UASs will automatically initiate return-to-base profiles.

Low Frequency: A frequency in the $30-300 \mathrm{kHz}$ band normally received by an automatic direction finder navigation radio. (Jeppesen Sanderson, Inc., 1983)

Magnetic Course: The true course or track, corrected for magnetic variation between two points on the surface of the earth. (Jeppesen Sanderson, Inc., 1983)

Maneuvering Speed: Maximum speed at which the flight controls can be fully deflected without damage to the aircraft structure. It may be found in the airplane flight manual and is useful for guidance in performing flight maneuvers, or normal operations in severe turbulence. (Jeppesen Sanderson, Inc., 1983)

Maximum Gross Weight: The maximum weight authorized by FAA for operation of the aircraft. (Jeppesen Sanderson, Inc., 1983)

May: "May" and "need not" mean procedure is optional. (US Navy, 2016)

Mean Sea Level (MSL): The average level of the sea; used to compute barometric pressure to determine altitude.

Military Operations Area (MOA): According to FAA, a MOA is "airspace established outside Class A airspace to separate or segregate certain nonhazardous military activities from instrument flight rule traffic and to identify for visual flight rule traffic where these activities are conducted." Similar structures exist under international flight standards. These are designed for routine training or testing maneuvers. Areas near actual combat or other military emergencies are generally designated as restricted airspace. (Wikipedia, 2016)

Mission Payload Operator (MPO): Supports UAS flight operations by performing duties as an MPO for a particular academic, industrial, or technical area. Controls high priority UAS mission intelligence collection sensors. Controls and manages data as required. The MPO is responsible for assisting the remote pilot in command in coordinating ground and flight operations including mission planning, execution, and debriefing; safe operation of the aircraft; aircrew resource management; and customer coordination and coordination with the public. An MPO may also be referred to as a sensor operator.

Model Aircraft: A UAS that is (1) capable of sustained flight in the atmosphere, (2) flown within visual line of sight of the person operating the aircraft, and (3) flown for hobby or recreational purposes. (FAA, 2016)

National Airspace System (NAS): “The airspace, navigation facilities, and airports of the United States along with their associated information, services, rules, regulations, policies, procedures, personnel, and equipment. It includes components shared jointly with the military. It is one of the most complex aviation systems in the world and services air travel in the United States and over large portions of the world's oceans. ... As of February 2015, NAS was transitioning to a new system known as NextGen, which applies nonradar surveillance of aircraft equipped with GPS satellite-based navigation systems continuously reporting their locations. Aircraft also receive the broadcast location of others nearby, which improves safety. The system also allows pilots to use more precise and efficient landing paths, saving time and fuel. NextGen is being phased in piece by piece. About 14,500 air traffic controllers, 4,500 aviation safety inspectors, and 5,800 technicians operate and maintain services for NAS. It has more than 19,000 airports and 600 ATC facilities. In all, there are 41,000 NAS operational facilities. In addition, 
there are over 71,000 pieces of equipment, ranging from radar systems to communication relay stations. On average, about 50,000 flights use NAS services each day." (Wikipedia, 2016)

National Security Area (NSA): A designated airspace through which flight is discouraged for reasons of national security. Flight through NSAs is not prohibited, and no special advance clearance or authorization need be obtained to enter them. However, remote pilots in command are strongly encouraged to either stay clear of NSAs or obtain prior authorization to pass through them in order to reassure the controlling agency that no threat to national security exists. NSAs are a compromise between normal airspace and restricted or prohibited airspace. NSAs can be temporarily converted into restricted airspace by NOTAMs. On visual flight rule sectional charts, NSAs are delimited by a heavy dashed magenta border and a special notation. (Wikipedia, 2016)

Nautical Mile (NM): Unit of distance used in navigation, equaling 6,080 ft; the minimum length of one minute of longitude on the equator; about one minute of latitude; 1.15 statute miles. (Jeppesen Sanderson, Inc., 1983)

Navigation Light: Any one of a group of lights mounted on an aircraft to make its dimensions, position, and direction of motion visible at night or during poor visibility. (Jeppesen Sanderson, Inc., 1983)

Note: An operating procedure, practice, or condition that must be emphasized. (US Navy, 2016)

Notice to Airmen (NOTAM): A NOTAM is a notice filed with an aviation authority to alert aircraft pilots of potential hazards along a flight route or at a location that could affect the safety of the flight. NOTAMs are unclassified notices or advisories distributed by means of telecommunication that contain information concerning the establishment, conditions or change in any aeronautical facility, service, procedure or hazard, the timely knowledge of which is essential to personnel and systems concerned with flight operations. NOTAMs are created and transmitted by government agencies and airport operators under guidelines specified by Annex 15: Aeronautical Information Services of the Convention on International Civil Aviation (CICA). The term NOTAM came into common use rather than the more formal "Notice to Airmen" following the ratification of the CICA, which came into effect on 4 April 1947. Notices to Airmen were normally published in a regular publication by each country's air authorities (e.g., in Flight Magazine in the UK). A number of developments and amendments to the CICA have resulted in the more automated system available today. (Wikipedia, 2016)

Obstruction Light: A light, or a group of lights, usually red, mounted on a surface structure or natural terrain to warn pilots of the presence of a flight hazard. (Jeppesen Sanderson, Inc., 1983)

Operational Risk Management (ORM): ORM is defined as a continual cyclic process which includes risk assessment, risk decision making, and implementation of risk controls, which results in acceptance, mitigation, or avoidance of risk. ORM is the oversight of operational risk, including the risk of loss resulting from inadequate or failed internal processes and systems; human factors; or external events. (Wikipedia, 2016)

Operator: In respect of an aircraft, means the person that has possession of the aircraft or the UAS system, as owner, lessee or otherwise. (Transport Canada, 2016)

Owner: In respect of an aircraft, means the person who has legal custody and control of the aircraft. (Transport Canada, 2016)

Park Flyer: "The term 'park flyer' denotes a class of small, primarily electric-powered, radio-controlled aircraft, so named because their size enables some of them to be operated within the confines of a large 
public park. Some are slow and docile enough to fly within an enclosed area such as a gymnasium, or even a living room, while others require the open space needed for larger models due to size and/or speed. Because of their size and relative ease of setup, ready-to-fly park flyers are among the most popular class of remote control aircraft for beginners and advanced pilots alike." (Wikipedia, 2016)

Payload: Means all elements of the aircraft that are not necessary for flight but are carried for the purpose of fulfilling specific mission objectives. This may include subsystems such as intelligence and surveillance assets, communication relay equipment, sensors, cargo, and cameras. (Transport Canada, 2016)

Person Manipulating the Controls: A person other than the remote pilot in command (PIC) who is controlling the flight of a UAS under the supervision of the remote PIC. (FAA, 2016)

Pilot: A person holding a valid pilot certificate issued by the FAA. (Jeppesen Sanderson, Inc., 1983)

Pilotage: Navigation by visual reference to landmarks. (Jeppesen Sanderson, Inc., 1983)

Pitch: The blade angle of a propeller. Also, the movement of an aircraft about its lateral axis. (Jeppesen Sanderson, Inc., 1983)

Positive Control: Control of all air traffic, within designated airspace, by air traffic control. (Jeppesen Sanderson, Inc., 1983)

Prohibited Airspace: "Refers to an area (volume) of airspace within which flight of aircraft is not allowed, usually due to security concerns. It is one of many types of special use airspace designations and is depicted on aeronautical charts with the letter "P" followed by a serial number. It differs from restricted airspace in that entry is typically forbidden at all times from all aircraft and is not subject to clearance from air traffic control or the airspace's controlling body. According to FAA, "Prohibited areas contain airspace of defined dimensions identified by an area on the surface of the earth within which the flight of aircraft is prohibited. Such areas are established for security or other reasons associated with the national welfare. These areas are published in the Federal Register and are depicted on aeronautical charts." Some prohibited airspace may be supplemented via NOTAMs. . . Aircraft violating or about to violate prohibited airspace will often be warned beforehand on $121.5 \mathrm{MHz}$, the emergency frequency for aircraft." (Wikipedia, 2016)

Propeller: Device for propelling an aircraft, with blades mounted on an engine-driven shaft that, when rotated, produces a thrust approximately perpendicular to its plane of rotation. (Jeppesen Sanderson, Inc., 1983)

Radio Line of Sight: Means the limit of direct point-to-point contact between a transmitter and a receiver given the equipment being used and the prevailing conditions. (Transport Canada, 2016)

Range Maximum: Maximum distance a given aircraft can cover under given conditions by flying at the most economical speed and altitude at all states of the flight. (Jeppesen Sanderson, Inc., 1983)

Ready to Fly: Ready-to-fly (RTF) model airplanes come preassembled and usually only require wing attachment or other basic assembly. Typically, everything that is needed is provided, including the transmitter, receiver, and battery. RTF airplanes can be up in the air in just a few minutes and have all but eliminated assembly time (at the expense of the aircraft model's configuration options.) (Wikipedia, 2016) 
Recovery: Means the phase of a UAS flight that involves the return of an aircraft to the ground or to base. (Transport Canada, 2016)

Remote Pilot in Command (Remote PIC or Remote Pilot): A person who holds a remote pilot certificate with a sUAS rating and has the final authority and responsibility for the operation and safety of a sUAS under Part 107. (FAA, 2016) The remote PIC is responsible for coordinating ground and flight operations including mission planning, execution, and debriefing; safe operation of the aircraft; aircrew resource management; along with customer coordination and coordination with the public.

Restricted Airspace: Restricted airspace is an area (volume) of airspace typically used by the military in which the local controlling authorities have determined that air traffic must be restricted (if not continually prohibited) for safety or security concerns. It is one of many types of SUA designations and is depicted on aeronautical charts with the letter " $R$ " followed by a serial number. According to the FAA: "Restricted areas denote the existence of unusual, often invisible, hazards to aircraft such as artillery firing, aerial gunnery, or guided missiles. Penetration of restricted areas without authorization from the using or controlling agency may be extremely hazardous to the aircraft and its occupants." Restricted airspace zones may not be active ("hot") at all times; in such cases there are typically schedules of local dates and times available to aviators specifying when the zone is active, and at other times, the airspace is subject to normal visual flight rule/instrument flight rule operation for the applicable airspace class. A few zones are activated by NOTAM. (Wikipedia, 2016)

Rhumb Line: Line drawn on a chart between points for navigational purposes. In practice, it is the line on the map which the pilot attempts to follow. (Jeppesen Sanderson, Inc., 1983)

Roll: Movement of an aircraft about its longitudinal axis. (Jeppesen Sanderson, Inc., 1983)

Rotary Wing: A rotorcraft, or rotary-wing aircraft, is a heavier-than-air flying machine that uses lift generated by wings, called rotary wings or rotor blades, that revolve around a mast. Several rotor blades mounted on a single mast are referred to as a rotor. Rotorcraft generally include those aircraft where one or more rotors are required to provide lift throughout the entire flight. (Wikipedia, 2016)

Route: Defined path, consisting of one or more courses, which an aircraft traverses in a horizontal plane over the surface of the earth. (Jeppesen Sanderson, Inc., 1983)

Runway: Strip, either paved or improved, on which takeoffs and landings are effected. (Jeppesen Sanderson, Inc., 1983)

Separation: In air traffic control, the spacing of aircraft to achieve safe and orderly movement in flight and while landing and taking off. (Jeppesen Sanderson, Inc., 1983)

Shall: Means a procedure that is mandatory. (US Navy, 2016)

Should: Means a procedure that is recommended. (US Navy, 2016)

Situational Awareness: Situational awareness is the perception of environmental elements with respect to time or space, the comprehension of their meaning, and the projection of their status after some variable such as time or a predetermined event has changed. It is also a field of study concerned with understanding the environment critical to decision makers in complex, dynamic areas from aviation, air traffic control, ship navigation, power plant operations, military command and control, and emergency services such as fire-fighting and policing to more ordinary but nevertheless complex tasks such as driving an automobile or riding a bicycle. (Wikipedia, 2016) 
Slant Range: The line-of-sight distance between two points not at the same elevation. (Jeppesen Sanderson, Inc., 1983)

Small Unmanned Aircraft: An aerial vehicle weighing less than $55 \mathrm{lb}$, including everything that is onboard or otherwise attached to the aircraft, that can be flown without the possibility of direct human intervention from within or on the aircraft. (FAA, 2016)

Small Unmanned Aerial System: A small unmanned aircraft (sUA) and the associated elements (including communication links and the components that control the sUA) that are required for the safe and efficient operation of the sUA in the National Airspace System. (FAA, 2016)

Spar: Principal longitudinal structure member in an airfoil. (Jeppesen Sanderson, Inc., 1983)

Special Use Airspace: “An area designated for operations of a nature such that limitations may be imposed on aircraft not participating in those operations. Often these operations are of a military nature. The designation of 'SUA' identifies for other users the areas where such activity occurs, provides for segregation of that activity from other users, and allows charting to keep airspace users informed of potential hazards. Most SUAs are depicted on aeronautical charts, and FAA maintains a page showing the current status of most SUAs. ... Flights within restricted areas are only allowed with specific FAA clearance and may be subject to restrictions, while in prohibited areas flights are forbidden except in emergency situations. Flying in military operations areas or 'Warning Areas' is allowed by nonmilitary aircraft without clearance but can be hazardous." (Wikipedia, 2016)

Special Visual Flight Rule (VFR) Conditions (special VFR minimum weather conditions): Weather conditions which are less than basic VFR weather conditions and which permit flight under VFRs in a control zone. (Jeppesen Sanderson, Inc., 1983)

Spin: Prolonged stall in which an airplane rotates about its center of gravity while it descends, usually with its nose well down. (Jeppesen Sanderson, Inc., 1983)

Spiral: Prolonged gliding or climbing turn during which at least $360^{\circ}$ change of direction is affected. (Jeppesen Sanderson, Inc., 1983)

Stability: Tendency of an airplane in flight to remain in straight, level, upright flight, or to return to this attitude if displaced, without attention of the pilot. (Jeppesen Sanderson, Inc., 1983)

Stall: Flight maneuver or condition caused by an excessive angle of attack, which the air passing over and under the wings stops providing sufficient lift to hold the aircraft aloft. (Jeppesen Sanderson, Inc., 1983)

Statute Mile: 5,280 ft or 0.867 NM.

Subject Matter Expert (SME): Supports UAS flight operations by performing duties as an SME for a particular academic, industrial, or technical area. The SME assists in the technical aspects of UAS mission operation and collection (e.g., sensor work). The SME is responsible for assisting the remote pilot in command in coordinating ground and flight operations including mission planning, execution, and debriefing; safe operation of the aircraft; aircrew resource management; along with customer coordination and coordination with the public.

Taxi: To operate an airplane under its own power on the ground except for that movement related to actual takeoff and landing. (Jeppesen Sanderson, Inc., 1983) 
Temporary Flight Restriction (TFR): A TFR is a geographically limited, short-term, airspace restriction, typically in the United States. TFRs often encompass major sporting events, natural disaster areas, air shows, space launches, and presidential movements. Before the September 11, 2001, attacks, most TFRs were in the interest of safety to flying aircraft, with occasional small restrictions for presidential movements. Since the September 11 attacks, TFRs have been routinely used to restrict airspace for $30 \mathrm{NM}$ around the president, with a $10 \mathrm{NM}(20 \mathrm{~km})$ radius no-fly zone for nonscheduled flights. They are also available to other important people such as presidential and vice-presidential candidates. The responsibility for screening requests for TFRs and for subsequently granting or denying them lies with the FAA Office of System Operations Security. (FAA, 2016)

Thrust: Forward force on an airplane in the air provided by the engine. (Jeppesen Sanderson, Inc., 1983)

Track: Flight path made good over the ground by an aircraft. A track may be called a course when in reference to the charted route and is described in terms of direction from north. (Jeppesen Sanderson, Inc., 1983)

Transponder: Airborne radar beacon receiver-transmitter which receives radio signals from all interrogators on the ground and selectively replies with specific radio wave pulses to only those interrogations being received on the specific radio frequencies to which it is set to respond. (Jeppesen Sanderson, Inc., 1983)

True Altitude: The altitude above mean sea level. (Jeppesen Sanderson, Inc., 1983)

Turbulence: Irregular motion of the atmosphere produced when air flows over a comparatively uneven surface, such as the surface of the earth, or when two currents of air flow past or over each other in different directions or at different speeds. (Jeppesen Sanderson, Inc., 1983)

Uncontrolled Airspace: Airspace where an air traffic control service is not deemed necessary or cannot be provided for practical reasons. According to the airspace classes set by the International Civil Aviation Organization, both class F and class $\mathrm{G}$ airspace are uncontrolled. It is the opposite of controlled airspace. Air traffic control does not exercise any executive authority in uncontrolled airspace, but may provide basic information services to aircraft in radio contact. Flight in uncontrolled airspace will typically be under visual flight rules. Aircraft operating under instrument flight rules should not expect separation from other traffic: however, in certain uncontrolled airspace, this might be provided on an 'as far as is practical' advisory basis. (Wikipedia, 2016)

Unmanned Aircraft: An aircraft operated without the possibility of direct human intervention from within or on the aircraft. (FAA, 2016)

Useful Load: In airplanes, the difference, in pounds, between the empty weight and the maximum authorized gross weight. (Jeppesen Sanderson, Inc., 1983)

Utility Forest: Consists of the land base supporting tree species that could now, or in the future, interfere with safe, reliable electric service. (Transmission \& Distribution World, 2011)

Vegetation Management: A broad term that includes tree pruning; brush removal through the use of power saws and mowers; the judicious use of herbicides and tree growth regulators; hazard tree identification and removal; the implementation of strategies to minimize the establishment of incompatible species under and near power lines; and the control of weeds. (Transmission \& Distribution World, 2011) 
Very High Frequency: Frequency band from 30 to $300 \mathrm{MHz}$.

Visibility: In weather observing practice, the greatest distance in a given direction at which it is possible to see and identify with the unaided eye (or the instrumentally determined equivalent) prominent unlighted objects by day and prominent lighted objects at night. For weather observing purposes, visibility is categorized as flight visibility, ground visibility, or runway visual range. (Jeppesen Sanderson, Inc., 1983)

Visual Flight Rules for UASs: When weather conditions are above the minimums prescribed for visual meteorological conditions, remote PICs may fly with visual reference to the UAS and other structures without continuous referral to other visual or locating aids.

Visual Meteorological Conditions (VMCs): VMCs refers to an aviation flight category in which visual flight rules flight is permitted - that is, conditions in which remote pilots in command have sufficient visibility to fly the aircraft maintaining visual separation from terrain and other aircraft. They are the opposite of instrument meteorological conditions (IMCs). The boundary criteria between IMCs and VMCs are known as the VMC minima and are defined by visibility, cloud ceilings (for takeoffs and landings), and cloud clearances. (Wikipedia, 2016)

Visual Observer (VO): A person acting as a flight crew member who assists the remote pilot in command (PIC) and the person manipulating the controls to see and avoid other air traffic or objects aloft or on the ground. (FAA, 2016) The VO is responsible for supporting the remote PIC in coordinating ground and flight operations including mission planning, execution, and debriefing; safe operation of the aircraft; aircrew resource management; along with customer coordination and coordination with the public. A VO is sometimes referred to as a "Spotter."

Warning: An operating procedure, practice, or condition that may result in injury or death if not carefully observed or followed. (US Navy, 2016)

Warning Areas: A warning area is airspace of defined dimensions, extending from 3 NM outward from the coast of the United States, that contains activity that may be hazardous to nonparticipating aircraft. The purpose of such warning areas is to warn nonparticipating remote PICs of the potential danger. A warning area may be located over domestic or international waters or both. (FAA, 2016)

Waypoint: An intermediate point on a route or line of travel. (Merriam-Webster, 2016)

Weather Depiction Chart: Weather analysis, portraying areas of precipitation and obstructions to vision, cloud cover, and cloud heights. (Jeppesen Sanderson, Inc., 1983)

Wind Shear: The change of either wind speed or direction or both, in any direction, conventionally expressed as vertical wind shear or horizontal wind shear. (Jeppesen Sanderson, Inc., 1983)

Wind Sock: Fabric sleeve, mounted aloft at and airport or operating area used to estimate wind direction and velocity. (Jeppesen Sanderson, Inc., 1983)

Will: Indicates futurity and never indicates any degree of requirement for application of a procedure. (US Navy, 2016)

Yaw: To turn about the vertical axis. An airplane is said to yaw as the nose turns without the accompanying appropriate bank. (Jeppesen Sanderson, Inc., 1983) 


\section{APPENDIX B. UNMANNED AERIAL SYSTEM OPERATIONS- PUBLIC NOTIFICATION}

Ensure that landowners and associated stakeholders are provided accommodations through adequate prior notification of unmanned aerial system (UAS) flight operations, including the following.

- For all UAS flights being conducted over or near local roadways, provide notification to stakeholders at least 20 working days before the flight to allow for UAS traffic management planning if required.

- For all UAS operations being conducted in an area, provide a local newspaper notice addressing specifics, including intended takeoff and landing zones, at least 20 working days before the flight.

- For all UAS operations being conducted in an area, provide letters to landowners with property within $150 \mathrm{ft}(46 \mathrm{~m})$ in urban areas and $500 \mathrm{ft}(152 \mathrm{~m})$ in rural areas advising owners or managers of upcoming UAS overflight path at least 10 working days before the intended flight. ${ }^{1}$

- For all UAS flights being conducted near airports or other airborne operating areas, provide notification to stakeholders at least 10 working days before the intended flight. ${ }^{2}$

- For all UAS flights being conducted over local distribution lines, provide notification to stakeholders at least 5 working days before the intended flight.

- For all UAS flights, provide a Notice to Airmen/Drone Notice to Airmen at least 2 working days before the intended flight.

Note: Operator must gain the consent of any person the UAS will fly above.

\footnotetext{
${ }^{1}$ Operator should notify the landowner, or persons responsible, of the area to be flown above before conducting flight operations.

${ }^{2}$ Never fly within 5 miles of an airport without contacting airport authorities and the airport's traffic control facility. The Airport Advisory Area is an area of 5 miles encircling an airport. If this area is to be entered for UAS flight operations; the airport authorities must be contacted before flight operations.
} 


\section{S A M PLE NOT I F I C A T I O N L E T T E R}

(For Organization Letterhead)

(Date)

(First Last Name)

(Job Position)

(Organization)

(Address)

Dear (Landowner or Guardian's Name):

Visual inspection of [Electric Distribution/Transmission Line Name] by Unmanned Aerial System (UAS)

As you are aware, [Electric Utility Name] owns and operates the above electric power infrastructure that crosses your property. This power network forms part of the large electricity transmission network for the larger national grid, which transports electricity from where it is generated to rural, suburban, and urban municipalities.

We, [Service Provider] act on behalf of [Electric Utility Name] in maintaining this line. We would like to take this opportunity to thank you for your continued co-operation with us in relation to access to the electric network.

As part of the work to ensure this power line continues to provide safe and reliable service to the communities it serves, we need to undertake visual inspections for vegetation management, general maintenance, or infrastructure upgrade. This now will involve the new technology of UASs flying at a low altitude so that the conductors (wires) and joints of the infrastructure can be inspected.

Because the work requires crossing the airspace above your property, we want to ensure that you are fully aware of this proposed action.

Details of when this work is proposed to take place and what you can expect are outlined below.

Timing and Duration We intend to operate a UAS over your property — above and adjacent to the transmission line-between [Operating Hours] during the week beginning [Date: DD MMM YYYY]. The work is weather dependent, and we will inform you of any changes.

Point of Contact $\quad$ Please contact [First Last Name] on [phone number] or [mobile number] for any further information regarding this work.

If you have any special requests regarding the timing and effect of this work, please contact us as soon as possible and we will try t to accommodate your needs in our work plan.

Yours sincerely,

[Signature]

[First Last Name]

[Job Title], [Service Provider] 


\title{
APPENDIX C. UNMANNED AERIAL SYSTEM WORK IN SUPPORT OF ELECTRIC UTILITIES-MISSION PLAN
}

\author{
Unmanned Aerial System (UAS) Work Order
}

\begin{tabular}{|c|c|c|}
\hline Job Description & Visual inspection of joints and towers betw & towers [\#] and [\#] \\
\hline Nearest Address (if applicable) & GPS Coordinates & \\
\hline Date & Weather Contingency Date & \\
\hline Time & Weather Contingency Time & \\
\hline
\end{tabular}

\section{Personnel Checklist}

\begin{tabular}{|l|l|l|l|l|}
\hline \multicolumn{1}{|c|}{ Staff Assigned } & Name & Company & Email Address & Mobile Phone \\
\hline $\begin{array}{l}\text { Remote pilot in } \\
\text { command }\end{array}$ & & & & \\
\hline Visual observer & & & & \\
\hline $\begin{array}{l}\text { Mission payload } \\
\text { operator }\end{array}$ & & & & \\
\hline Subject matter expert & & & & \\
\hline
\end{tabular}

Landowner and Associated Stakeholder Communications Checklist

\begin{tabular}{|l|l|l|l|}
\hline \multicolumn{1}{|c|}{$\begin{array}{c}\text { Landowners and } \\
\text { Stakeholders }\end{array}$} & $\begin{array}{c}\text { Contact Information } \\
\text { (Address and Phone) }\end{array}$ & $\begin{array}{c}\text { Timeline of } \\
\text { Documentation } \\
\text { Requirements }\end{array}$ & \multicolumn{1}{c|}{ Description of/Reason for Notifications } \\
\hline $\begin{array}{l}\text { Road Controlling } \\
\text { Authority }\end{array}$ & $\begin{array}{l}\text { 20 working days } \\
\text { before flight } \\
\text { operations }\end{array}$ & $\begin{array}{l}\text { Notification of work-For all UAS flights } \\
\text { being conducted over or near local roadways, } \\
\text { provide notification to stakeholders to allow } \\
\text { for UAS traffic management planning if } \\
\text { required. }\end{array}$ \\
\hline Local Newspaper & $\begin{array}{l}\text { 20 working days } \\
\text { before flight } \\
\text { operations }\end{array}$ & $\begin{array}{l}\text { Notification of work via local newspaper } \\
\text { notice-If applicable, local newspaper notice } \\
\text { addressing specifics of UAS operations is to } \\
\text { be printed, to include intended takeoff and } \\
\text { landing zones. }\end{array}$ \\
\hline $\begin{array}{l}\text { Landowner } \\
\text { (appropriate authority } \\
\text { and/or land use } \\
\text { agreement) }\end{array}$ & $\begin{array}{l}10 \text { working days } \\
\text { before flight } \\
\text { operations }\end{array}$ & $\begin{array}{l}\text { Notification of work via letter to } \\
\text { landowners-Landowners with property } \\
\text { within 150 ft (46 m) in urban areas and 500 ft } \\
\text { (152 m) in rural areas advising owners or } \\
\text { managers of upcoming UAS overflight path. } \\
\text { UAS operator must gain the consent of any } \\
\text { person in the overflight path. }\end{array}$ \\
\hline
\end{tabular}




\section{Stakeholder Communications Checklist (continued)}

\begin{tabular}{|c|c|c|c|}
\hline $\begin{array}{l}\text { Landowners and } \\
\text { Stakeholders }\end{array}$ & $\begin{array}{l}\text { Contact Information } \\
\text { (Address and Phone) }\end{array}$ & $\begin{array}{c}\text { Timeline of } \\
\text { Documentation } \\
\text { Requirements }\end{array}$ & Description of/Reason for Notifications \\
\hline $\begin{array}{l}\text { Airport } \\
\text { (if operating within } \\
5 \text { statute miles) }\end{array}$ & & $\begin{array}{l}10 \text { working days } \\
\text { before flight } \\
\text { operations }\end{array}$ & $\begin{array}{l}\text { Never fly within } 5 \text { miles of an airport without } \\
\text { contacting airport authorities and the airport's } \\
\text { traffic control facility. The Airport Advisory } \\
\text { Area is an area of } 5 \text { statute miles encircling an } \\
\text { airport. If this area is to be entered for UAS } \\
\text { flight operations; the airport authorities must be } \\
\text { contacted before flight operations. }\end{array}$ \\
\hline $\begin{array}{l}\text { Local Distribution } \\
\text { Network }\end{array}$ & & $\begin{array}{l}5 \text { working days } \\
\text { before flight } \\
\text { operations }\end{array}$ & Notification of work \\
\hline $\begin{array}{l}\text { Service Provider Local } \\
\text { Field Services Office }\end{array}$ & & $\begin{array}{l}2 \text { working days } \\
\text { before flight } \\
\text { operations }\end{array}$ & Notification of work \\
\hline $\begin{array}{l}\text { National Grid } \\
\text { Operating Center }\end{array}$ & & $\begin{array}{l}2 \text { working days } \\
\text { before flight } \\
\text { operations }\end{array}$ & Notification of work \\
\hline Others (as required) & & $\begin{array}{l}\text { As early as } \\
\text { practicable }\end{array}$ & $\begin{array}{l}\text { Notification of work via letter or home visit if } \\
\text { required }\end{array}$ \\
\hline
\end{tabular}

UAS and Control Station Checklist

\begin{tabular}{|c|c|c|c|}
\hline \multicolumn{4}{|l|}{ UAS Make } \\
\hline \multicolumn{4}{|l|}{ UAS Model } \\
\hline \multicolumn{4}{|l|}{ UAS Communications } \\
\hline \multicolumn{4}{|l|}{ UAS Data } \\
\hline Target Maximum Height & Span & Tower & Return-to-Base Height \\
\hline $\begin{array}{l}\text { Description of UAS } \\
\text { Markings (N-Number) }\end{array}$ & & & \\
\hline
\end{tabular}

\section{If UAS Uses GPS Navigation}

\begin{tabular}{|l|l|}
\hline Minimum GPS Satellites Required & \\
\hline GPS Constellation Forecast & \\
\hline
\end{tabular}

\section{Airspace Checklist}

\begin{tabular}{|l|l|}
\hline \multicolumn{1}{|c|}{ Task } & Date Active or Not Applicable (NA) \\
\hline $\begin{array}{l}\text { Necessary Airspace Clearances Obtained (NA if none are } \\
\text { required) }\end{array}$ & \\
\hline Current Visual Flight Rules Sectional Chart & \\
\hline Nearby Alert Areas & \\
\hline Nearby Caution Areas & \\
\hline Nearby Controlled Airspace & \\
\hline
\end{tabular}


Airspace Checklist (continued)

\begin{tabular}{|l|l|}
\hline \multicolumn{1}{|c|}{ Task } & Date Active or Not Applicable (NA) \\
\hline Nearby Danger Areas & \\
\hline Nearby High Traffic Airspace & \\
\hline Nearby Military Operation Areas & \\
\hline Nearby National Security Areas & \\
\hline Nearby Prohibited Airspace & \\
\hline Nearby Restricted Airspace & \\
\hline Nearby Special Use Airspace & \\
\hline Nearby Temporary Flight Restrictions & \\
\hline Nearby Uncontrolled Airspace & \\
\hline Nearby Warning Areas & \\
\hline Flight Logged on Drone Notice to Airmen & \\
\hline Flight Logged on Notice to Airmen & \\
\hline
\end{tabular}

\section{Communications Checklist}

\begin{tabular}{|l|l|}
\hline & Frequencies \\
\hline Check for Electrical Signals in Area: Electromagnetic interference, Wi-Fi, etc. & \\
\hline Airspace Communications Receive (radio) & \\
\hline Mission Area Communications Transmit/Receive & \\
\hline
\end{tabular}





\section{APPENDIX D. UNMANNED AERIAL SYSTEM MISSION PLANNING CHECKLISTS}

Whether, or not, to fly is normally dictated by weather and mission considerations. The remote pilot in command (PIC) should allow a greater margin of safety when operational requirements permit.

\section{Mission Planning Considerations for Using Small Unmanned Aerial Systems (sUASs) Near Energized Infrastructure}

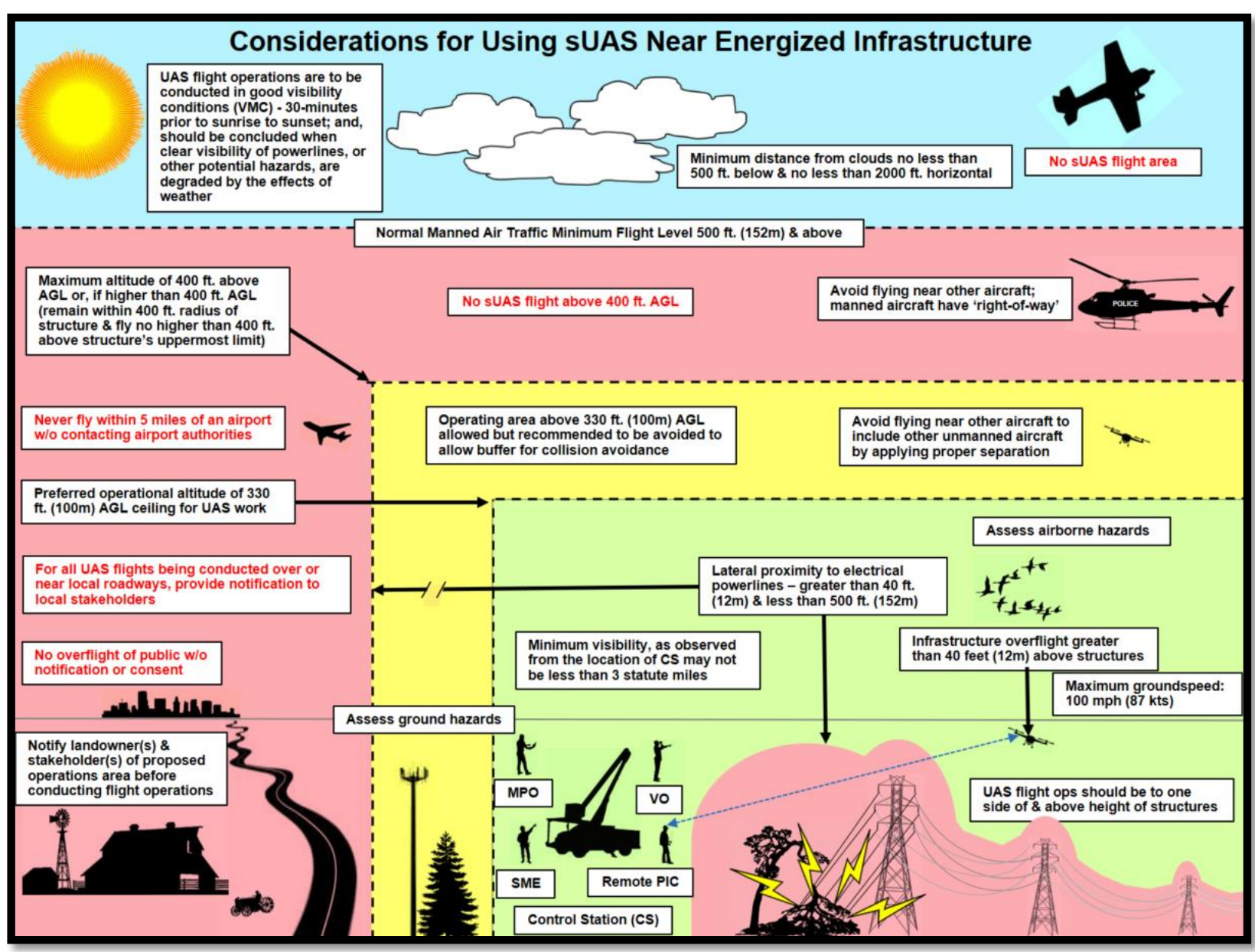

Figure C-1. Mission planning considerations for using small unmanned aerial systems near energized infrastructure. (Source: Bill Monday.)

\section{Mission Planning Weather Forecast}

Weather is an important factor that influences aircraft performance and flight safety. Atmospheric pressure and density, wind, and uneven surface heating are all factors that affect UAS performance and must be considered before flight. UAS flight operations must be conducted during daylight hours within the local flying area in visual meteorological conditions (VMCs). ${ }^{1}$

\footnotetext{
${ }^{1}$ Uncontrolled airspace usually imposes lower weather minimums than are applicable in controlled airspace (instrument flight rules).
} 
Minimum distance from clouds is no less than $500 \mathrm{ft}$ below and no less than 2,000 ft horizontally. UAS flight operations are to be conducted in good visibility conditions and should be terminated when clear visibility of power lines or other potential hazards is degraded by the effects of weather.

UAS flight operations should be terminated when clear visibility of power lines or other potential hazards is degraded by the effects of weather (e.g., low sun, cloud, dust, mist, rain, smoke, or snow). UAS remote PICs should be located so as not to face into the sun while conducting flight operations.

The established weather criteria are minimums.

- Commercial weather forecasting services may be used.

- Minimum weather visibility of 3 miles from the control station (CS).

- Visual flight rules (VFRs) are a set of regulations for operating aircraft; for UASs VFRs come into play when weather conditions are above the minimums prescribed for VMCs and remote PICs may fly with visual reference to the UAS, and other structures, without continuous referral to other visual or locating aids.

- Visibility is categorized as flight visibility, ground visibility, or CS visual range.

\section{Weather Checklist}

\begin{tabular}{|r|l|l|l|}
\hline & \multicolumn{1}{|c|}{$\begin{array}{c}\text { Forecast Weather or Not Applicable } \\
\text { (NA) }\end{array}$} & Actual Weather or NA \\
\hline \multicolumn{3}{|c|}{ Clouds } \\
\hline Cloud Cover & Clear & \\
\hline Cloud FL & $3,000 \mathrm{ft}$ & \\
\hline \multicolumn{3}{|c|}{ Precipitation } \\
\hline Dust & NA & \\
\hline Hail & NA & \\
\hline Rain & NA & \\
\hline Smoke & NA & \\
\hline Snow & NA & Wind \\
\hline Sun Angle & SSW & \\
\hline Temperature & $96^{\circ}$ & \\
\hline Direction & $270^{\circ}$ (Due West) & \\
\hline Speed (mph) & 5 & \\
\hline
\end{tabular}

(For Training Purposes Only) 
Planning Mission Profile Sheet

\section{S A M P L E-T E M P L A T E}

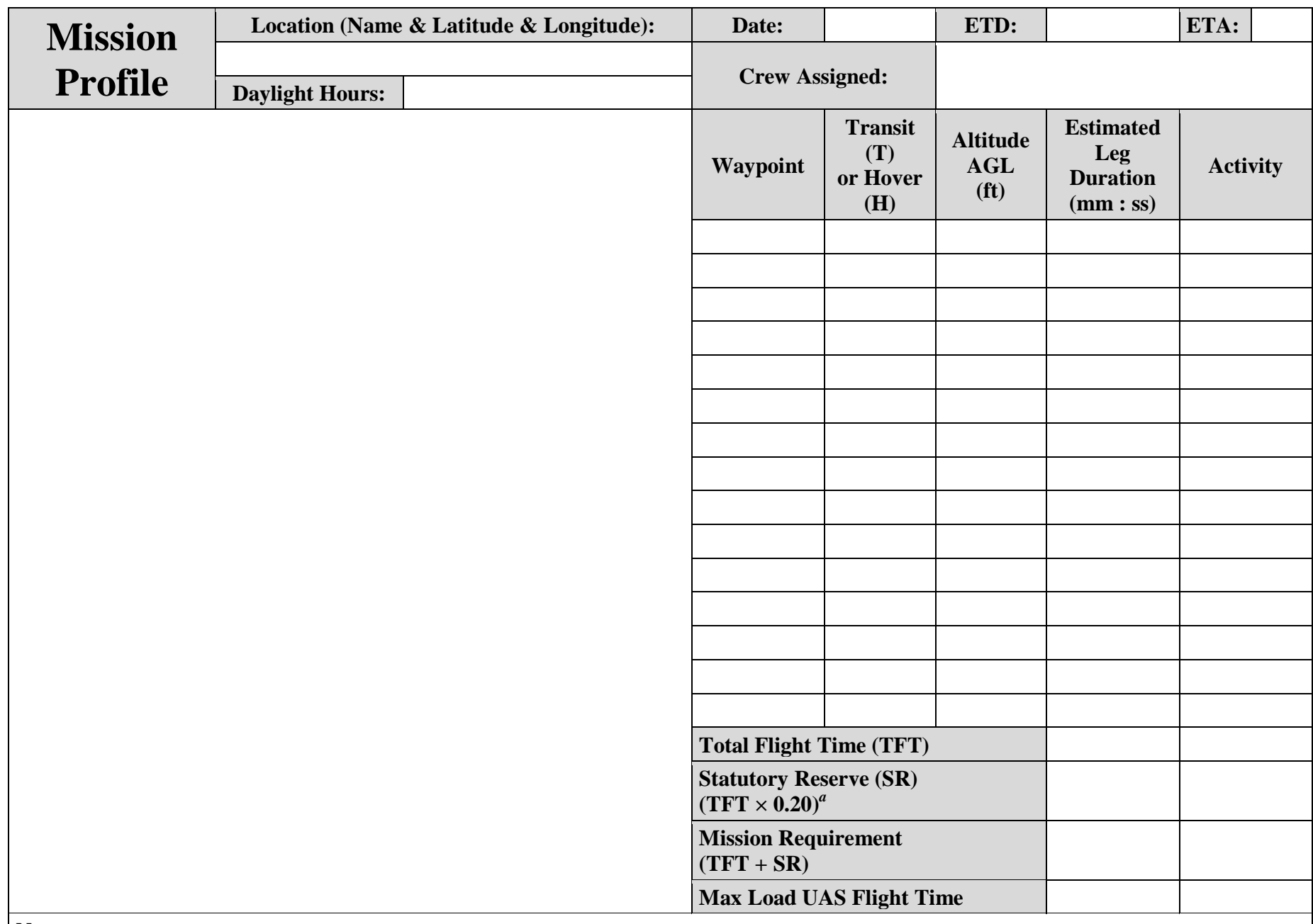

Notes:

${ }^{a}$ With respect to TFTs and SRs, a UAS flight should be able to be completed with 20\% energy reserves (fuel or battery) remaining or a 5-minute reserve or the manufacturer recommendation, whichever is greater. [Avion Solutions Inc./Avion Unmanned. (2016). Unmanned Aircraft Systems (UAS) Standard Operating Procedures (SOP). Huntsville, Alabama, Avion Solutions Inc./Avion Unmanned.]

Acronyms: ETD = estimated time of departure, ETA = estimated time of arrival, and AGL = above ground level. 


\section{E X A M P L E}

(For Training Purposes Only)

\begin{tabular}{|c|c|c|c|c|c|c|}
\hline \multirow{3}{*}{$\begin{array}{c}\text { Mission } \\
\text { Profile }\end{array}$} & Location (Name \& Latitude \& Longitude): & \multicolumn{2}{|c|}{\begin{tabular}{l|l} 
Date: & 01AUG16 \\
Crew Assigned:
\end{tabular}} & \multicolumn{2}{|c|}{\begin{tabular}{|l|l|}
\multicolumn{1}{|c|}{ ETD: } & 1400 \\
Remote PIC: Joe Airdale \\
MPO: Jonny Paycheck \\
VO: Jack Smuckatelli \\
\end{tabular}} & \begin{tabular}{l|l} 
ETA: & 1430 \\
\end{tabular} \\
\hline & 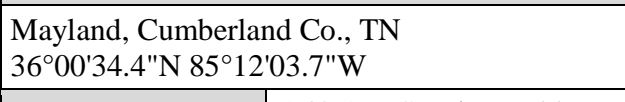 & \multirow{2}{*}{\multicolumn{2}{|c|}{ Crew Assigned: }} & \multirow{2}{*}{\multicolumn{3}{|c|}{$\begin{array}{l}\text { Remote PIC: Joe Airdale } \\
\text { MPO: Jonny Paycheck } \\
\text { VO: Jack Smuckatelli }\end{array}$}} \\
\hline & 5:48 AM Sunrise; 7:44 PM & & & & & \\
\hline 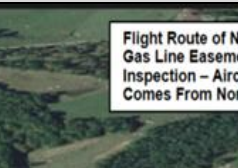 & & Waypoint & $\begin{array}{l}\text { Transit } \\
\text { (T) } \\
\text { or Hover } \\
(\mathbf{H}) \\
\end{array}$ & $\begin{array}{l}\text { Altitude } \\
\text { AGL } \\
\text { (ft) }\end{array}$ & $\begin{array}{l}\text { Estimated } \\
\text { Leg } \\
\text { Duration } \\
(\mathbf{m m}: \mathbf{s s}) \\
\end{array}$ & Activity \\
\hline & & $\begin{array}{l}\text { Takeoff/land } \\
\text { ing zone } \\
\text { (TO/LZ) } \\
\end{array}$ & $\mathrm{T}$ & 0 & - & $\begin{array}{l}\text { Pre-Flight } \\
\text { Checklist }\end{array}$ \\
\hline & & TO to 1 & $\mathrm{~T}$ & 100 & 02:00 & $2,588 \mathrm{ft} \mathrm{leg}$ \\
\hline & & 1 & $\mathrm{H}$ & 50 & $00: 45$ & $\begin{array}{c}\text { UAS Flight } \\
\text { Check by PIC }\end{array}$ \\
\hline & & 1 to 2 & $\mathrm{~T}$ & 50 & 00:30 & $\mathrm{T}$ to 2 \\
\hline & & 2 & $\mathrm{H}$ & 50 & 02:00 & Inspect \\
\hline & & 2 to 3 & $\mathrm{~T}$ & 50 & $00: 30$ & T to 3 \\
\hline & & 3 & $\mathrm{H}$ & 50 & 02:00 & Inspect \\
\hline & & 3 to 4 & $\mathrm{~T}$ & 50 & 00:30 & T to 4 \\
\hline & & 4 & $\mathrm{H}$ & 50 & 02:00 & Inspect \\
\hline & & 4 to 5 & $\mathrm{~T}$ & 50 & $00: 30$ & T to 5 \\
\hline & & 5 & $\mathrm{H}$ & 50 & 02:00 & Inspect \\
\hline LEGEND & & 5 to 6 & $\mathrm{~T}$ & 50 & $00: 30$ & T to 6 \\
\hline / Electrical Powerline Ease & & 6 & $\mathrm{H}$ & 50 & 02:00 & Inspect \\
\hline Filght Route of Manned-A & In tor cas Line & 6 to $\mathrm{LZ}$ & $\mathrm{T}$ & 100 & 04:00 & $\begin{array}{l}\text { T to } \mathrm{LZ} \\
(7,700 \mathrm{ft})\end{array}$ \\
\hline $\begin{array}{c}\star \text { Mission Payload Operator } \\
\leftarrow \text { Remote Pilot in Commanc }\end{array}$ & 100 & $\mathrm{LZ}$ & $\mathrm{T}$ & 0 & $00: 45$ & $\begin{array}{c}\text { Mission } \\
\text { Complete }\end{array}$ \\
\hline - Visual Observer (NO) & $\frac{C S}{M P O}=\frac{1}{4}$ & Total Flight & Time (TFT) & & 20:00 & \\
\hline$\diamond$ waypoint $\ominus$ & $N$ & $\begin{array}{l}\text { Statutory Re } \\
(\text { TFT } \times \mathbf{0 . 2 0}) \\
\end{array}$ & erve (SR) & & 04:00 & \\
\hline & & $\begin{array}{l}\text { Mission Req } \\
\text { (TFT + SR) }\end{array}$ & irement & & 24:00 & \\
\hline & & Max Load U & AS Flight $T$ & ime (+ $5 \mathrm{~m})$ & 29:00 & \\
\hline
\end{tabular}

Notes: Identified heavy summertime foliage along power line easement during flight route ground inspection. Utility forest consists of both hardwood and softwood. In February 2014 this region experienced heavy icing, which caused utility poles and several associated power lines to go down along the survey route. Power was out for 9 days while repairs were effected. Several poles have since been replaced with updated support infrastructure. Also, numerous danger and hazard trees have been removed along this route by company crews at local residents' request. Substation to north is also being currently upgraded due to wider Tennessee Valley Authority upgrade of network within county. Visual inspection using UAS optics is for both infrastructure maintenance and vegetation management. Visual Observer (VO) will be required due to length of flight route and configuration of easement/roadway. Mission payload operator (MPO) will be required to manage survey sensors at control station (CS) located in a farmer's field to south of route. Remote Pilot in Command (PIC) will locate at midpoint to obtain a clear view along entire route of flight. There are populated areas and a roadway parallel to flight route. All landowners and stakeholders have been informed of UAS Work Order. Afternoon flight will result in expected sun glare from the west allowing for increased visibility by crew of flight route. There is no restricted airspace near the flight route; however, a manned aircraft flies an inspection flight of the natural gas line easement (depicted on image) Monday, Wednesday, and Friday of each week and will be at or above $500 \mathrm{ft}$ AGL. Local airport is 7.6 miles to the southeast of tasked flight operations.

Acronyms: ETD = estimated time of departure, ETA = estimated time of arrival, and AGL = above ground level. 


\section{Safety Plan Checklist}

\begin{tabular}{|l|l|l|}
\hline & \multicolumn{1}{|c|}{ Identified Hazard Details } & \multicolumn{1}{c|}{ Mitigating Actions } \\
\hline $\mathbf{1}$ & Overall Mission Profile Hazards & Operational Risk Management (ORM) Review \\
\hline $\mathbf{2}$ & Crew Status Check & Review 'IMSAFE Checklist' \\
\hline $\mathbf{3}$ & $\begin{array}{l}\text { Per 14 CFR Part 107 (Part 107), no careless or reckless } \\
\text { operations }\end{array}$ & Execute 'Mission Profile' - as briefed \\
\hline $\mathbf{4}$ & Per Part 107, no carriage of hazardous materials & Flight of sensor payload—as briefed \\
\hline $\mathbf{5}$ & Populated Areas & Avoid overflight—as briefed \\
\hline $\mathbf{6}$ & Vegetation & Avoid—as briefed \\
\hline $\mathbf{7}$ & Structures such as utility poles, towers, windmills, etc. & Avoid—as briefed \\
\hline $\mathbf{8}$ & Traffic Along Roadway & Avoid—as briefed \\
\hline $\mathbf{9}$ & Wildlife; both airborne and on the ground & Time-critical ORM: Avoid and do not/not harass \\
\hline $\mathbf{1 0}$ & Other Aircraft; both manned and unmanned & Time-critical ORM: Avoid \\
\hline $\mathbf{1 1}$ & Emergency Situations (e.g., car wreck or fire) & Time-critical ORM: Avoid overflight \\
\hline $\mathbf{1 2}$ & Etc. & Maintain situational awareness \\
\hline
\end{tabular}

(For Training Purposes Only)

\section{Contingency Plan Checklist}

\begin{tabular}{|l|l|l|}
\hline \multicolumn{1}{|c|}{ Event } & \multicolumn{1}{|c|}{ Result } & \multicolumn{1}{c|}{ Procedure } \\
\hline Battery Depletes & $\begin{array}{l}\text { Unmanned aerial system (UAS) } \\
\text { incapable of continuing flight } \\
\text { operations }\end{array}$ & $\begin{array}{l}\text { UAS return to base (RTB) as soon as } \\
\text { practical; cease data collection }\end{array}$ \\
\hline Ditch Procedures & $\begin{array}{l}\text { UAS incapable of continuing flight } \\
\text { operations }\end{array}$ & $\begin{array}{l}\text { Identify safe landing area; attempt a } \\
\text { controlled landing; if able, land UAS } \\
\text { in water (shallow preferred for ease of } \\
\text { recovery) away from public }\end{array}$ \\
\hline Fuel Depletes & $\begin{array}{l}\text { UAS incapable of continuing flight } \\
\text { operations }\end{array}$ & $\begin{array}{l}\text { UAS RTB as soon as practical; cease } \\
\text { data collection }\end{array}$ \\
\hline Hazardous Weather & $\begin{array}{l}\text { UAS incapable of continuing flight } \\
\text { operations }\end{array}$ & $\begin{array}{l}\text { UAS RTB as soon as practical; cease } \\
\text { data collection }\end{array}$ \\
\hline Hostile Environment & $\begin{array}{l}\text { Mission impacted by hazard (e.g., air } \\
\text { traffic, public activity) }\end{array}$ & $\begin{array}{l}\text { See and avoid; take evasive action as } \\
\text { required with safety taking } \\
\text { precedence; UAS RTB as soon as } \\
\text { practical }\end{array}$ \\
\hline Loss of Communications & $\begin{array}{l}\text { Mission impacted by lack of } \\
\text { communications hazard }\end{array}$ & $\begin{array}{l}\text { Maintain visual line of sight (VLOS); } \\
\text { take evasive action as required with } \\
\text { safety taking precedence; UAS RTB } \\
\text { as soon as practical }\end{array}$ \\
\hline Loss of Control Signal & $\begin{array}{l}\text { Maintain VLOS; UAS RTB and land } \\
\text { without harm to UAS or contacting } \\
\text { surrounding objects }\end{array}$ \\
\hline Loss of Direct Visual of UAS & $\begin{array}{l}\text { UAS could become hazard if unable } \\
\text { to regain visual control }\end{array}$ & $\begin{array}{l}\text { Regain direct visual of UAS; contact } \\
\text { mission payload operator and/or } \\
\text { visual observer to determine status }\end{array}$ \\
\hline
\end{tabular}




\section{Contingency Plan Checklist (continued)}

\begin{tabular}{|l|l|l|}
\hline \multicolumn{1}{|c|}{ Event } & \multicolumn{1}{c|}{ Result } & \multicolumn{1}{c|}{ Procedure } \\
\hline Loss of GPS Signal & $\begin{array}{l}\text { Use extreme caution as the positional } \\
\text { data for the UAS will not be accurate }\end{array}$ & $\begin{array}{l}\text { Assume manual control of the UAS; } \\
\text { Maneuver and climb UAS to } \\
\text { reacquire GPS signal; if GPS signal } \\
\text { cannot be acquired, determine } \\
\text { whether safe UAS control can be } \\
\text { maintained; if safe flight cannot be } \\
\text { maintained, land as soon as possible }\end{array}$ \\
\hline Loss of Situational Awareness (SA) & $\begin{array}{l}\text { UAS could become hazard if unable } \\
\text { to regain SA }\end{array}$ & $\begin{array}{l}\text { Climb to safe altitude; reorient with } \\
\text { use of sensors; RTB as required }\end{array}$ \\
\hline Privacy Impact & Possible public complaint & $\begin{array}{l}\text { Cease data collection; after RTB, } \\
\text { complete an assessment }\end{array}$ \\
\hline UAS Failure & $\begin{array}{l}\text { UAS incapable of continuing flight } \\
\text { operations }\end{array}$ & $\begin{array}{l}\text { Maintain VLOS; UAS RTB as soon } \\
\text { as practical }\end{array}$ \\
\hline
\end{tabular}

\section{Emergency Contact List}

\begin{tabular}{|l|c|}
\hline \multicolumn{1}{|c|}{ Organizational Point of Contact } & Contact Numbers (For training purposes only) \\
\hline National grid operations center & 202.555 .1231 \\
\hline Local electric utility distribution network office & 865.555 .1232 \\
\hline Service provider local field services office & 931.555 .1233 \\
\hline County road supervisor & 931.555 .1234 \\
\hline County sheriff dispatch office & 931.555 .1235 \\
\hline County fire department & 931.555 .1236 \\
\hline Closest medical facility & 931.555 .1237 \\
\hline Internet/phone providers & 931.555 .1238 \\
\hline Site manager & 931.555 .1239 \\
\hline Remote pilot in command & 931.555 .1240 \\
\hline Visual observer & 931.555 .1241 \\
\hline Mission payload operator & 931.555 .1242 \\
\hline Subject matter expert & 931.555 .1243 \\
\hline
\end{tabular}

(For training purposes only)

\section{Mission Planning Documentation and Source References}

- Aircraft Registration (N-Number)

- Aviation Charts

- Battery Logbook

- Certificate of Waiver (COW) or Certificate of Authorization (COA)

- Commercial or Government Weather Forecasting Service Reports

- Contingency Plan

- Drone Notices to Airmen (DROTAMs)

- Emergency Procedures

- Emergency Contact List

- Federal Aviation Administration (FAA)

- FAA Medical Certificate 


\section{Mission Planning Documentation and Source References (continued)}

- FAA Part 107 (14 CFR Part 107)

- FAA Remote Pilot in Command (PIC) Certificate

- FAA Section 333 Exemption (Section 333 of the FAA Modernization and Reform Act of 2012 (PL 112-095)

- Flight Logbook

- Flight Manual

- Flight Plan

- Internet Map Programs

- IMSAFE Checklist (see Appendix F)

- Insurance Policy

- Maintenance Logbook

- Manufacturer User Guide

- Mishap Notification Procedures

- Mission Plan

- Mission Planning Weather Forecast

- Mission Planning Considerations for Using sUAS Near Energized Infrastructure

- Mission Profile

- National Weather Service

- Notices to Airmen (NOTAMs)

- Operator's Manual

- Operational Risk Management Process

- Pilot Logbook

- Remote PIC Records: Remote Pilot Certificate

- Safety Plan

- UAS Flight Operations-Execution

- UAS Pre-Flight Checklist

- UAS Post-Flight Report

- Work Order

- Weather Depiction Charts 



\section{APPENDIX E. UNMANNED AERIAL SYSTEM PRE-FLIGHT CHECKLISTS}

\section{Test Flight Checklist}

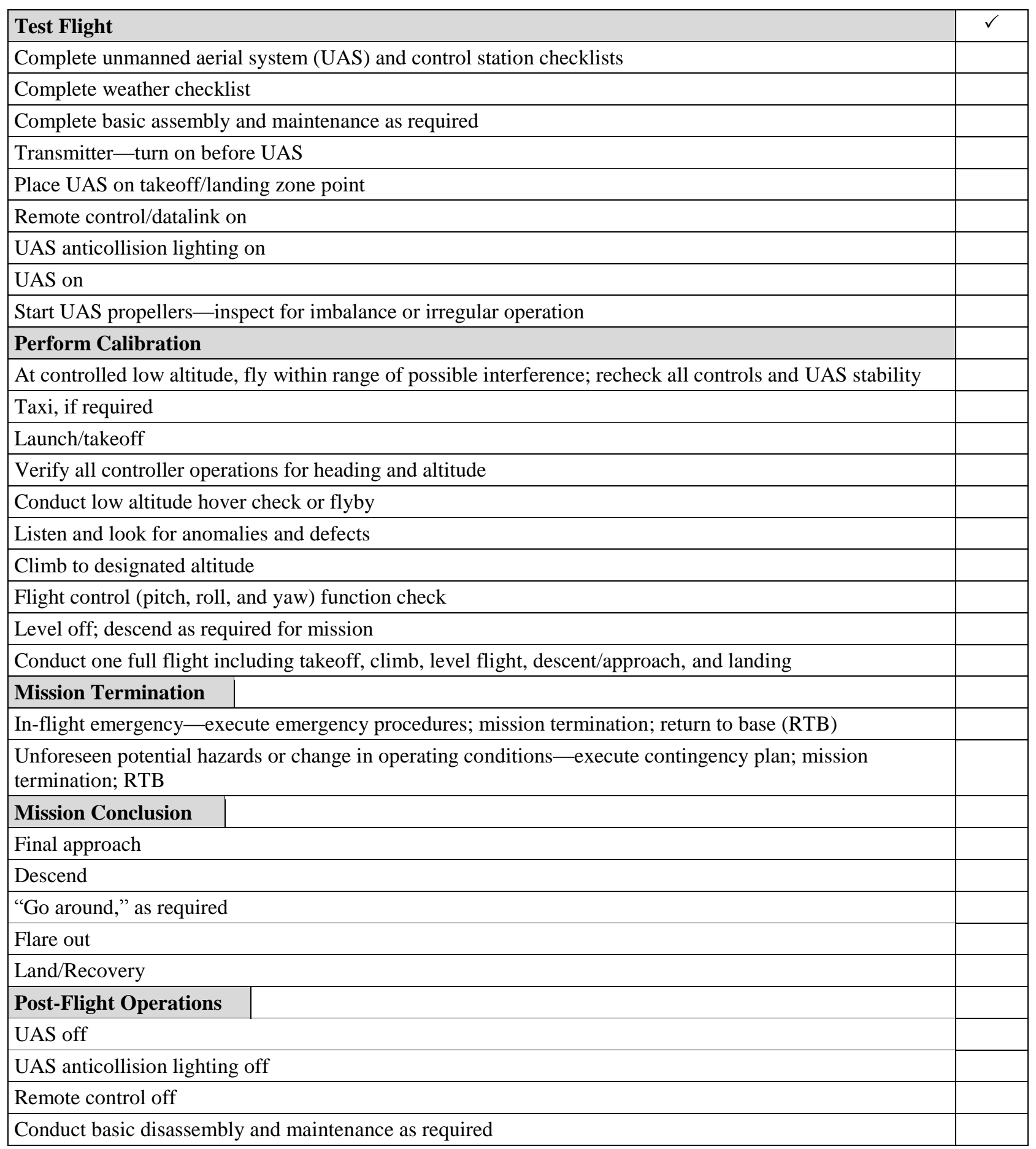




\section{Administration Checklist-Before Mission Execution Date}

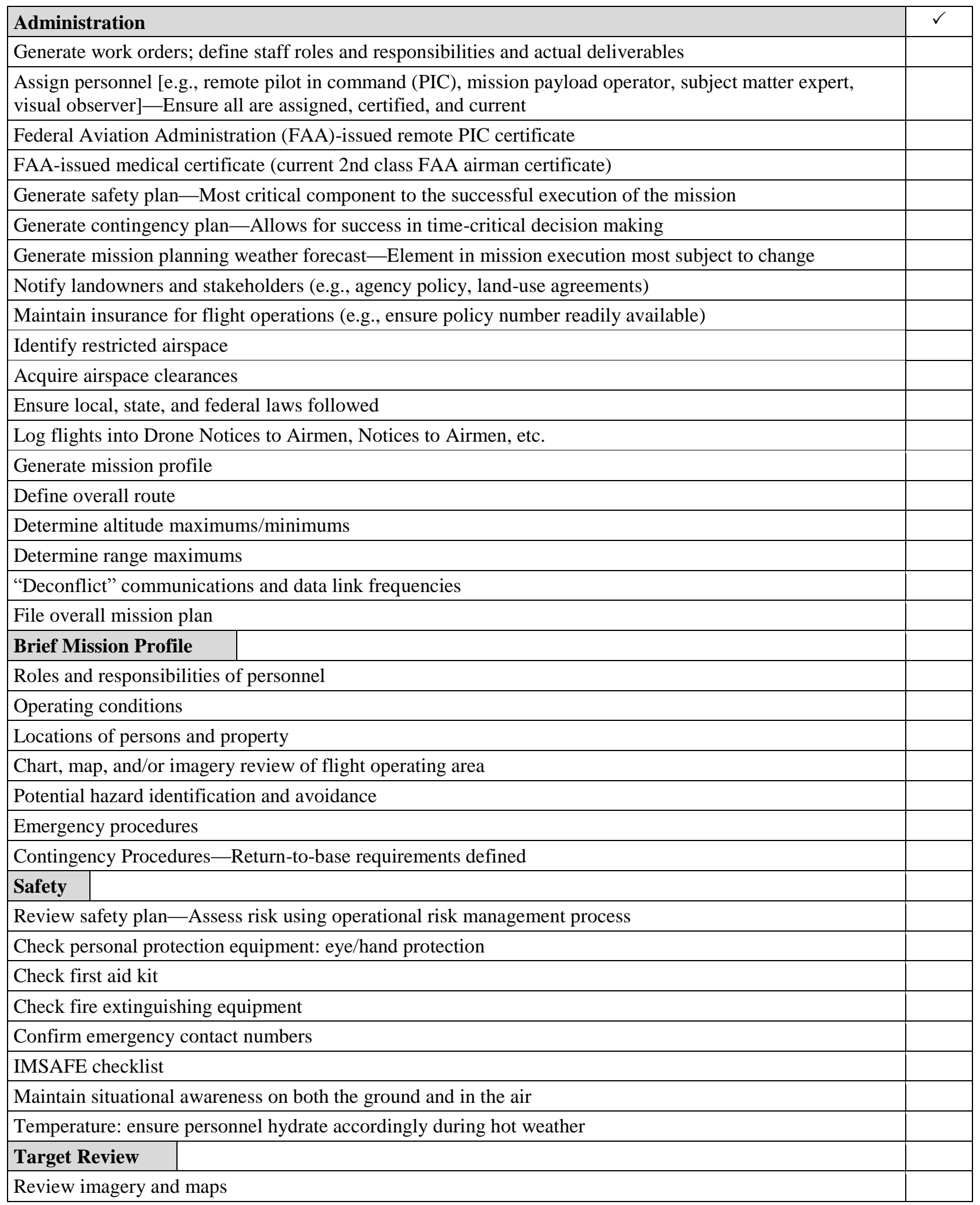




\section{Administration Checklist (continued)}

\begin{tabular}{|l|l|}
\hline Risk Mitigation & \\
\hline Ensure authorized personnel only_-No bystanders or crowds in control station & \\
\hline Ensure hazards identified (air traffic, population centers, roadways, structures, etc.) & \\
\hline $\begin{array}{l}\text { Ensure all stakeholders and potentially affected members of the public identified—Permission for potential } \\
\text { overflight obtained }\end{array}$ & \\
\hline Confirm alternate safe landing areas/divert airfields identified & \\
\hline Ensure rotors shrouded to prevent entanglement; cut hazard—Safety gloves & \\
\hline Ensure fire hazard prevention—Battery charging, transport, and storage & \\
\hline
\end{tabular}

\section{Operating Area: Environment and Hazards Checklist}

\begin{tabular}{|l|l|}
\hline Environment & $\checkmark$ \\
\hline Flight Operating Area & \\
\hline Takeoff/Landing Zone_Use large, open area and apply P.O.W.E.R. ${ }^{1}$ concept for safety & \\
\hline No People—No animals, bystanders, crowds or distractions & \\
\hline No Obstacles—No animal activity, construction work, downed trees, etc. & \\
\hline No Weather Concerns_-Precipitation, winds, etc. & \\
\hline No Electronic or electromagnetic interference & \\
\hline No Restrictions to flight operations & \\
\hline $\begin{array}{l}\text { Local Weather Conditions: UAS Flight Operations Must Be Conducted During Daylight Hours within } \\
\text { Mission Profile Area in Visual Meteorological Conditions }\end{array}$ & \\
\hline Check commercial or government weather forecasting services & \\
\hline Establish weather criteria at minimums & \\
\hline Review mission planning weather forecast to determine actual weather conditions & \\
\hline Clouds & \\
\hline Minimum distance from clouds no less than 500 ft below and no less than 2,000 ft horizontal & \\
\hline Precipitation & \\
\hline Precipitation within acceptable range & \\
\hline Sun & \\
\hline Direction for visibility & \\
\hline Temperature & \\
\hline Temperature within acceptable range to conduct flight operations & \\
\hline Visibility & \\
\hline $\begin{array}{l}\text { Minimum weather visibility of } 3 \text { miles from the control station; clear visibility of UAS, power lines, potential } \\
\text { hazards, without degradation by the effects of weather }\end{array}$ & \\
\hline Wind & \\
\hline Wind Direction & \\
\hline Wind Speed-25 mph or UAS capability (whichever is lower) & \\
\hline
\end{tabular}

\footnotetext{
${ }^{1}$ From Avion Solutions, Inc. UAS standard operating procedure: verify takeoff and recovery area is clear and safe of people/animals, obstacles, wind/weather, electronic/magnetic interference, restrictions.
} 


\section{UAS Status Checklist}

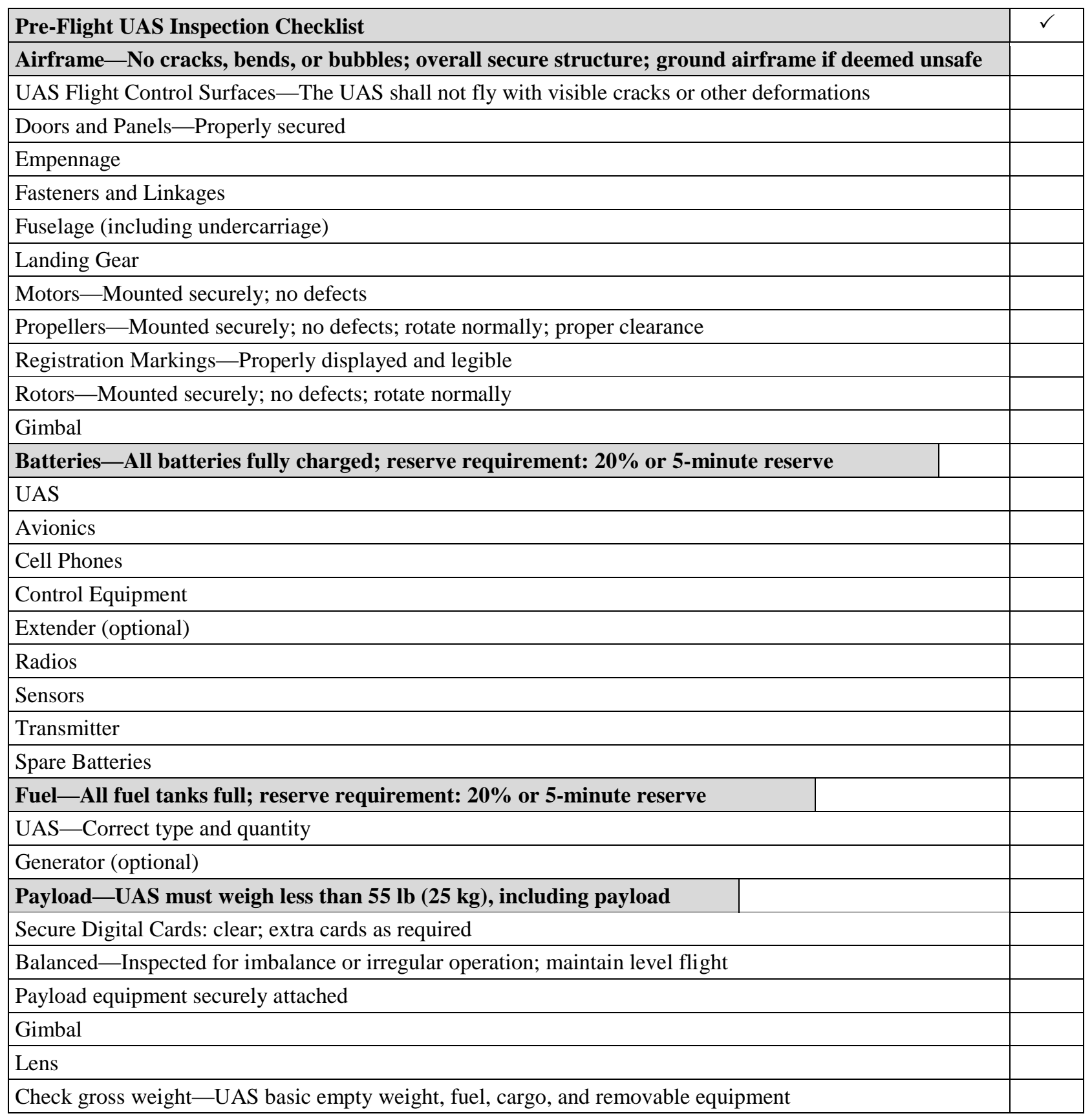




\section{Control Station (CS) Operations Checklist}

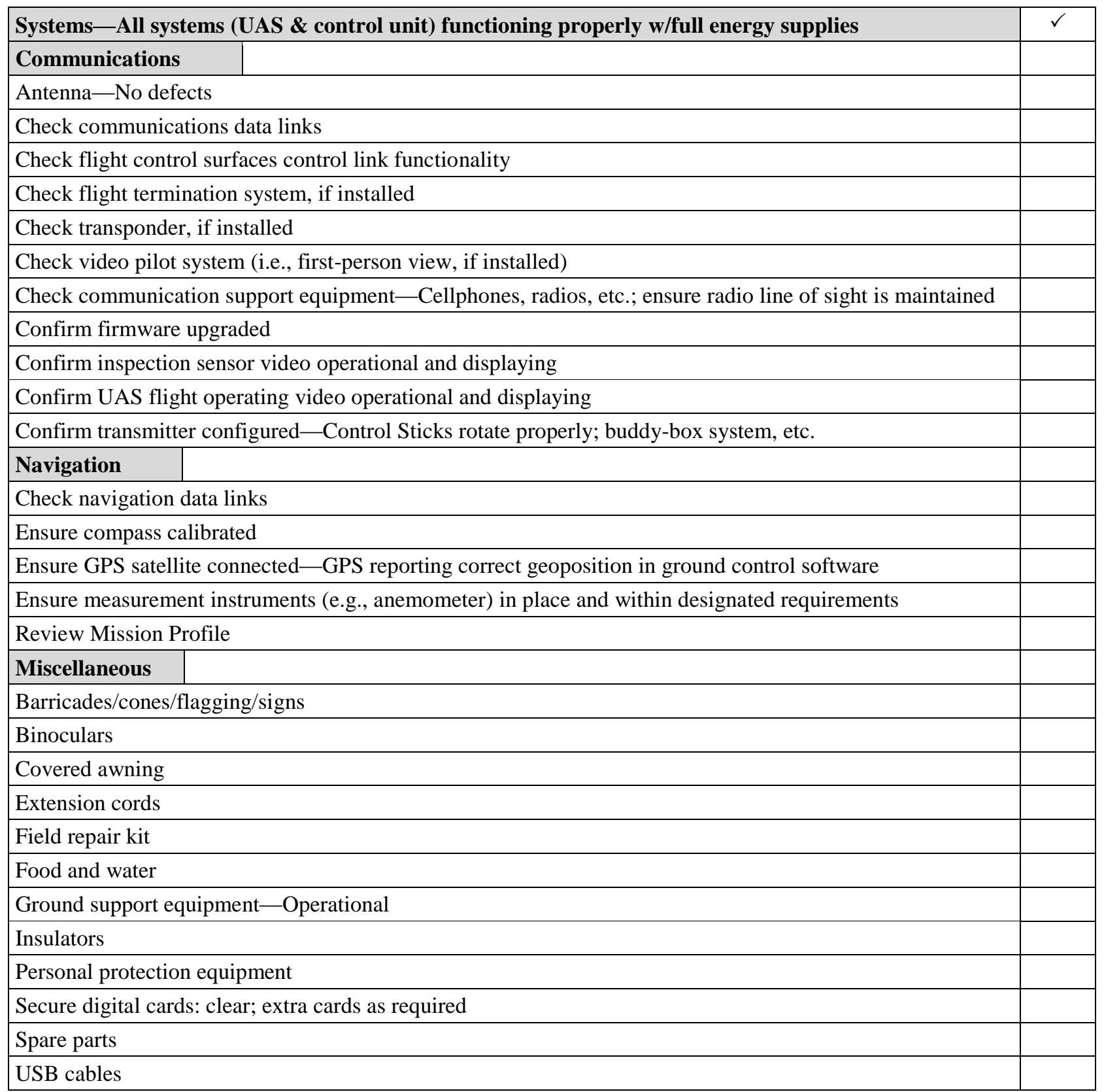





\section{APPENDIX F. IMSAFE CHECKLIST}

Per 14 CFR Part 107, "a person may not operate a sUAS if he, or she, knows or has reason to know of any physical or mental condition that would interfere with the safe operation of a sUAS."

Before each flight, the remote pilot in command (PIC) should ensure that all personnel on the assigned crew are physically and mentally fit to perform the tasked flight operations. The following IMSAFE checklist is provided as a resource to analyze crew members for their fitness:

- Illness: Are you, as the remote PIC, mission payload operator, visual observer, etc. suffering from any illness or any symptom of illness that might affect you in flight?

- Medication: Are you currently taking prescription or over-the-counter drugs?

- $\quad$ Stress: Are there any psychological or emotional factors that might affect your judgment or performance?

- Alcohol: What was your alcohol intake within the last 8 to $24 \mathrm{~h}$ ?

- $\quad$ Fatigue: Have you had sufficient sleep and rest in the recent past?

- Eating: Are you adequately nourished?

(FAA, 2016) 



\section{APPENDIX G. UNMANNED AERIAL SYSTEM FLIGHT OPERATIONS-EXECUTION CHECKLIST}

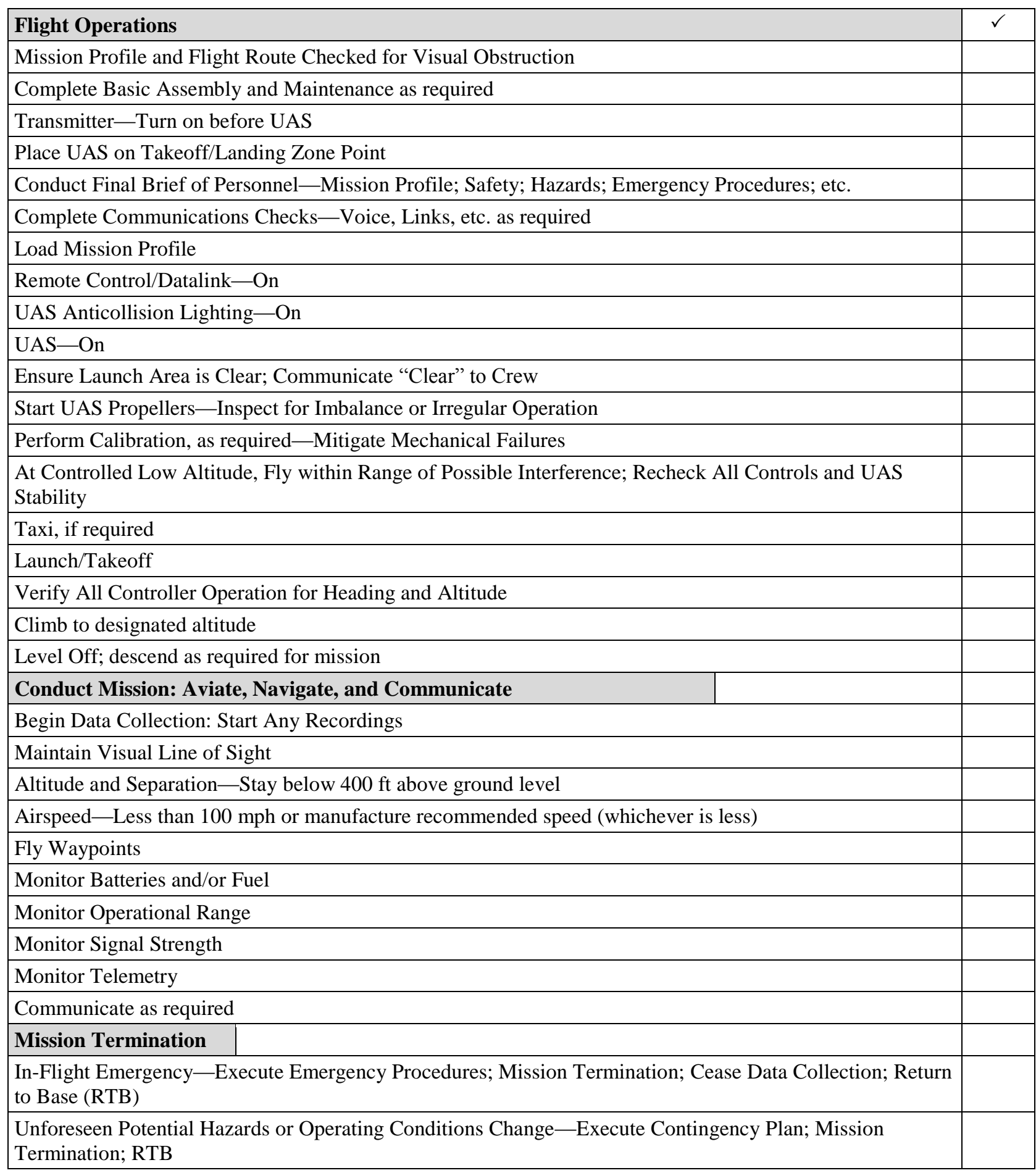




\begin{tabular}{|l|l|}
\hline Mission Conclusion & \\
\hline Cease Data Collection—Stop any recordings & \\
\hline Ensure Recovery Area is “Clear”; Communicate “Clear” to Crew & \\
\hline Final Approach & \\
\hline Descend & \\
\hline Go Around, as required & \\
\hline Flare Out & \\
\hline Land/Recovery & \\
\hline Post-Flight Operations & \\
\hline UAS—Off & \\
\hline UAS Anticollision Lighting-Off & \\
\hline Remote Control—Off & \\
\hline Notify Tower/Common Traffic Advisory Frequency & \\
\hline Close Out Flight in Drone Notices to Airmen, Notices to Airmen, etc. & \\
\hline Remove All Data Collected from Platform & \\
\hline Complete Basic Disassembly and Maintenance as required; Lubricate According to User Manual & \\
\hline Debrief Personnel & \\
\hline Record Flight Log and Complete Post-Flight Reporting as required & \\
\hline Secure Data Collected & \\
\hline
\end{tabular}




\section{APPENDIX H. HAND SIGNALS}
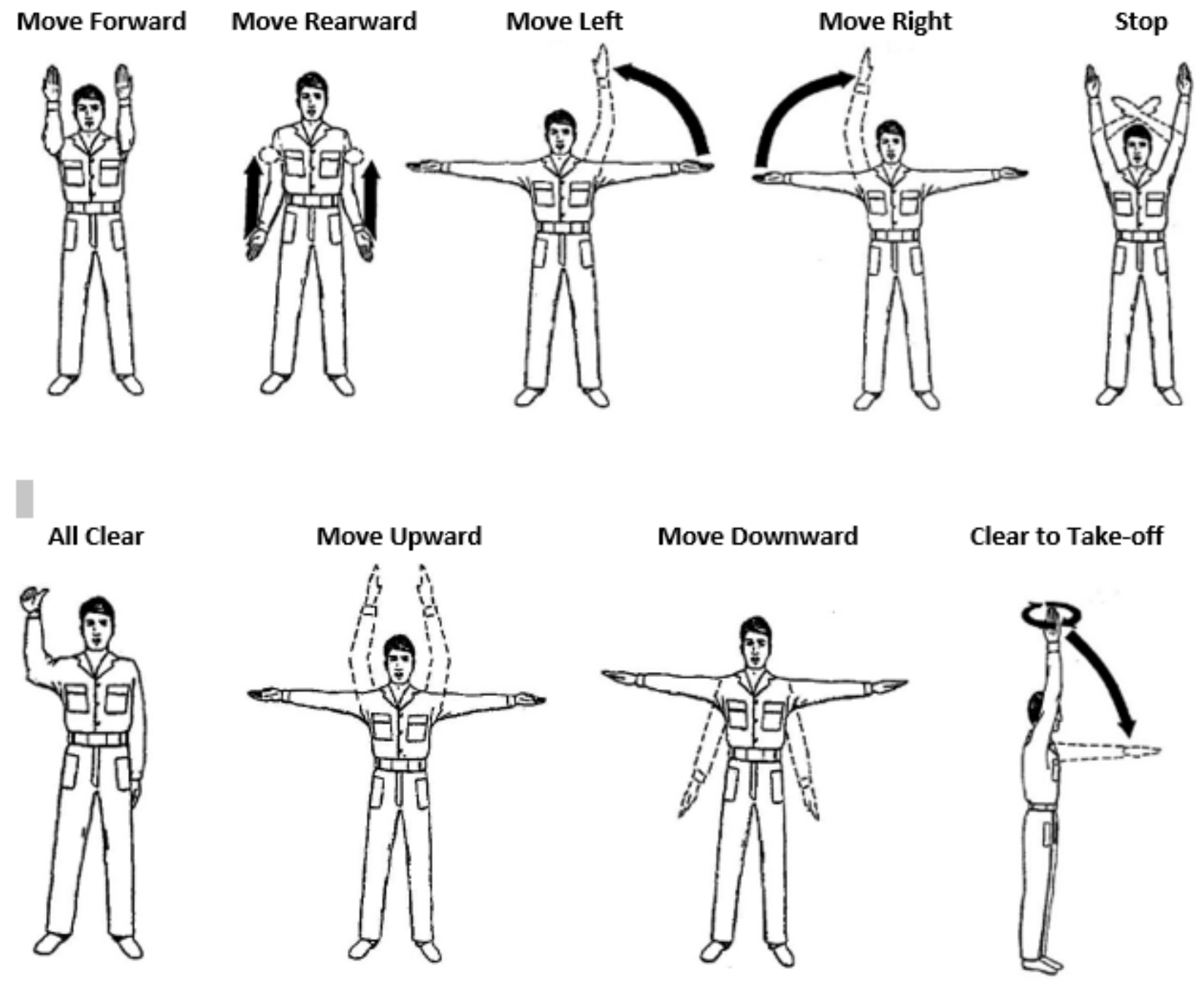

(EdgeData, 2016) 



\section{APPENDIX I. UNMANNED AERIAL SYSTEM POST-FLIGHT CHECKLIST}

Following the completion of a flight, the remote pilot in command will prepare and submit a post-flight document package that should include, but not be limited to, the items in the following checklist.

\begin{tabular}{|l|c|}
\hline Post-Flight Checklist & $\checkmark$ \\
\hline Summary of work performed & \\
\hline Summary of how the work performed conformed to the flight plan & \\
\hline Justification for any changes to the flight plan & \\
\hline Lessons learned to ensure flight plans are adhered to in the future & \\
\hline Record of all stakeholder communications & \\
\hline Completed Pre-flight Checklist (with dates and times each section was completed) & \\
\hline Weather forecasts for the area during the flight window and actual readings & \\
\hline Safety Plan-Hazards identified/adjusted for specific site and time of day & \\
\hline
\end{tabular}





\section{APPENDIX J. SMALL UNMANNED AERIAL SYSTEM MAINTENANCE AND INSPECTION BEST PRACTICES}

Note: Appendix J was taken entirely from Federal Aviation Administration Advisory Circular 107-2, Appendix C. (Table number adjusted to coordinate with numbering system in this manual.)

In the interest of assisting varying background levels of sUAS knowledge and skill, below is a chart offering conditions that, if noticed during a preflight inspection or check, may support a determination that the UAS is not in a condition for safe operation. Further inspection to identify the scope of damage and extent of possible repair needed to remedy the unsafe condition may be necessary prior to flight.

Table J-1. sUAS Condition Chart

Conditions that may be found may include, but are not limited to, the following:

\begin{tabular}{|c|c|}
\hline Condition & Action \\
\hline 1. Structural or skin cracking & $\begin{array}{l}\text { Further inspect to determine scope of damage } \\
\text { and existence of possible hidden damage that } \\
\text { may compromise structural integrity. Assess } \\
\text { the need and extent of repairs that may be } \\
\text { needed for continued safe flight operations. }\end{array}$ \\
\hline 2. Delamination of bonded surfaces & $\begin{array}{l}\text { Further inspect to determine scope of damage } \\
\text { and existence of possible hidden damage that } \\
\text { may compromise structural integrity. Assess } \\
\text { the need and extent of repairs that may be } \\
\text { needed for continued safe flight operations. }\end{array}$ \\
\hline 3. Liquid or gel leakage & $\begin{array}{l}\text { Further inspect to determine source of the } \\
\text { leakage. This condition may pose a risk of fire } \\
\text { resulting in extreme heat negatively impacting } \\
\text { aircraft structures, aircraft performance } \\
\text { characteristics, and flight duration. Assess the } \\
\text { need and extent of repairs that may be needed } \\
\text { for continued safe flight operations. }\end{array}$ \\
\hline 4. Strong fuel smell & $\begin{array}{l}\text { Further inspect to determine source of the } \\
\text { smell. Leakage exiting the aircraft may be } \\
\text { present and/or accumulating within a sealed } \\
\text { compartment. This condition may pose a risk } \\
\text { of fire resulting in extreme heat negatively } \\
\text { impacting aircraft structures, aircraft } \\
\text { performance characteristics, and flight } \\
\text { duration. Assess the need and extent of repairs } \\
\text { that may be needed for continued safe flight } \\
\text { operations. }\end{array}$ \\
\hline 5. Smell of electrical burning or arcing & $\begin{array}{l}\text { Further inspect to determine source of the } \\
\text { possible electrical malfunction. An electrical } \\
\text { hazard may pose a risk of fire or extreme heat } \\
\text { negatively impacting aircraft structures, }\end{array}$ \\
\hline
\end{tabular}




\begin{tabular}{|c|c|}
\hline & $\begin{array}{l}\text { aircraft performance characteristics, and flight } \\
\text { duration. Assess the need and extent of repairs } \\
\text { that may be needed for continued safe flight } \\
\text { operations. }\end{array}$ \\
\hline $\begin{array}{l}\text { 6. Visual indications of electrical burning } \\
\text { or arcing (black soot tracings, sparking) }\end{array}$ & $\begin{array}{l}\text { Further inspect to determine source of the } \\
\text { possible electrical malfunction. An electrical } \\
\text { hazard may pose a risk of fire or extreme heat } \\
\text { negatively impacting aircraft structures, } \\
\text { aircraft performance characteristics, and flight } \\
\text { duration. Assess the need and extent of repairs } \\
\text { that may be needed for continued safe flight } \\
\text { operations. }\end{array}$ \\
\hline $\begin{array}{l}\text { 7. Noticeable sound (decibel) change } \\
\text { during operation by the propulsion system }\end{array}$ & $\begin{array}{l}\text { Further inspect entire aircraft with emphasis on } \\
\text { the propulsion system components (i.e., motors } \\
\text { and propellers) for damage and/or diminished } \\
\text { performance. Assess the need and extent of } \\
\text { repairs that may be needed for continued safe } \\
\text { flight operations. }\end{array}$ \\
\hline $\begin{array}{l}\text { 8. Control inputs not synchronized or } \\
\text { delayed }\end{array}$ & $\begin{array}{l}\text { Discontinue flight and/or avoid further flight } \\
\text { operations until further inspection and testing } \\
\text { of the control link between the ground control } \\
\text { unit and the aircraft. Ensure accurate control } \\
\text { communications are established and reliable } \\
\text { prior to further flight to circumvent possible } \\
\text { loss of control resulting in the risk of a } \\
\text { collision or flyaway. Assess the need and } \\
\text { extent of repairs that may be needed for } \\
\text { continued safe flight operations. }\end{array}$ \\
\hline 9. Battery casing distorted (bulging) & $\begin{array}{l}\text { Further inspect to determine integrity of the } \\
\text { battery as a reliable power source. Distorted } \\
\text { battery casings may indicate impending failure } \\
\text { resulting in abrupt power loss and/or } \\
\text { explosion. An electrical hazard may be } \\
\text { present, posing a risk of fire or extreme heat } \\
\text { negatively impacting aircraft structures, } \\
\text { aircraft performance characteristics, and flight } \\
\text { duration. Assess the need and extent of repairs } \\
\text { that may be needed for continued safe flight } \\
\text { operations. }\end{array}$ \\
\hline $\begin{array}{l}\text { 10. Diminishing flight time capability } \\
\text { (electric powered propulsion systems) }\end{array}$ & $\begin{array}{l}\text { Further inspect to determine integrity of the } \\
\text { battery as a reliable power source. Diminishing } \\
\text { battery capacity may indicate impending } \\
\text { failure due to exhausted service life, internal, } \\
\text { or external damage. An electrical hazard may }\end{array}$ \\
\hline
\end{tabular}




\begin{tabular}{|ll|}
\hline $\begin{array}{l}\text { be present, posing a risk of fire or extreme heat } \\
\text { negatively impacting aircraft structures, } \\
\text { aircraft performance characteristics, and flight } \\
\text { duration. Assess the need and extent of repairs } \\
\text { that may be needed for continued safe flight } \\
\text { operations. }\end{array}$ \\
\hline 11. Loose or missing hardware/fasteners & $\begin{array}{l}\text { Further inspect to determine structural integrity } \\
\text { of the aircraft and/or components with loose or } \\
\text { missing hardware/fasteners. Loose or missing } \\
\text { hardware/fasteners may pose a risk of } \\
\text { negatively impacting flight characteristics, } \\
\text { structural failure of the aircraft, dropped } \\
\text { objects, loss of the aircraft, and risk to persons } \\
\text { and property on the grounds. For continued } \\
\text { safe flight operations, secure loose } \\
\text { hardware/fasteners. Replace loose } \\
\text { hardware/fasteners that cannot be secured. } \\
\text { Replace missing hardware/fasteners. }\end{array}$ \\
\hline
\end{tabular}

Source: Federal Aviation Administration. Advisory Circular 107-2, Appendix C, "sUAS Maintenance and Inspection Best Practices," June 21, 2016. 

APPENDIX K. PILOT LOGBOOK EXAMPLE

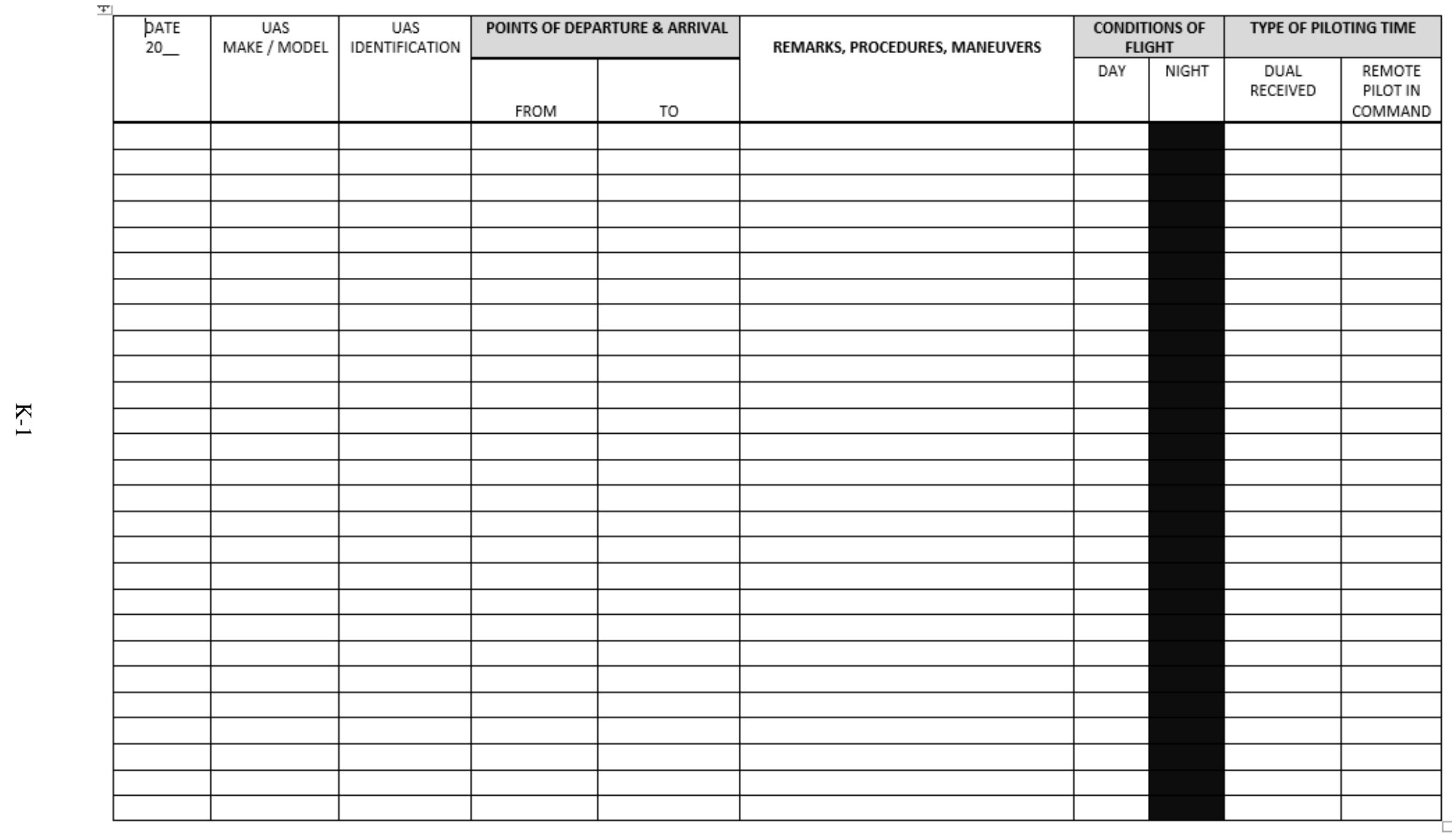





\section{APPENDIX L. CONSIDERATIONS FOR USING UNMANNED AERIAL SYSTEMS NEAR WIND INFRASTRUCTURE}

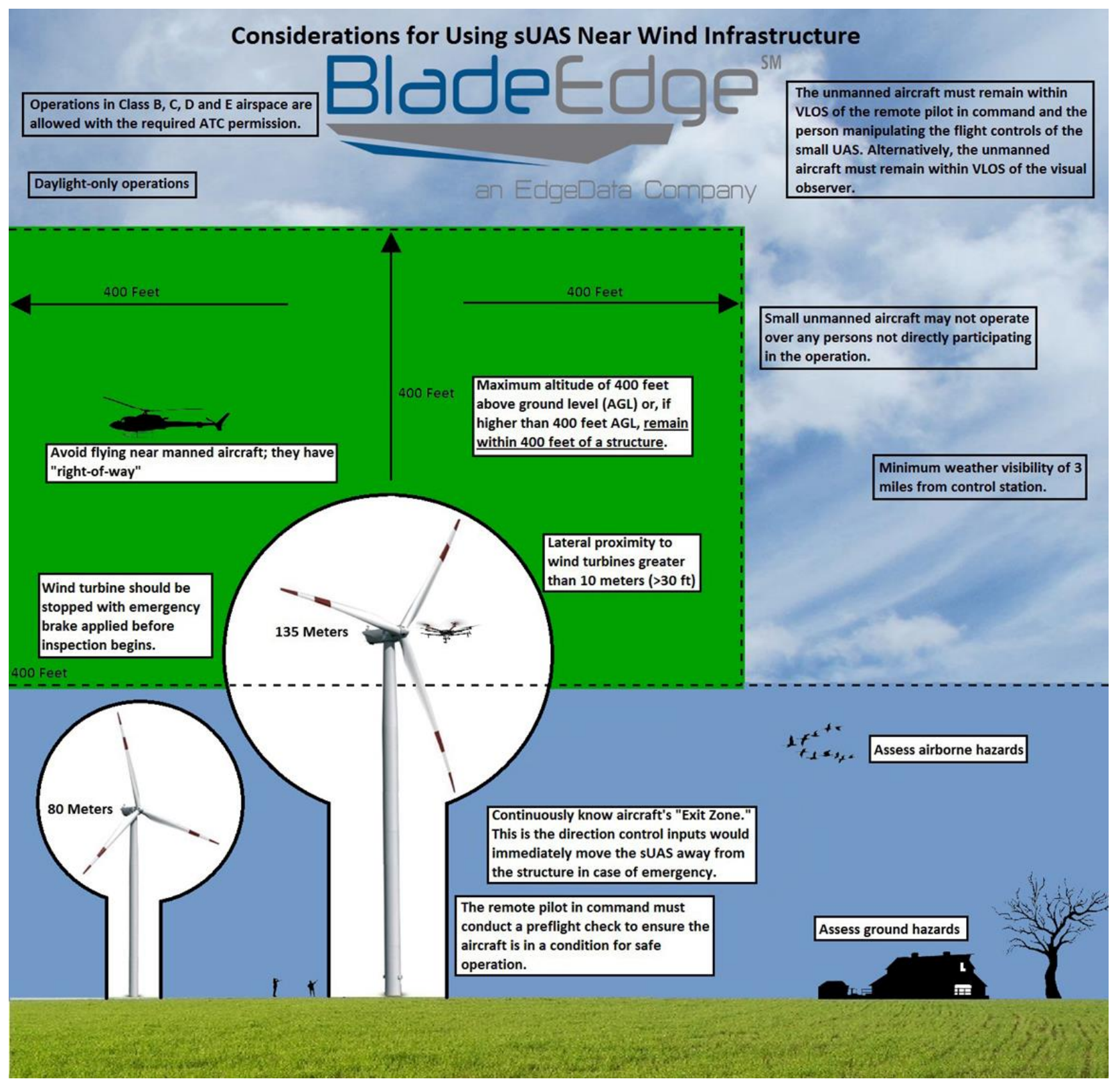

(EdgeData, 2016) 



\section{APPENDIX M. FAQS REGARDING UNMANNED AERIAL SYSTEM USE FOR THE ELECTRIC UTILITY INDUSTRY}

(Note: Except where indicated below, the bulk of this appendix was extracted in its entirety from a 2016 presentation by Doug Olsen of the University of North Dakota Unmanned Aircraft Systems Center of Excellence.)

- How are unmanned aerial systems (UASs) helping the electric power industry?

One of the earliest, and more widespread, commercial applications being developed for UAS work is the monitoring and inspection of electric power generation systems, transmission lines, substations, and similar facilities and critical infrastructure. Use of manned aircraft-both fixed-wing and rotorcraft - has long been a tool of the electric power industry. Due to both their expense and safety considerations, their use to date has been limited to infrastructure that is inaccessible through other means, has high value, and/or is highly critical in nature. With the advent of UASs, the cost and risk of airborne inspections is expected to drop dramatically; combined with new highly sophisticated cameras and sensor systems, a much greater share of the power industry infrastructure is likely to be inspected with these new tools in the very near future.

- What is the difference between a drone and a UAS and a remotely piloted aircraft (RPA)?

Generally, there is no difference; the difference in terminology typically depends on who is doing the communicating. The Federal Aviation Administration (FAA) defines an aircraft flying with the crew not onboard as an "unmanned aircraft system." The general media and the small UAS (sUAS) industry providers typically use the term "drone." The US Department of Defense, as well as segments of the international community, generally uses the term RPA. In commercial practice the terms are effectively interchangeable.

\section{- What is new in UAS regulations?}

UASs are aircraft and, as such, are subject to FAA regulations when operating in the National Airspace System, including any operation for commercial purposes. On August 29, 2016, FAA issued new regulations under 14 CFR Part 107 (Part 107) authorizing the use of UASs for commercial purposes under limited operational and environmental conditions. More commonly known as the "small UAS rule" or "sUAS rule," the basic regulations call for the aircraft to weigh less than $55 \mathrm{lb}$; for operation to occur within visual line of sight of the crew and only during daylight/clear weather conditions; for these operations to not occur higher than $400 \mathrm{ft}$ above ground level, over populated areas, or within certain congested airspace (such as close to an airport); and other limitations. For specialized situations, an operator can apply to FAA to waive most of these individual limitations if he/she can demonstrate a safety case for doing so. However, the sUAS rule is so new it will take some time before waivers are routinely granted by FAA. Under Part 107 the operator must obtain a Remote Pilot Certificate, and does not need to hold an FAA pilot's license, though having one makes acquiring a Remote Pilot Certificate much easier.

- What is the difference between a "Part 107" operator and a "Section 333" operator?

Beginning in 2012, before issuance of the new Part 107 regulations, FAA began issuing commercial UAS operators Certificates of Waiver or Authorization (COWs or COAs) under Section 333 of the FAA Modernization and Reform Act of 2012. Operators who have been granted a COA or COW can fly commercially under limited operational and environmental conditions. To some extent, the 
"Section 333 provision" was enacted to enable initial and limited commercial operations to commence in advance of the formal regulation changes recently authorized under Part 107, and most Section 333 petitions granted have similar limitations to those outlined in the basic Part 107 regulations, though differences could have been requested and approved. Operations can and will continue under both sets of regulations for some time. However, there are key differences; for example, under Section 333 the operator of the aircraft must be an FAA licensed pilot, and a separate visual observer (VO) is required to help the pilot "see and avoid" other aircraft. Another key difference is that Section 333 authorizations are given for the specific commercial applications (e.g., agriculture, cinematography) that were requested in the Section 333 petition by the operator; thus not all Section 333 operators are authorized to fly inspections of infrastructure.

\section{- Do such UAS operators have to follow all the rules of Part 107? How about Section 333?}

Yes. Unless specifically authorized by FAA for a waiver of, or exemption to, a specific regulation. In other words, the basic rules apply to everyone initially. Waivers, or exemptions, to a number of the Part 107 regulations may be possible. Any waivers later granted for any of the rules will be for a specific operator and application use. For example, a Part 107 operator's waiver request may ask to use an aircraft heavier than $55 \mathrm{lb}$, to operate at night, to operate beyond visual line of sight (BVLOS), or for other such exceptions. However, such exceptions will be granted by FAA only on a case-bycase basis and after careful consideration of the specific situation and the associated safety risks. With regard to a Section 333 operator, each holder of a Section 333 exemption may have differences that apply just to them, though most approvals granted have limits similar to those established by the basic Part 107 rule set. Whether operating under Part 107 or Section 333, any operator who violates the terms of its flight authorization puts not only its own aircraft and any ground/infrastructure below at significant risk, but more importantly, the lives of those aboard other aircraft. Such actions are also subject to significant fines or other enforcement action by FAA, the latter of which can include partnerships with state and local law enforcement agencies.

\section{- Are there additional changes coming to FAA regulations for flying UASs?}

Yes. Via the FAA Extension, Safety, and Security Act of 2016, Congress authorized FAA to begin development of new rules specifically to benefit the electric power industry and other operators of critical infrastructure. Under this new legislation, FAA will begin to develop rules enabling BVLOS flights, night flights, and additional changes that are expected to streamline the permitting of UAS flights and improve commercial viability and safety while inspecting critical infrastructure. However, any such new rules are not expected to become part of formal regulations until the 2018 time frame or beyond. That said, many operators under Part 107 are expected to apply for waivers to a number of Part 107 regulations, such as flying at BVLOS distances; some such waivers are likely to be granted in advance of more formal regulation changes that arise from the 2016 act.

\section{- How do FAA regulations apply outside the United States?}

They do not. Each country's designated NAS regulatory agency sets its own rules. However, most countries abide by a common set of aviation rules and guidelines established by the International Civil Aviation Organization (ICAO); ICAO is also working to establish common UAS rules among countries. That said, regulations authorizing limited commercial UAS operations have existed in a number of countries well in advance of those established in the United States, and in some cases with greater flexibility. For example, certain countries in Europe, Asia, and elsewhere already authorize BVLOS operations under select limited conditions; this has enabled inspection of power lines by UAS across greater distances than currently allowed in the United States. US-based electric industry 
companies with international operations should consult regulators for each country in which they have such operations.

- Can a power generation or utility company fly its own UASs for inspections and how?

Yes. A number of such companies have applied for, and been granted, Section 333 COAs for inspecting their own infrastructure, and even more are likely applying for Remote Pilot Certificates under Part 107. Becoming an authorized UAS operator is a valid path for those electric industry companies with extensive and diverse infrastructure and the resources to invest in UAS equipment, including sensors, as well as in personnel and procedures to not only fly and operate the system but also to perform aircraft maintenance and to process and analyze sensor data. The FAA provides resources for those wishing to become authorized to fly under Part 107; as a place to start, see https://www.faa.gov/uas/getting_started/fly for_work business/becoming_a pilot/.

\section{- How do I find an authorized commercial operator of UASs?}

There are already thousands of Section 333 authorized operators, and while not all can be hired to perform inspections, many can; soon there will likely be many thousands of Part 107 authorized operators as well. As of yet there is no central list of Part 107 authorizations. Section 333 exemptions are a matter of public record, so the names of those who have been granted exemptions can be obtained from FAA. In addition, there are various third-party providers of such information such as sUAS News ( http://www.suasnews.com/faa-drone-333-exemption-holders/).

- What are important considerations for selecting a UAS commercial operator?

Beyond the usual good business practices for selecting a contractor, there are several factors that should be considered when evaluating potential UAS operators. These include the following.

- FAA Airspace Authorization: Proof of Section 333 Exemption, Part 107, Remote Pilot Certificate

- Proof of Insurance

$\circ$ Sensor and Data Processing Capabilities

\section{- How far from power lines or other infrastructure, should the UAS fly?}

For routine inspections, the UAS should approach only as close as is necessary to meet the inspection needs given the capabilities of the sensors. A typical combination of sensor capabilities and inspection needs may call for a standoff distance of 65-100 ft $(20-30 \mathrm{~m})$. For specialized inspection tasks, requiring unique "look angles" for hard to reach views (including potentially from below), 30$65 \mathrm{ft}(10-20 \mathrm{~m})$ may be required. Given potential variability due to wind gusts, aircraft stability, and other uncertainties, flights at less than $30 \mathrm{ft}(10 \mathrm{~m})$ from infrastructure should be done only under controlled conditions that are well understood by the UAS operator. In addition, the power industry customer needs to ensure the UAS operator is fully aware of any safety "keep out" zones or other limits on UAS operator locations, such as required minimum distances from energized systems.

\section{- Are UASs affected by electromagnetic interference (EMI)?}

Yes. When operating close to energized systems, UASs can be affected by EMI; especially when high voltages are involved. 


\section{- How far along a linear infrastructure can a UAS be flown from a given crew location?}

Under airspace authorization, which requires visual line of sight to be maintained, the UAS operator's crew (remote pilot in command or VO) must be able to view the aircraft at all times for safe maneuvering of the UAS itself and to see and avoid other aircraft. Maintaining a safe distance from infrastructure becomes more problematic the further away the aircraft gets from the crew; highly capable autopilots and related autonomy capabilities may help mitigate this. In addition, the aircraft cannot traverse populated areas, and safe landing areas must be accessible at all times. Further, care must be taken to ensure radio line of sight is maintained throughout the flight; hills, foliage, and large turns in the flight path can cause radio communications issues. For any future airspace authorizations that enable BVLOS flights, these factors all still apply along the entire flight path.

\section{- What are the benefits or limitations of fixed-wing versus rotorcraft UASs?}

Fixed-wing aircraft are more typically used for survey of general conditions along linear infrastructure; rotorcraft can be used in this manner but also can perform detailed inspections of specific components or problems. With aircraft of comparable size and payload capacity, a fixed wing UAS generally has greater endurance and thus can fly longer distances between refueling or battery recharge/change-out. Fixed wing aircraft need adequate space for takeoff and landing - for example, a small fixed-wing system might be hand-launched into the wind and "belly-landed," though variations exist (wheeled landing gear, catapult launcher, etc.). Conversely, a rotorcraft can take off and land almost anywhere and can loiter in a single location for inspections but can have limited flight times; 30-40 min may be a typical expectation, though larger sensors or cameras (or cold weather) may add significant limitations. A fuel-based system can be much more efficient and have much longer duration than one operating strictly on batteries, but it can also be much more expensive.

\section{- Should a demonstration flight be required before extensive inspections are performed?}

This is highly recommended. UAS aircraft, flight sensors, and ground control systems, as well as data capture, delivery, and processing platforms, vary widely from system to system. Further, each inspection task and the specifics of geography and environmental conditions - wind, temperature, cloud cover, etc. - can add unique complexities. Also, demonstrated maturity, efficiency, and professionalism can vary from operator to operator. Verifying that the knowledge gained from inspections matches with expected results using a small representative infrastructure sample can improve the confidence of both the electric industry customer and the UAS operator before committing to larger scale, more extensive operations. Further, for both safety and efficiency, flight planning by the UAS operator may require access to geographic information, which demonstration flights can help identify, or otherwise benefit from the expertise of the electric industry customer. (Olsen, 2016)

- Should a utility company choose to employ a third-party provider for UAS support, research should be done to determine the professional view of safety from the provider's perspective. Below are examples of questions that should be asked.

\section{What is the company's background?}

"One of the first steps in determining a credible provider, or any subcontractor, is to research the background of the company. For UASs, this is an especially true statement. Although Part 107 no longer requires manned aviation experience for operators to gain their licenses, it should be noted that those providers with manned experience may have a better understanding of aviation safety in general. These operators are familiar with procedures, checklists, rules and regulations, and dealings 
with FAA and may be able to offer a more well-rounded candidate for UAS support than brand new 107 operators." (Hendrix, 2016)

\section{What is the training approach of the provider?}

"The first step toward any professional safety program is having a well-trained work force. The aviation industry is no different. Providers should have documented training programs, complete with training outlines and syllabi, training records, annual certifications if applicable, summaries of currency, and appropriate FAA documentation. Documentation should also include platforms each pilot is certified on per company standards.

"It is also important to note that training does not stop upon completion of initial training. Responsible providers will have annual (at a minimum) refresher requirements for flight, safety, maintenance, risk management, and other related topics, as well as a well-defined operator currency program." (Hendrix, 2016)

\section{What corporate safety programs does the provider have in place?}

"Safe operations should be the cornerstone of any UAS service provider and should be backed by documentable safety programs followed by all employees. An overarching safety manual such as a Safety Management System (SMS) tool should be used. SMS is a tool that AUV Flight Services uses that is borrowed from manned aviation programs related to government agencies. An allencompassing program, SMS incorporates safety into every aspect of a service provider's function, from before equipment deployment until after the return from a flight operation. While not all providers may have something as in depth, a company wishing to use a UAS service provider should ensure that the company has stated directives and published standards to hold crew members to a safe, responsible, and reliable attitude toward flight." (Hendrix, 2016)

\section{How are flight operations documented?}

"Flight service providers should be able to demonstrate the ability to perform expected operations and establish a pattern of safe flight. Those providers that have detailed checklists and procedures for preflight, during flight, any emergencies that may happen, and landing/post-flight demonstrate the overarching knowledge and the desire for safe operations.

"Along with the preceding documentation, a service provider should have a system that tracks flights and flight hours for operators and equipment. Flight hours can be tracked either electronically or through a database, but it should be detailed enough that each employee not only knows how much flight time he/she has, but the amount of flight time on each platform flown. Additionally, equipment hours must be tracked to ensure scheduled platform maintenance, if any, is performed on time in accordance with manufacturer specifications." (Hendrix, 2016)

\section{Does the provider enlist a currency requirement for its operators?}

“As previously mentioned, a well-defined currency program is a must-have for any service provider. Just as with manned aviation, currency requirements should be in place to ensure an operator maintains the skill level required for safe flight. At a minimum, there should be semiannual requirements for both the number of flights flown and the total flight hours; however, more stringent requirements are acceptable as determined necessary. Currency requirements are especially important in the contractor service provider arena, where some companies and their pilots may go weeks or longer without direct work in support of a customer. Ensuring that pilots are given the opportunity to 
fly as needed to conduct safe operations when called upon demonstrates a provider's investment in its employees' skill sets and also its commitment to maintaining a culture of safety." (Hendrix, 2016)

\section{REFERENCES}

Hendrix, J. (2016). Recommendations for Ensuring Safe UAS Operations within the Utilities Industry. AUV Flight Services, Tucson, Arizona.

Olsen, D. (2016). "UAS Inspections of Electrical Power Industry Systems - UND Best Practices Recommendations." University of North Dakota, Unmanned Aircraft Systems Center of Excellence, John D. Odegard School of Aerospace Sciences. Grand Forks, North Dakota. 


\section{APPENDIX N. FAA CONTROLLED AIRSPACE CLASSIFICATIONS}

All operations must be conducted in accordance with a certificate of waiver (COW) or certificate of authorization (COA). If operations cannot be conducted under the terms of an approved COA, a new or amended COA must be applied for through your organization with final approval by the Federal Aviation Administration (FAA).

In planning and conducting flight paths, all entities operating unmanned aerial systems (UASs) must select and adhere to those tracks and altitudes that completely minimize the possibility of UASs falling into a congested area in the event of electronic or material malfunction, including those that could lead to loss of control. Aerobatics should not be performed. Because one of the top hazards to flight is improper level off, flight levels should be determined as a part of route planning. Manned aircraft have the right-ofway; however, every effort should be made to avoid other aircraft in flight, including other unmanned aircraft such as park flyers.

Never fly within 5 miles of an airport without contacting airport authorities and the airport's traffic control facility. The Airport Advisory Area is an area of 5 statute miles encircling an airport. If this area is to be entered for UAS flight operations, the airport authorities must be contacted before flight operations.

Operation Near Airports, in Certain Airspace, in Prohibited or Restricted Areas, or in the Proximity of Certain Areas Designated by a Notice to Airmen. Though many small UAS (sUAS) operations will occur in uncontrolled airspace, there are some that may need to operate in controlled airspace [i.e., instrument flight rules (IFRs)] (see Figure N-1). Operations in Class B, Class C, or Class D airspace, or within the lateral boundaries of the surface area of Class $\mathrm{E}$ airspace designated for an airport, are not allowed unless that person has prior authorization from air traffic control (ATC). FAA has the authority to approve or deny aircraft operations based on traffic density, controller workload, communication issues, or any other type of operations that could potentially impact the safe and expeditious flow of air traffic in that airspace. Those planning sUAS operations in controlled airspace are encouraged to contact FAA as early as possible. (FAA, 2016)

Class A Airspace - generally, the airspace from $18,000 \mathrm{ft}$ to $60,000 \mathrm{ft}$ above mean sea level (MSL), including the airspace overlying the waters within $12 \mathrm{NM}$ of the coast of the 48 contiguous states and Alaska.

Class B Airspace - generally, the airspace from the surface to $10,000 \mathrm{ft}$ above MSL surrounding the nation's busiest airports in terms of airport operations or passenger enplanements. The configuration of each Class B airspace is individually tailored. An ATC clearance is required for all aircraft to operate in the area, and all aircraft that are so cleared receive separation services within the airspace.

Class C Airspace-generally, the airspace from the surface to 4,000 ft above an airport that has an operational control tower, is serviced by a radar approach control, and has a certain number of instrument flight rule operations or passenger enplanements. The configuration of each Class $\mathrm{C}$ airspace is individually tailored. Class $\mathrm{C}$ airspace usually consists of a surface area surrounding an airport in a 5-nautical-mile radius and an outer circle with a 10-nautical-mile radius that extends from 1,200 to $4,000 \mathrm{ft}$ above the airport elevation.

Class D Airspace - generally, airspace from the surface to 2,500 ft above airports that have operational control towers. The configuration of each Class D airspace is individually tailored. Unless otherwise authorized, each aircraft must establish two-way radio communications with the ATC facility providing 
air traffic services before entering the airspace and thereafter maintain those communications while within the airspace.

Class E Airspace-airspace that does not fall into Class A, B, C, or D but which is considered controlled airspace. No specific pilot certifications or equipment is required to operate in Class $\mathrm{E}$ airspace.

Class F Airspace-The United States does not use the International Civil Aviation Organization Class F airspace designation.

Class G Airspace - is uncontrolled airspace; the designation typically is used for a small layer of airspace near the ground, but there are larger areas of Class $\mathrm{G}$ airspace in remote regions of the United States. Flight operations may be conducted under IFRs or VFRs. ATC has no authority but VFR minimums are to be known by pilots. Traffic Information may be given as far as is practical in respect of other flights. (FAA, 2016)

Note: For in-depth descriptions of the controlled airspace classes see FAA Order 7400.9.

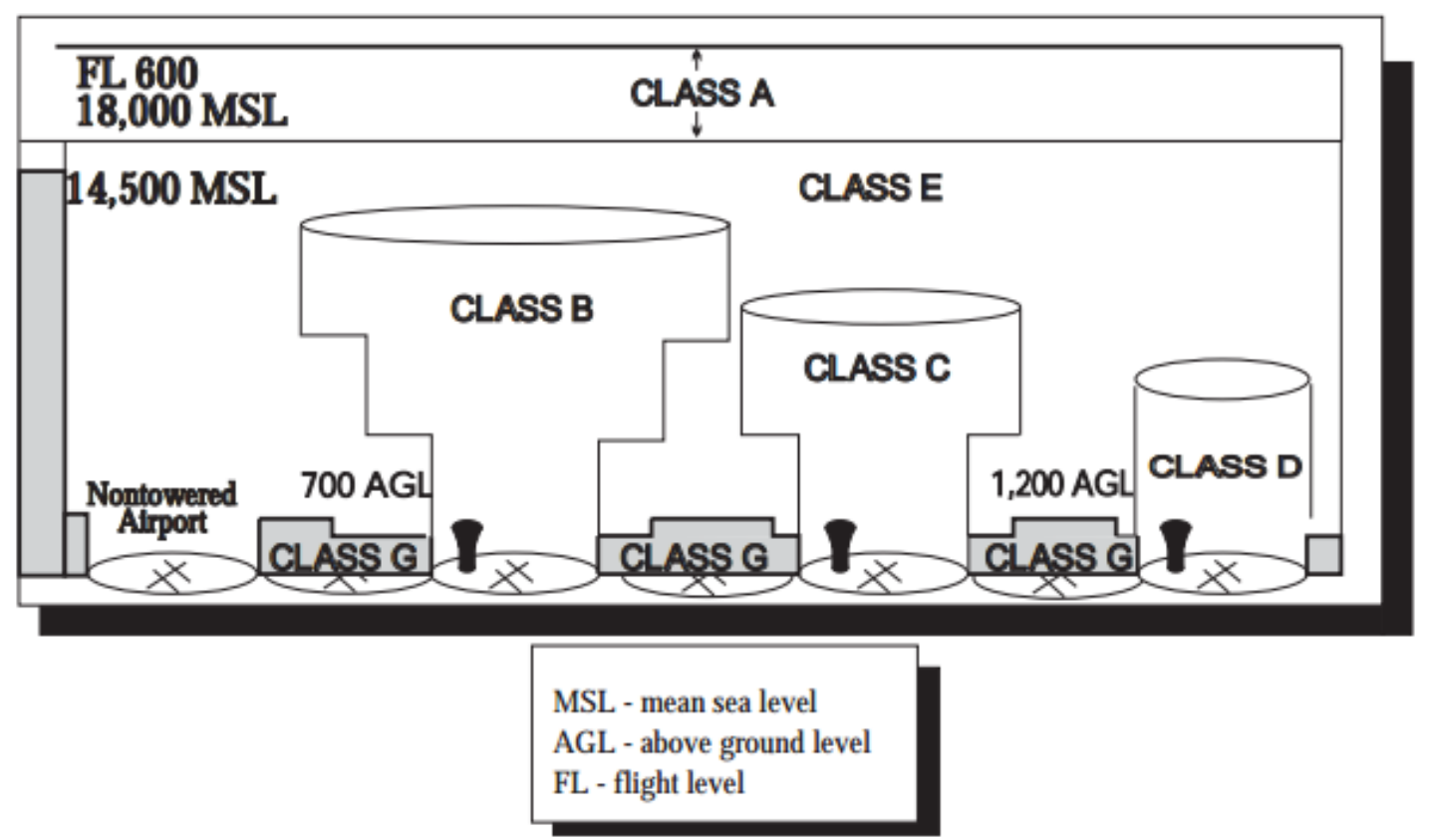

Figure N-1. FAA controlled airspace classes. (Source: Federal Aviation Administration, 2016. Aeronautical Information Manual, Federal Aviation Administration, Washington, DC, p. 3-2-1; https://www.faa.gov/air traffic/publications/media/aim.pdf.) 


\section{APPENDIX O. FAA ACCIDENT REPORTING AND REGIONAL OPERATIONS CENTERS TELEPHONE LIST}

Per Part 107, report to the Federal Aviation Administration (FAA) within 10 days of any operation that results in at least serious injury, loss of consciousness, or property damage of at least $\$ 500$.

\section{Accident Reporting}

The remote pilot in command (PIC) of the small unmanned aerial system (sUAS) is required to report an accident to FAA within 10 days if it meets any of the following thresholds.

At least serious injury to any person or any loss of consciousness. A serious injury is an injury that qualifies as Level 3 or higher on the Abbreviated Injury Scale (AIS) of the Association for the Advancement of Automotive Medicine. AIS is an anatomical scoring system that provides a means of ranking the severity of an injury and is widely used by emergency medical personnel. Within the AIS system, injuries are ranked on a scale of 1 to 6 , with Level 1 being a minor injury, Level 2 is moderate, Level 3 is serious, Level 4 is severe, Level 5 is critical, and Level 6 is a nonsurvivable injury. FAA currently uses serious injury (AIS Level 3 ) as an injury threshold in other FAA regulations.

Note: It would be considered a "serious injury" if a person required hospitalization, but the injury were fully reversible (including, but not limited to, head trauma, broken bones, or lacerations to the skin that require suturing).

Damage to any property other than the sUAS if the cost is greater than $\$ 500$ to repair or replace the property (whichever is lower). Note: For example, a sUAS damages a property whose fair market value is $\$ 200$, and it would cost $\$ 600$ to repair the damage. Because the fair market value is below $\$ 500$, this accident is not required to be reported. Similarly, if the aircraft causes $\$ 200$ worth of damage to property whose fair market value is $\$ 600$, that accident is also not required to be reported because the repair cost is below $\$ 500$.

Submitting the Report. The accident report must be made within 10 calendar days of the operation that created the injury or damage. The report may be submitted to the appropriate FAA Regional Operations Center (ROC) electronically or by telephone. Electronic reporting can be completed at www.faa.gov/uas/. To make a report by phone, see Figure O-1, FAA Regional Operations Centers telephone list. Reports may also be made to the nearest FAA Flight Standards District Office (http://www.faa.gov/about/office org/field offices/fsdo/). The report should include the following information:

- $\quad$ SUAS remote PIC's name and contact information;

- $\quad$ sUAS remote PIC's FAA airman certificate number;

- $\quad$ sUAS registration number issued to the aircraft, if required (FAA registration number);

- location of the accident;

- date of the accident;

- time of the accident;

- persons injured and extent of injury, if any or known;

- property damaged and extent of damage, if any or known; and

- description of the incident. 


\begin{tabular}{|c|c|}
\hline \multicolumn{2}{|l|}{ FAA REGIONAL OPERATIONS CENTERS } \\
\hline LOCATION WHERE ACCIDENT OCCURRED: & TELEPHONE: \\
\hline DC, DE, MD, NJ, NY, PA, WV, and VA & 404-305-5150 \\
\hline AL, CT, FL, GA, KY, MA, ME, MS, NC, NH, PR, RI, SC, TN, VI, and VT & 404-305-5156 \\
\hline AK, AS, AZ, CA, CO, GU, HI, ID, MP, MT, NV, OR, UT, WA, and WY & 425-227-1999 \\
\hline AR, IA, IL, IN, KS, LA, MI, MN, MO, ND, NE, NM, OH, OK, SD, TX, and & $817-22-5006$ \\
\hline
\end{tabular}

Figure O-1. FAA Regional Operations Centers telephone list. (FAA, 2016)

National Transportation Safety Board (NTSB) Reporting. In addition to the report submitted to ROC, and in accordance with the criteria established by NTSB, certain sUAS accidents must also be reported to NTSB. For more information, visit www.ntsb.gov. (FAA, 2016) 


\section{ABOUT THE AUTHORS}

\section{Rick Lusk}

Rick Lusk is the director of the Unmanned Aerial Systems (UAS) Research Center (UASRC) and leader of the Data System Sciences and Engineering Group in the Computing and Computational Sciences Directorate at Oak Ridge National Laboratory (ORNL). With more than 30 years of professional experience, he is an expert in designing and planning integrated technology platforms and managing their creation and transformation into comprehensive, authoritative, and intuitive decision support systems.

Before joining ORNL, Lusk designed and developed multiple complex strategic technology, operation, and marketing plans for multinational businesses and US government agencies. These include the first global client-server network for imagery analysis, VOIP, and WebTV. His career has ranged from working at the MIT Media Lab to providing business solutions to customers such as Jack Nicklaus Golf, Gary Player, and Bankrate to representing US interests abroad.

A former Marine Corps Officer, Lusk holds a BS in communications from the University of Idaho and an MBA from Boston University. He is a graduate of the National Defense University Advanced Management Program and is a federally certified enterprise architect and chief information officer. Additionally, he holds certificates in International Management from Sanyo Leadership School in Japan and in International Terrorism Studies from the University of St. Andrews in Scotland. Rick is also an ISO TAG member and UAS expert for the United States. Rick has a Remote Pilot Certificate with a small UAS rating.

\section{William H. (Bill) Monday}

Bill Monday currently serves as the UASRC project manager in the Data System Sciences and Engineering Group within the Computing and Computational Sciences Directorate at ORNL. He is a member of the ORNL Field Intelligence Element for national security special projects work where he supports the dynamic needs of numerous national security-related programs and projects. He has more than 30 years of professional experience and involvement with flight operations, including worldwide intelligence, surveillance, and reconnaissance flights that supported both US and allied forces in addition to the wider US intelligence community.

Before coming to ORNL, he served as a naval officer and was assigned to various fleet and joint tour duties serving in global combat operations that also included flight operations as a qualified naval air crewman. Some of his prominent duties included collection and analysis; flight planning, imagery, and intelligence; and targeting.

He earned his BS from Tennessee Technological University in Cookeville, Tennessee, and holds an MA degree in National Security Affairs and Strategic Studies from the US Naval Postgraduate School in Monterey, California. His postgraduate work focused on the potential of unconventional attacks on our nation's resources and infrastructure using weapons of mass destruction. Bill has a Remote Pilot Certificate with a small UAS rating. 


\section{QUESTIONS OR COMMENTS}

Any recommendations for addition, deletion, or update should be forwarded to the following points of contact.

Rick Lusk

Director, UAS Research Center and Group Leader, Data System Sciences and Engineering Oak Ridge National Laboratory

Oak Ridge, TN 37831-6085

luskrm@ornl.gov

W. (865) 574-8864

C. (865) 576-3858 (fax)

http://uasresearch.ornl.gov/

William H. Monday

Project Manager, UAS Research Center

Oak Ridge National Laboratory

Oak Ridge, TN 37831-6085

mondayw@ornl.gov

W. (865) 241-0234

C. (865) 576-3858 (fax)

http://uasresearch.ornl.gov/ 